\title{
Lake Borgne Surge Barrier Study
}

S. Keith Martin, Gaurav Savant, and Darla C. McVan

September 2010

US Army Corps of Engineers ${ }_{\circledast}$

Engineer Research and Development Center 


\section{Lake Borgne Surge Barrier Study}

S. Keith Martin, Gaurav Savant, and Darla C. McVan

Coastal and Hydraulics Laboratory

U.S. Army Engineer Research and Development Center

3909 Halls Ferry Road

Vicksburg, MS 39180-6199

Final report

Approved for public release; distribution is unlimited.

Prepared for U.S. Army Corps of Engineers

New Orleans District, Hurricane Protection Office

7400 Leake Avenue, P.O. Box 60267

New Orleans, LA 70160-0267 


\begin{abstract}
A two-dimensional hydrodynamic model of the Lake Borgne Surge Barrier was developed specifically for simulating currents within the surge protection structure on the Gulf Intracoastal Waterway (GIWW) for the purposes of determining the impacts of the GIWW structure on navigation. The model was validated against observed data and applied using boundary conditions capable of producing currents in the structure that would be hazardous to navigation.
\end{abstract}

DISCLAIMER: The contents of this report are not to be used for advertising, publication, or promotional purposes. Citation of trade names does not constitute an official endorsement or approval of the use of such commercial products. All product names and trademarks cited are the property of their respective owners. The findings of this report are not to be construed as an official Department of the Army position unless so designated by other authorized documents. 


\section{Contents}

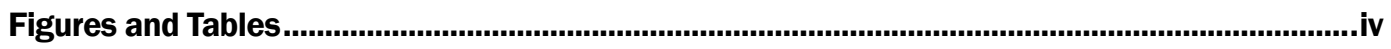

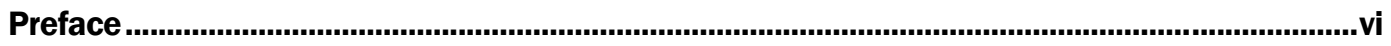

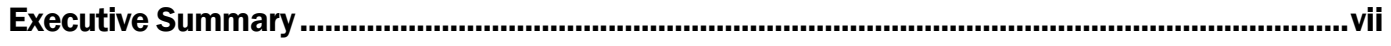

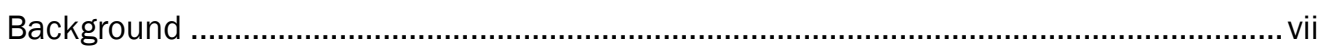

Hydrodynamic numerical model ..................................................................................

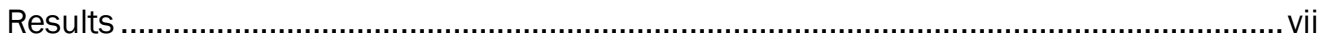

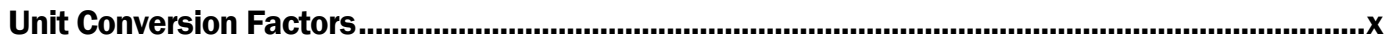

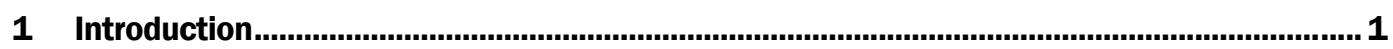

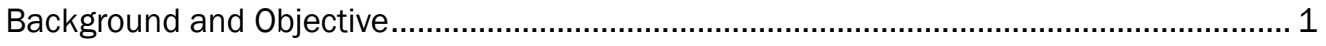

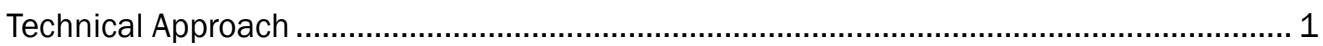

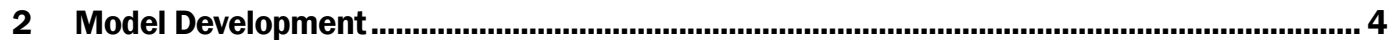

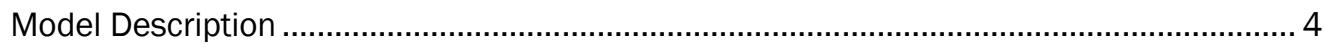

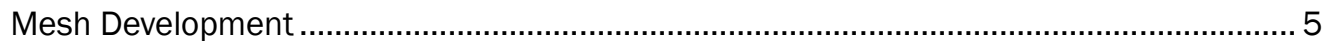

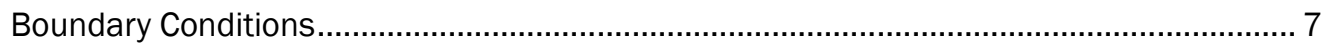

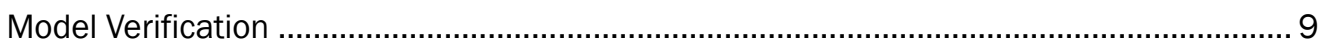

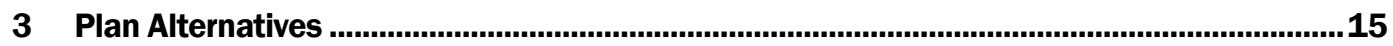

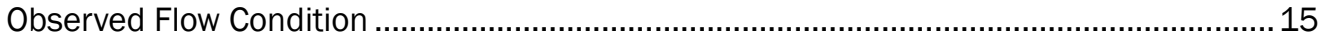

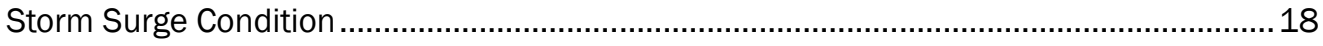

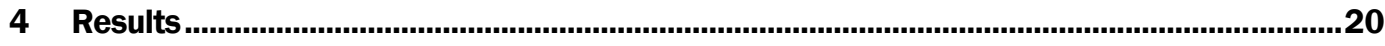

Observed Flow Condition ....................................................................................... 20

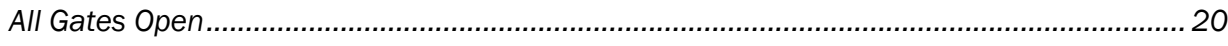

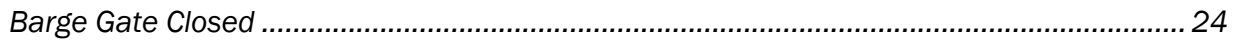

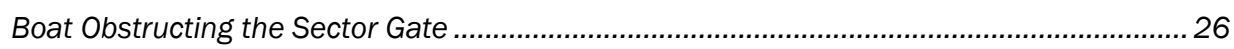

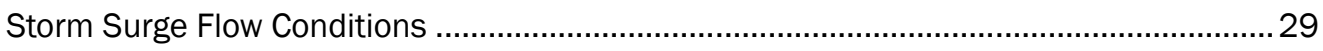

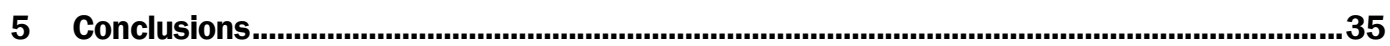

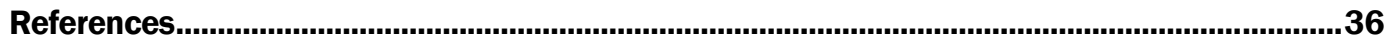

Appendix A: Description of the ADaptive Hydraulics (ADH) Modeling System...............................37

Report Documentation Page 


\section{Figures and Tables}

\section{Figures}

Figure 1-1. Vicinity Map.

Figure 1-2. Lake Borgne Surge Barrier (inset from Figure 1-1)......................................................... 2

Figure 2-1. Model Domain and Grid Resolution.............................................................................. 5

Figure 2-2. Model Elevations, meters NAVD88 (2004.65). ........................................................... 6

Figure 2-3. Study Area Elevations, meters NAVD88 (2004.65).................................................... 6

Figure 2-4. River Inflows for 2006............................................................................................ 7

Figure 2-5. Waveland Yacht Club Gage. ................................................................................ 8

Figure 2-6. Pilots Station East, SW Pass. .................................................................................... 9

Figure 2-7. Wind Boundary Condition.............................................................................................. 10

Figure 2-8. Verification at Paris Rd. ....................................................................................... 10

Figure 2-9. Tidal Component Analysis at Paris Rd - Amplitude. ....................................................... 11

Figure 2-10. Tidal Component Analysis at Paris Rd - Phase........................................................ 11

Figure 2-11. Field Data Transects....................................................................................... 12

Figure 2-12. Discharge Comparison - Line 1. …………………………………………..... 13

Figure 2-13. Discharge Comparison - Line 2................................................................................. 13

Figure 2-14. Discharge Comparison - Line 3.............................................................................. 14

Figure 3-1. Surge Barrier Configuration. .................................................................................... 16

Figure 3-2. GIWW Structure Configuration. ................................................................................ 16

Figure 3-3. GIWW Floodgate Structure Mesh............................................................................. 17

Figure 3-4. GIWW Floodgate Structure Contours. ........................................................................ 17

Figure 3-5. Storm Surge Signal.............................................................................................. 18

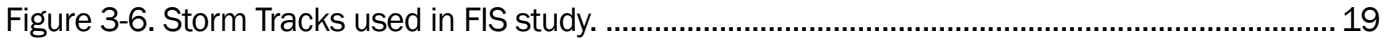

Figure 4-1. Velocity Measurement Locations. ............................................................................. 21

Figure 4-2. Maximum Flood Velocities in GIWW Structure............................................................... 21

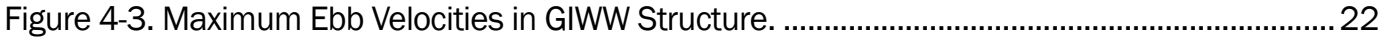

Figure 4-4. Exceedance Plot for year 2006.......................................................................... 23

Figure 4-5. Location of Seabrook Structure.................................................................................... 23

Figure 4-6. Maximum Flood Velocities in GIWW Structure with Seabrook Structure Closed. .......... 24

Figure 4-7. Maximum Ebb Velocities in GIWW Structure with Seabrook Structure Closed............... 24

Figure 4-8. Maximum Flood Velocities in the GIWW Sector Gate with the Barge Gate

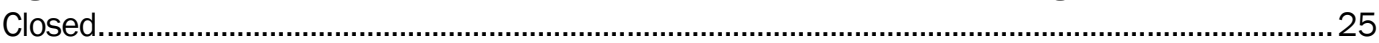

Figure 4-9. Maximum Ebb Velocities in the GIWW Sector Gate with the Barge Gate Closed. .......... 26

Figure 4-10. 54 foot Vessel Footprint.................................................................................. 27

Figure 4-11. 108 foot Vessel Footprint................................................................................... 27

Figure 4-12. Flood Condition with no Vessel. .............................................................................. 28 
Figure 4-13. Flood Condition with $54 \mathrm{ft}$ Wide Vessel...................................................................... 28

Figure 4-14. Flood Condition with 108 ft Wide Vessel. ..................................................................... 29

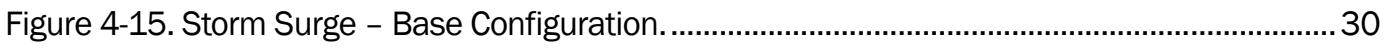

Figure 4-16. Storm Surge - Barrier with all gates open. ...................................................................3 30

Figure 4-17. Storm Surge - Barge Gate Closed..................................................................... 31

Figure 4-18. Storm Surge - BB Structure Closed. .......................................................................... 31

Figure 4-19. Storm Surge - Barrier with Seabrook Structure and Barge Gate Closed.................... 32

Figure 4-20. Storm Surge - Barrier with Seabrook Structure Closed, Barge Gate Closed,

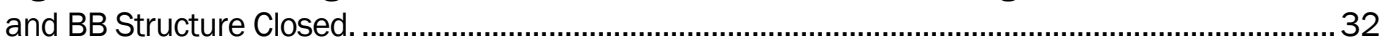

Figure 4-21. Velocity in Sector Gate versus Head Difference Across Gate...................................... 34

\section{Tables}

Table 2-1. Discharge Comparison - Line 1. ................................................................................. 14

Table 2-2. Discharge Comparison - Line 2 .............................................................................. 14

Table 2-3. Discharge Comparison - Line 3. ................................................................................. 14

Table 4-1. Velocity Comparison of All Structures Open to Barge Gate Closed. ................................. 26

Table 4-2. GIWW Structure Head Differences and Velocities. ....................................................... 33 


\section{Preface}

The model investigation presented in this report was authorized and funded by the U.S. Army Engineer Hurricane Protection Office (HPO), New Orleans. MAJ J eremy Chapman served as project manager for HPO. The Lake Borgne Surge Barrier Study was conducted by Keith Martin, Dr. Gaurav Savant, and Darla C. McVan.

This work was conducted at the Coastal and Hydraulics Laboratory (CHL) of the U.S. Army Engineer Research and Development Center (ERDC) during the period of J uly 2008 to May 2009 under the direction of Dr. William D. Martin, Director of the CHL; Dr. Rose Kress, Chief of the Navigation Division, CHL; Bruce Ebersole, Chief of the Flood and Storm Protection Division, CHL; Dennis W. Webb, Chief of the Navigation Branch, CHL; Dr. Robert T. McAdory, Chief of the Estuarine Engineering Branch, CHL.

Dr. J effery P. Holland was Director of ERDC. COL Gary E. J ohnston was Commander and Executive Director. 


\section{Executive Summary}

\section{Background}

The U.S. Army Engineer Hurricane Protection Office (HPO) requested that the USACE Engineering Research and Development Center (ERDC) at Waterways Experiment Station perform a numerical modeling study for the purpose of analyzing the hydrodynamic impacts of a proposed gate structure to be built as part of the storm surge barrier on the Gulf Intracoastal Waterway (GIWW) East of the Michoud Canal.

The GIWW merges with the Mississippi River Gulf Outlet (MRGO) and continues five miles further to the West where it joins the Inner Harbor Navigation Canal (IHNC). The IHNC proceeds approximately three more miles north from its intersection with the GIWW to connect with Lake Pontchartrain at Seabrook. The section of the GIWW that is of interest for this project extends southwest approximately 20 miles from its connection with Lake Borgne to its confluence with the MRGO (Figure 1-1).

\section{Hydrodynamic numerical model}

A two-dimensional hydrodynamic model was used to analyze the effects of a dual-gate structure on the GIWW. The model chosen for this study was the Adaptive Hydraulics ( $\mathrm{ADH}$ ) model, a state-of-the-art model developed at ERDC. The ADH model is among the Corps of Engineers' standard modeling tools for three-dimensional, open-channel flow and uses the finite element formulation. ADH also has adaptive meshing capability which enables the model to create more resolution when needed during a simulation to deal with complex geometry and flow conditions. The Surface Water Modeling System (SMS; see Brigham Young University, 1997) was used for model development and analysis.

\section{Results}

The base condition was simply a simulation performed using the existing conditions in the Lake Pontchartrain-Lake Borgne System.

The plan alternative was analyzed by placing the Lake Borgne Surge Barrier in the model using the Surface Water Modeling System (SMS) and 
performing two sets of simulations: (1) high flow under normal conditions and (2) flow under a storm surge condition without a tidal component.

While the normal condition simulations did show that velocities in the GIWW structure exceeded navigational thresholds, these events occurred twice per tidal cycle at most and then only under spring tidal conditions and/ or during passage of weather fronts. The low frequency of these high velocity events was illustrated through an exceedance analysis that showed these events occurring approximately two percent of the time for a yearly simulation.

A gate structure has been proposed at Seabrook. Sensitivity simulations of the model with this structure closed were performed. Analysis of these simulations showed the closure of the Seabrook structure produced approximately a 50 percent reduction in flow velocity in the GIWW structure. This velocity reduction puts the structure velocities well within limits set by the navigation industry.

Simulations were also performed with a vessel residing in the GIWW structure. These simulations illustrated the effects of vessel traffic on the currents and current patterns in the GIWW structure.

Storm surge simulations illustrated the impacts of each proposed structure on system circulation including the structure at Seabrook and correlated head differences across the structure and closures of the various structures in the system with velocities in the structure. The analysis of these simulations showed that even with all of the structures open, a head difference of $0.52 \mathrm{~m}$ produces a current velocity of $3.72 \mathrm{~m} / \mathrm{sec}$ in the GIWW structure. The benefit of closing the gates of the proposed Seabrook structure was again illustrated by the results of these simulations. By closing the Seabrook structure, the head difference across the GIWW structure was decreased by nearly $0.8 \mathrm{~m}$ and the velocity in the structure was reduced approximately 45 percent.

With the exception of the storm surge simulations, the results of all simulations were provided to ERDC navigation personnel for use in ERDC's ship simulator.

In summary, the numerical model simulations showed that implementation of the Lake Borgne Surge Barrier produces velocities in the GIWW floodgate 
structure which exceed thresholds set by the navigation industry. However, these events are low frequency events and most likely occur under spring tidal conditions that are exacerbated by passage of weather fronts. Furthermore, velocities in the GIWW structure can be reduced 45-50 percent by closing the proposed Seabrook gate structure. 


\section{Unit Conversion Factors}

\begin{tabular}{|c|c|c|}
\hline Multiply & By & To Obtain \\
\hline acres & $4,046.873$ & square meters \\
\hline acre-feet & 1,233.5 & cubic meters \\
\hline cubic feet & 0.02831685 & cubic meters \\
\hline cubic inches & 1.6387064 E-05 & cubic meters \\
\hline cubic yards & 0.7645549 & cubic meters \\
\hline degrees (angle) & 0.01745329 & radians \\
\hline degrees Fahrenheit & $(F-32) / 1.8$ & degrees Celsius \\
\hline fathoms & 1.8288 & meters \\
\hline feet & 0.3048 & meters \\
\hline foot-pounds force & 1.355818 & joules \\
\hline inches & 0.0254 & meters \\
\hline inch-pounds (force) & 0.1129848 & newton meters \\
\hline knots & 0.5144444 & meters per second \\
\hline microns & $1.0 \mathrm{E}-06$ & meters \\
\hline miles (nautical) & 1,852 & meters \\
\hline miles (U.S. statute) & $1,609.347$ & meters \\
\hline slugs & 14.59390 & kilograms \\
\hline square feet & 0.09290304 & square meters \\
\hline square yards & 0.8361274 & square meters \\
\hline yards & 0.9144 & meters \\
\hline
\end{tabular}




\section{Introduction}

\section{Background and Objective}

The U.S. Army Engineer Hurricane Protection Office (HPO) requested that the USACE Engineering Research and Development Center (ERDC) at Waterways Experiment Station perform a numerical modeling study for the purpose of analyzing the hydrodynamic impacts of a proposed gate structure to be built on the Gulf Intracoastal Waterway (GIWW) East of the Michoud Canal. This gate structure is part of the larger Lake Borgne Surge Barrier that includes a gate structure on Bayou Bienvenue (BB), a closure of the Mississippi River Gulf Outlet (MRGO) just south of BB, and a floodwall between the various structures and the MRGO closure (Figure 1-2).

The GIWW merges with the MRGO and continues five miles further to the West where it joins the Inner Harbor Navigation Canal (IHNC). The IHNC proceeds approximately three more miles north from its intersection with the GIWW to connect with Lake Pontchartrain at Seabrook. A gate structure is proposed at this location, as well. The section of the GIWW that is of interest for this project extends southwest approximately 20 miles from its connection with Lake Borgne to its confluence with the MRGO (Figure 1-1).

\section{Technical Approach}

The TABS-MDS hydrodynamic numerical model developed in previous studies (Martin et al, 2010) was modified for use as a two-dimensional ADaptive Hydraulics ( $\mathrm{ADH}$ ) model in this study. $\mathrm{ADH}$ was chosen over TABS-MDS for the present study due to the specification that a $5 \mathrm{ft}$ gap exist between the bottom of the guidewalls of the GIWW floodgate structure and the channel bottom thereby allowing flow under the guidewalls. TABS-MDS only allows walls to begin at the bottom of the channel and extend to an infinitely high location above the water surface thereby allowing no flow to pass over or under the wall. $\mathrm{ADH}$ has a stateof-the-art capability that allows the user to specify a lid on the water surface. This capability was originally intended to be used for modeling vessel traffic in a waterway. However, it was adapted for the guidewalls of the present model study by specifying the lid remain stationary and that it remain a constant $5 \mathrm{ft}$ from the bottom of the GIWW channel. 


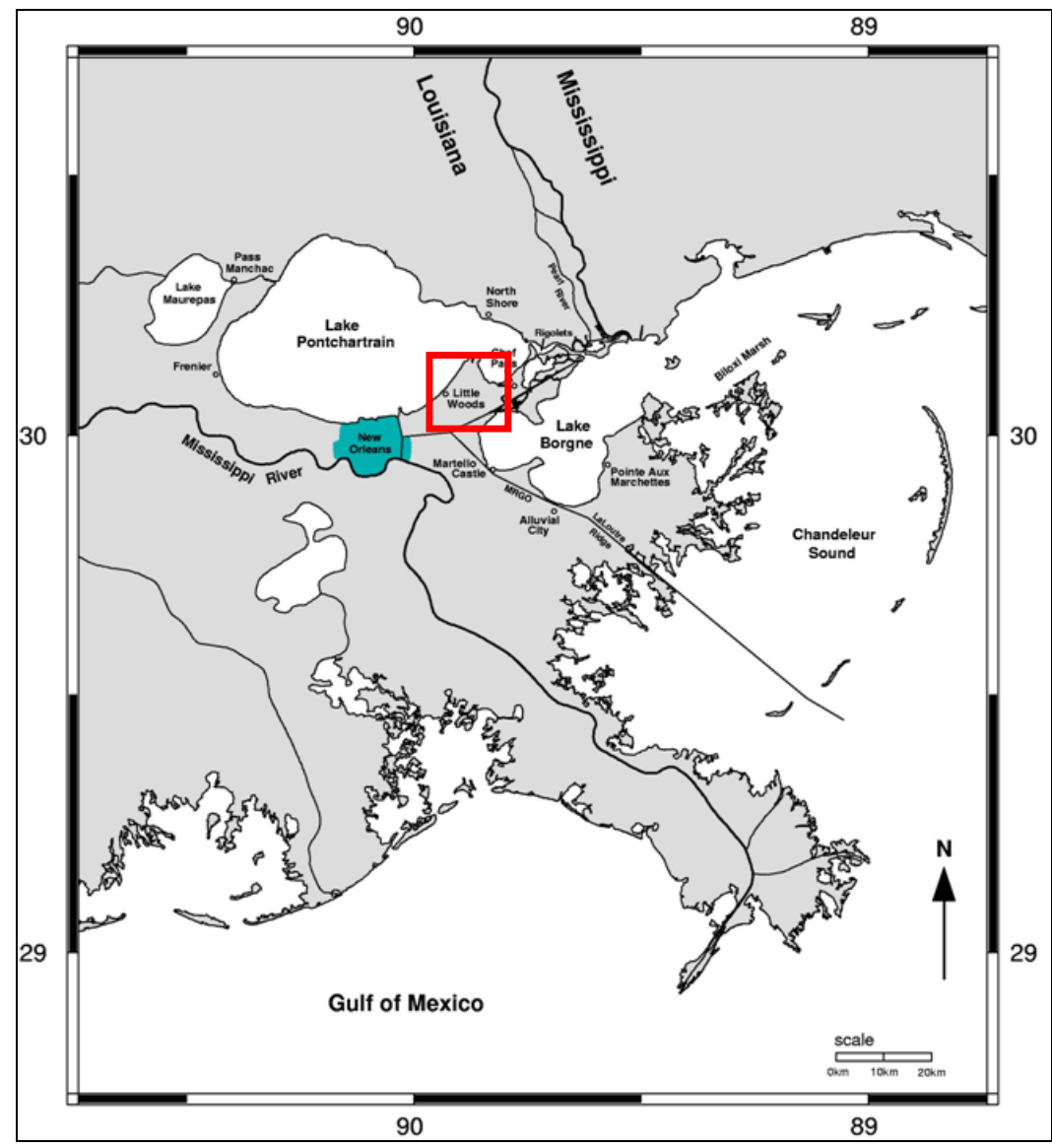

Figure 1-1. Vicinity Map.

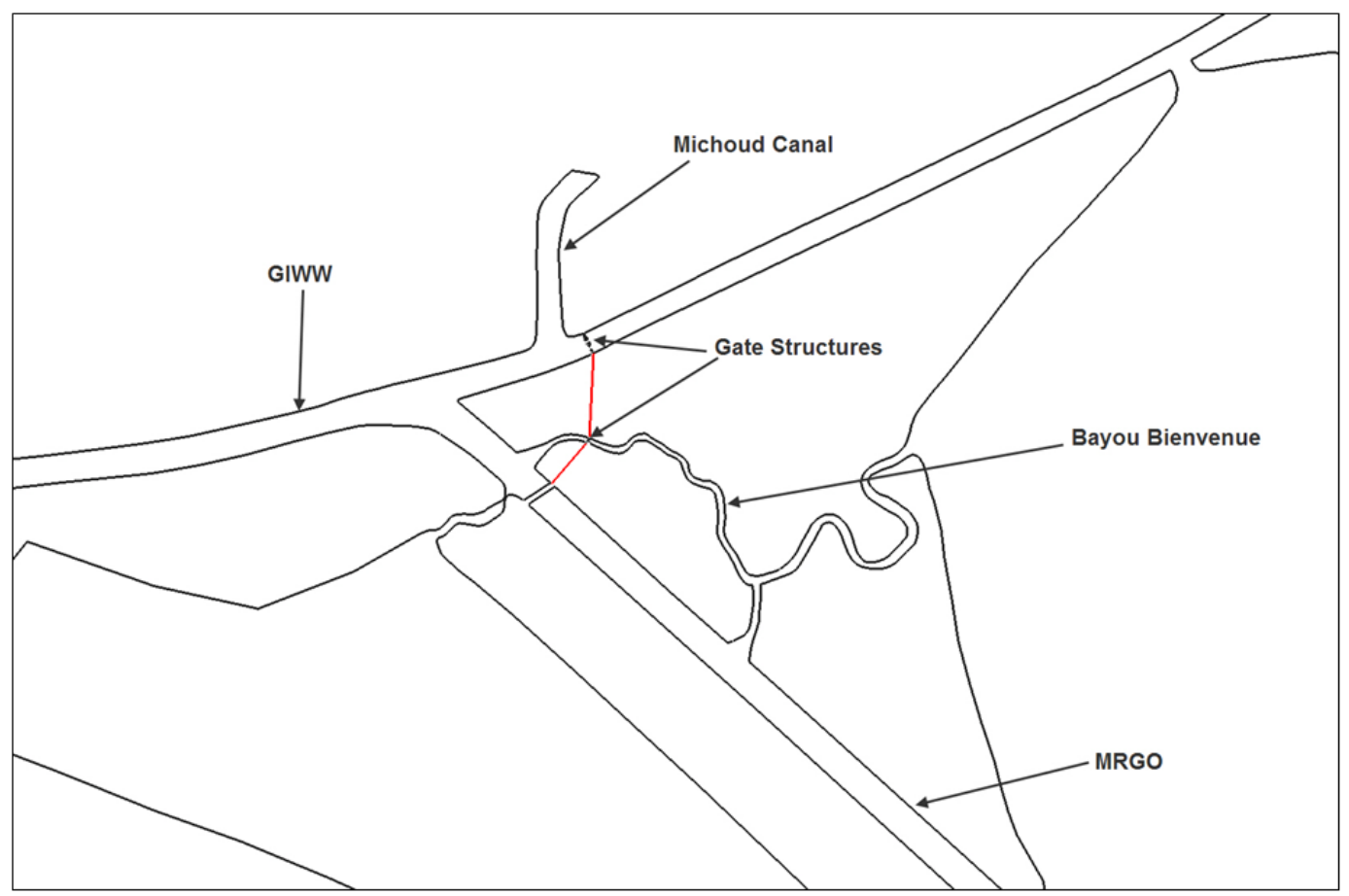

Figure 1-2. Lake Borgne Surge Barrier (inset from Figure 1-1). 
Wind effects were incorporated into the model to properly simulate the effects of frontal passage across the system. The previous model (Martin et al, 2010) was modified to reflect updated bathymetry data gathered by ERDC in 2008 in the GIWW and MRGO in the vicinity of the confluence of these two channels and to accurately represent the GIWW floodgate structure.

The boundary conditions used were data from J anuary through December 2006. These data included river inflows, tides, and winds.

After the verification was completed, the model was run with and without the plan alternative. The model results from the alternative simulation were then analyzed and compared to navigation requirements in order to evaluate the performance of the plan alternative for flow velocity and current patterns. The plan alternative was then run using a storm surge condition. 


\section{Model Development}

\section{Model Description}

A two-dimensional hydrodynamic model was used to predict the effects of the Lake Borgne Surge Barrier on flow velocities and current patterns in the GIWW floodgate structure. The model chosen for this study was ADH, a state-of-the-art model developed at ERDC.

$\mathrm{ADH}$ is a finite element model that is capable of simulating threedimensional Navier Stokes equations, two and three-dimensional shallow water equations, and groundwater equations. It can be used in a serial or multiprocessor mode on personal computers, UNIX, Silicon Graphics, and CRAY operating systems. The uniqueness of $\mathrm{ADH}$ is its ability to dynamically refine the domain mesh in areas where more resolution is needed at certain times due to changes in the flow conditions. ADH can simulate the transport of conservative constituents, such as dye clouds, as well as sediment transport that is coupled to bed and hydrodynamic changes. The ability of ADH to allow the domain to wet and dry within the marsh areas as the tide changes is good for the shallow marsh environment. This tool is being developed at ERDC's Coastal and Hydraulics Laboratory (CHL) and has been used for a wide variety of applications including flow and sediment transport in complex sections of the Mississippi River, tidal conditions in southern California, and flow field changes caused by vessel traffic in the Houston Ship Channel.

For this study, the two-dimensional shallow water module of $\mathrm{ADH}$ was used for all simulations. This tool solves for depth and depth averaged velocity throughout the model domain. Due to velocities/ turbulence in the GIWW the flow is considered well-mixed and therefore not subject to salinity stratification effects. The closure of MRGO removes the primary source of salinity stratification in the system. Therefore, we can assume a 2-d behavior. In this case, density effects due to salinity or other factors are considered negligible and therefore their effects on the flow are not included in these simulations and results. The effect of the guidewalls for the GIWW floodgate structure was simulated using the lid method described in the Technical Approach. More details of the two-dimensional shallow water module of $\mathrm{ADH}$ and its computational philosophy and equations can be found in Appendix A or at https:// adh.usace.army.mil. 


\section{Mesh Development}

The mesh was developed using the Surface-water Modeling System (SMS), a graphical user interface developed by ERDC for increasing the modeling productivity for a variety of Corps numerical models, including ADH (see Appendix A). The entire model domain is shown in Figures 2-1 and 2-2 and an inset of the model showing the study area is shown in Figure 2-3. Areas without elements (Figure 2-1) or without contours (Figures 2-2 and 2-3) should be considered as not part of the mesh. The mesh was developed by modifying the TABS-MDS mesh from a previous Hurricane Protection Office (HPO) study (Martin et al, 2010). The modifications consisted updating the bathymetry to reflect data gathered by ERDCin the vicinity of the confluence of the GIWW and the MRGO.

Although $\mathrm{ADH}$ has the capability to model wetting and drying, the marsh areas between Lake Borgne and the GIWW/ MRGO were deemed to provide little to no impact to the flow through the area of interest.

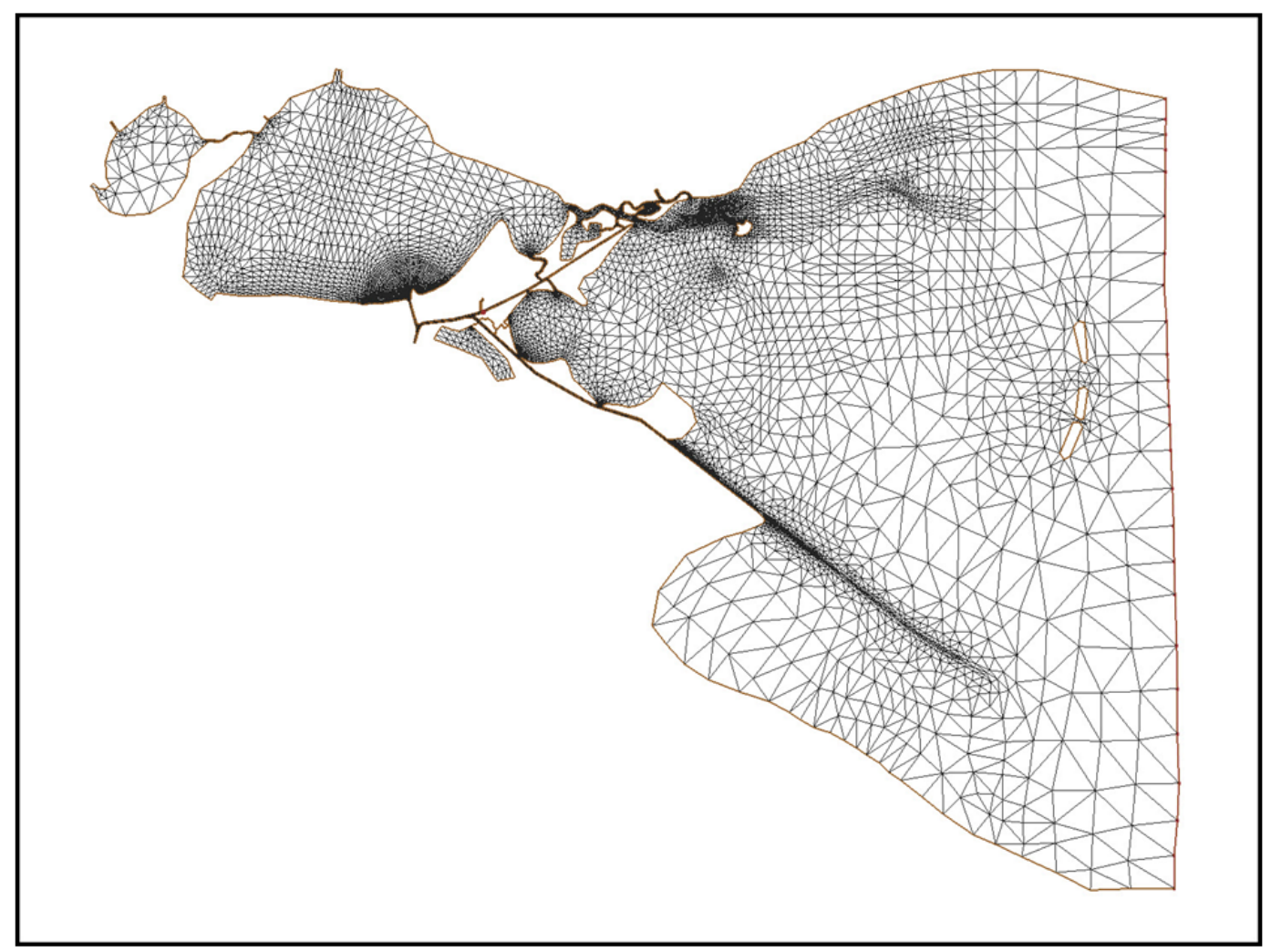

Figure 2-1. Model Domain and Grid Resolution. 


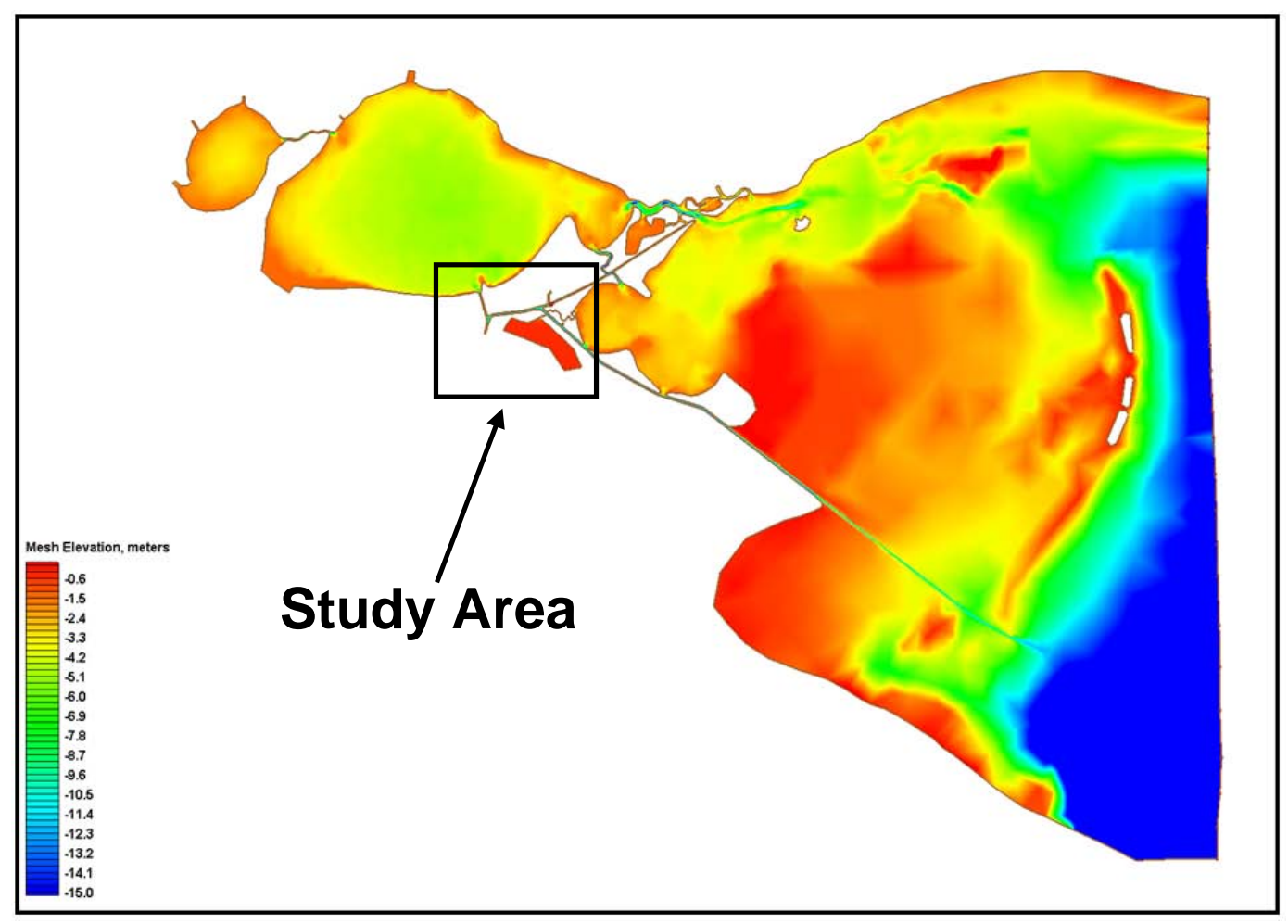

Figure 2-2. Model Elevations, meters NAVD88 (2004.65).

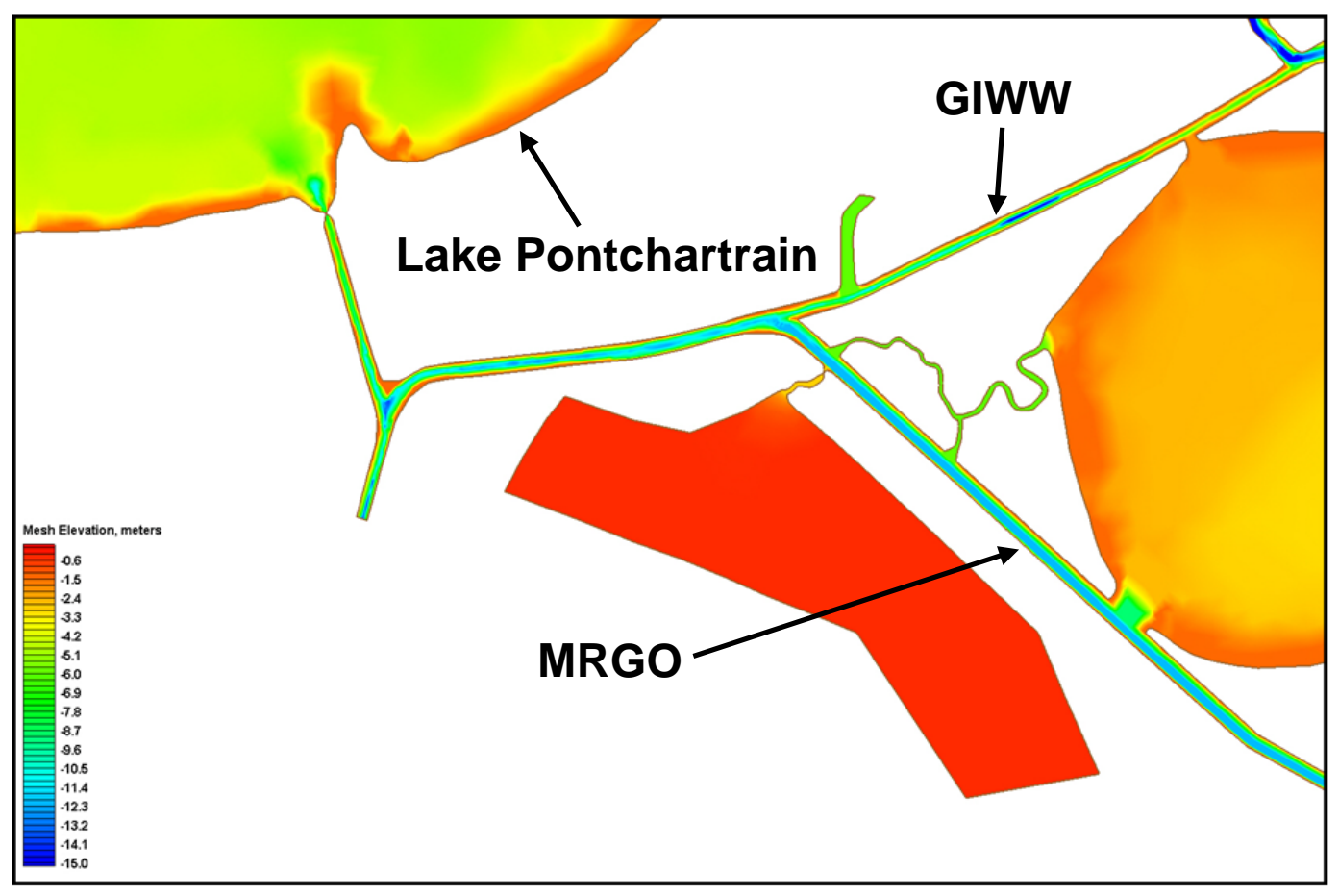

Figure 2-3. Study Area Elevations, meters NAVD88 (2004.65). 


\section{Boundary Conditions}

One set of boundary conditions was developed and applied for the base condition and all alternatives. These boundary conditions included river inflows, tidal forcings, and wind conditions.

The river inflows to the model domain were taken from the U.S. Geologic Survey streamflow database for the year 2006. Daily average values were applied to the model at six locations: the Pearl River, the Amite River, the Blind River, the Tchefuncte River, the Tickfaw River, and the Tangipahoa River. Ungaged flows were not factored into the model. The 2006 flows for each of the rivers are shown in Figure 2-4. The Blind River was not included on the plot, as a constant flow of 216 cfs was used for this river (see McAnally et al, 1997).

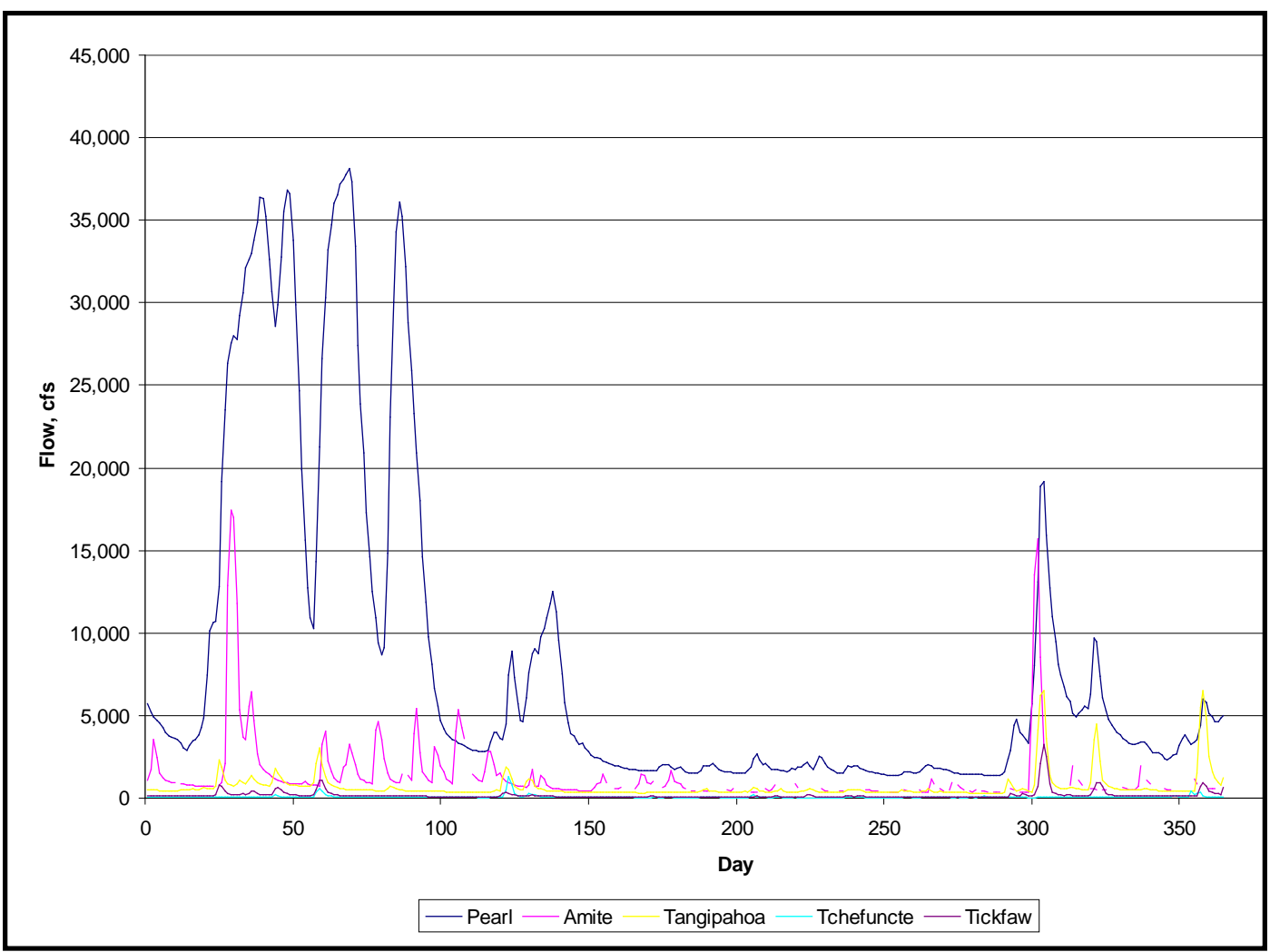

Figure 2-4. River Inflows for 2006.

The tidal forcings for the hydrodynamic model were generated using 2006 NOAA gage data located at the Waveland Yacht Club (gage \#8747437) in Waveland, MS and Pilots Station East, Southwest Pass (gage \#8760922) near the mouth of the Mississippi River. Although the SW Pass gage is located near the mouth of the Mississippi River, the river flow effects on the 
water level were found to be negligible. The time series of observed data for the endpoints of the tidal boundary are shown in Figures 2-5 and 2-6. First, the predicted tides were generated using version of NOAA's NTP program that was modified by ERDC personnel. This modified version of the NTP program generated the predicted tide at two gage locations, the boundary endpoints, and interpolated the amplitudes and phases between the endpoints to generate a predicted tide at each node along the boundary. The next step was to add the meteorological forcing to the tidal signal at each boundary node. This task was accomplished by subtracting the predicted tide from the observed tide at both endpoints leaving the meteorological forcing for each endpoint. These endpoints were then linearly interpolated to generate a meteorological forcing at each node along the tidal boundary. This linear interpolation used the distance from each of the gages as a weighting factor in the calculation. The meteorological forcings were then combined with the predicted tidal signals in order to generate an interpolated observed tidal signal at each node.

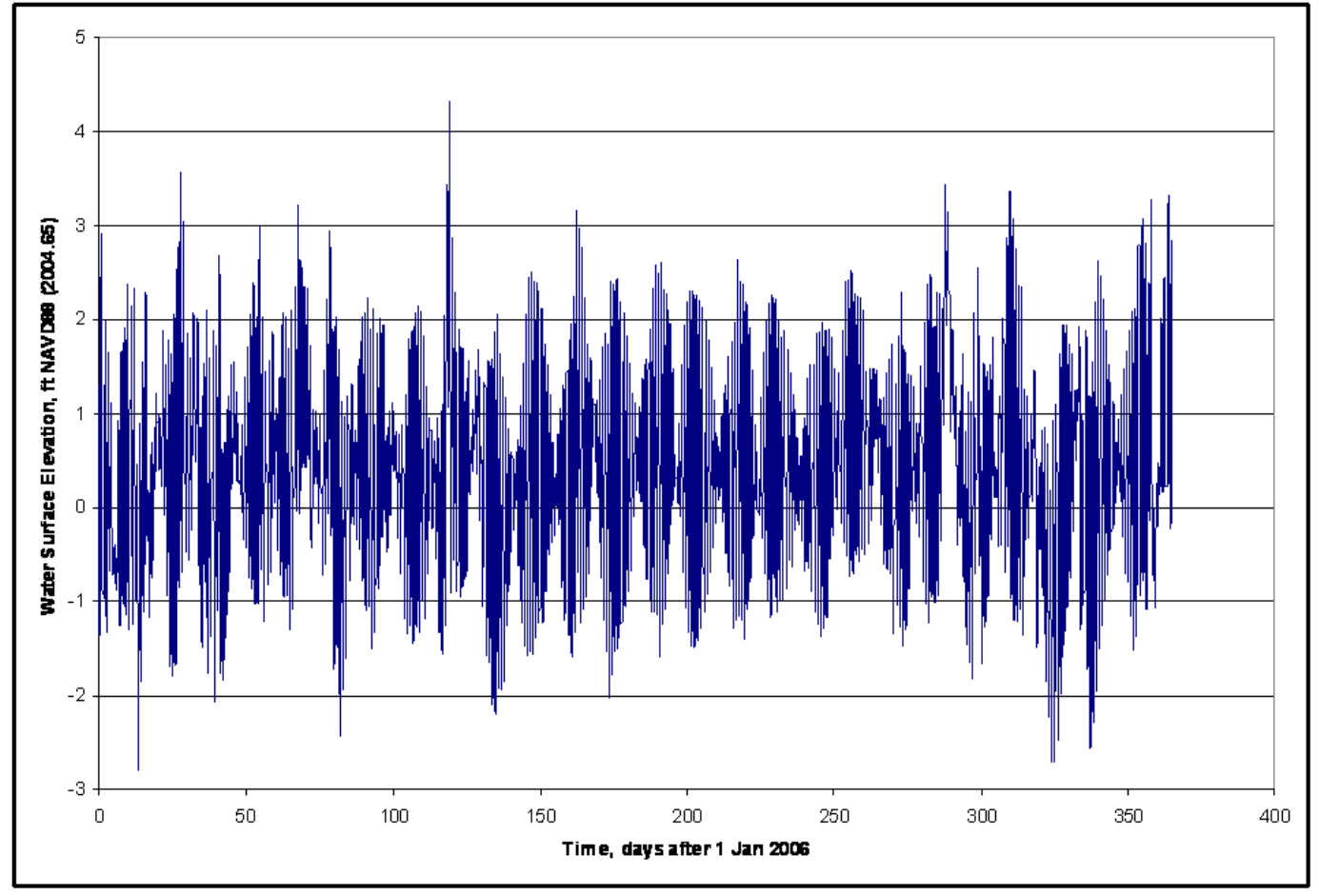

Figure 2-5. Waveland Yacht Club Gage. 


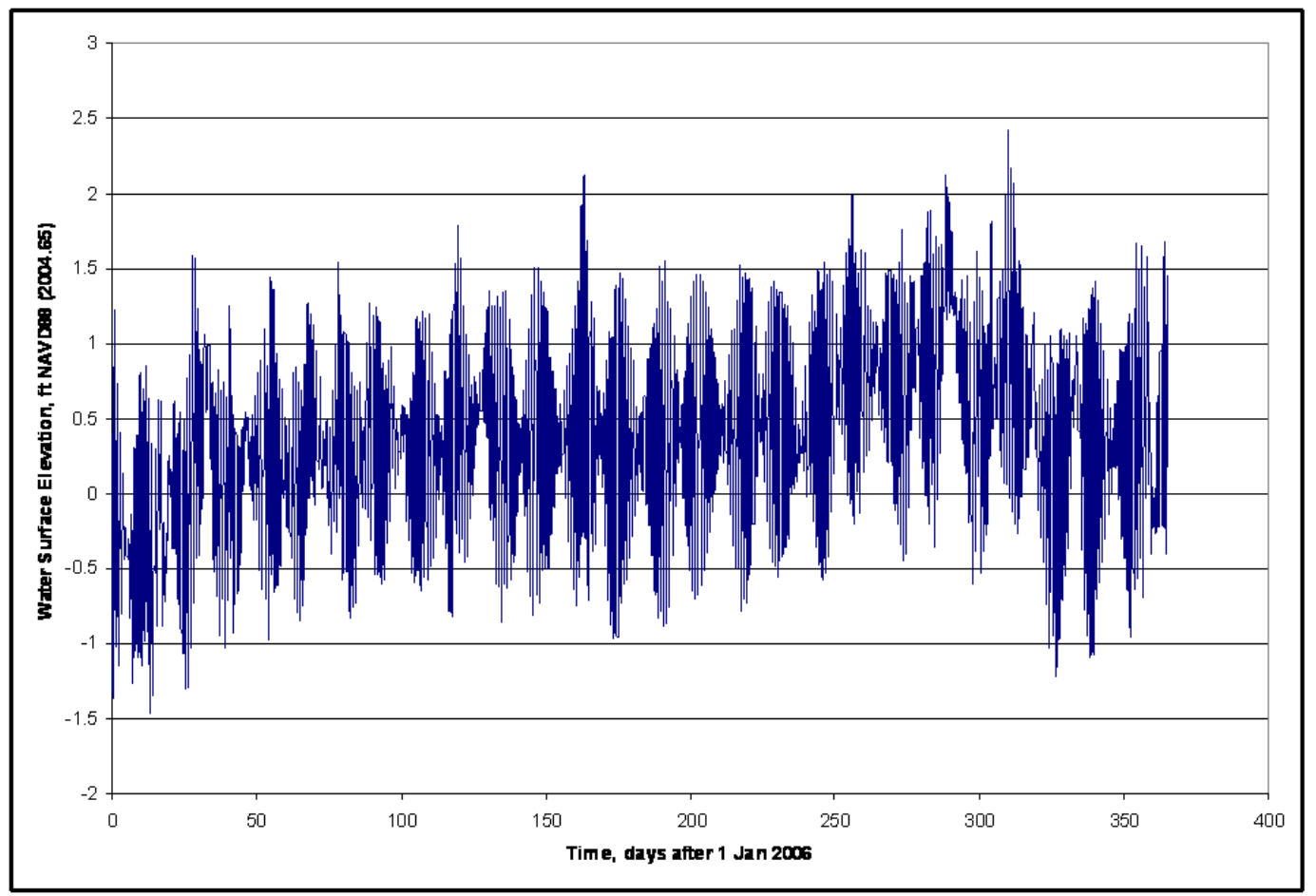

Figure 2-6. Pilots Station East, SW Pass.

The wind data used were obtained from the J oint Air Force and Army Weather Information Network and the Air Force Combat Climatology Center in Ashville, NC (see Figure 2-7). These data are hourly surface winds at the New Orleans International Airport (Station 722310 - KMSY) for calendar year 2006 and were collected at a height of $10 \mathrm{~m}$. This station was a land station and a land-sea correction was not performed on the data. This factor introduced some uncertainty to the wind shear stress calculations within the model due to wind speed differences over the land versus those over the water. No analyses were performed to compare the wind data from 2006 to prior years' wind data. One wind value per time increment was applied to the entire model domain.

\section{Model Verification}

The model was verified in a previous HPO study (Martin et al, 2010) for hydrodynamics using the TABS-MDS hydrodynamic code. However, a verification of the water surface elevations (Figure 2-8) and a tidal component analysis for the principal lunar tide (M2), principal solar tide (S2), Luni-solar (K1), and the long term (Mf) (Figures 2-9 and 2-10) were performed for the present study. The same boundary conditions were used for both models, $\mathrm{ADH}$ and TABS-MDS, with the only difference being that the TABS-MDS model was 3- $\mathrm{d}$ and the ADH model was 2-d. 


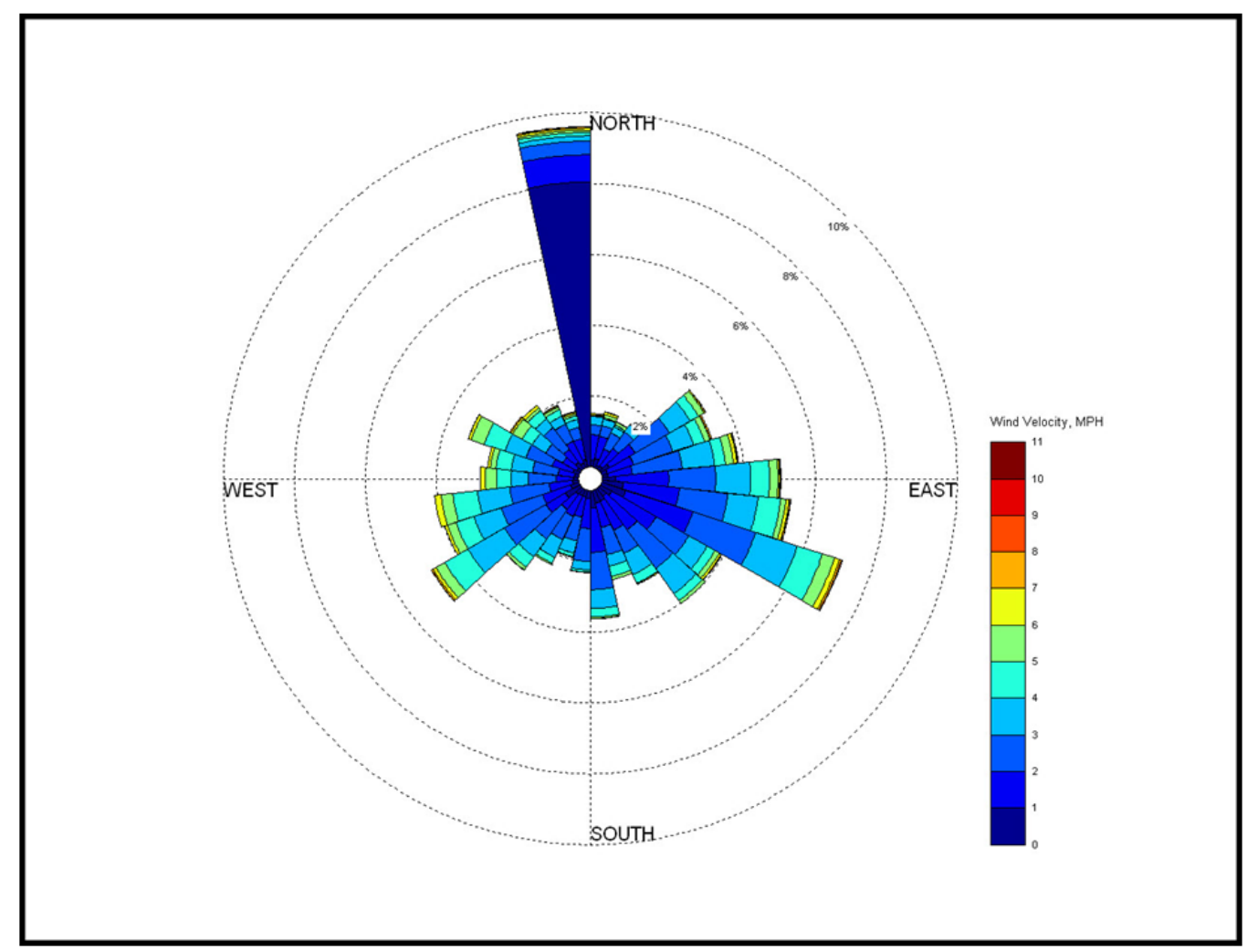

Figure 2-7. Wind Boundary Condition.

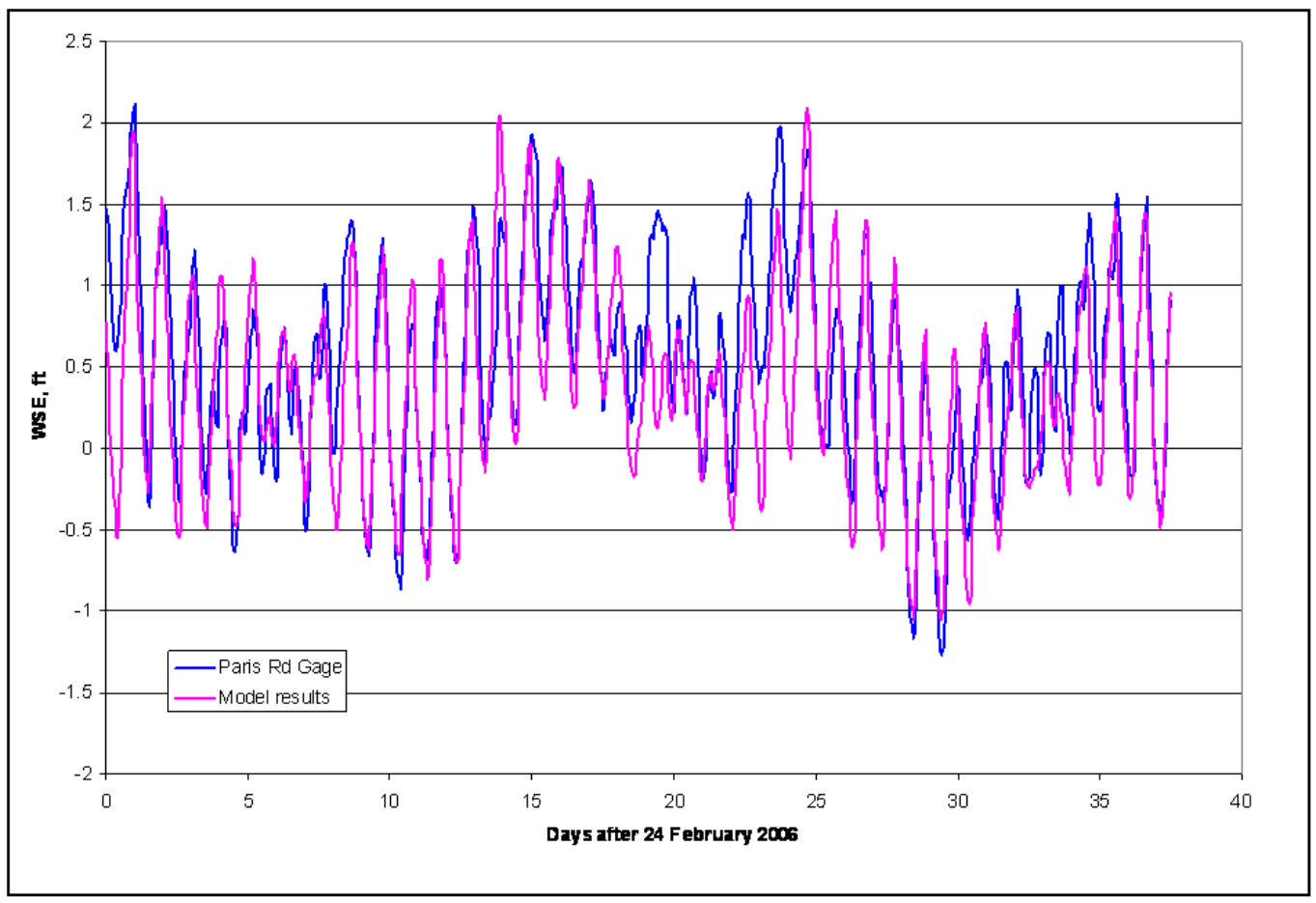

Figure 2-8. Verification at Paris Rd. 


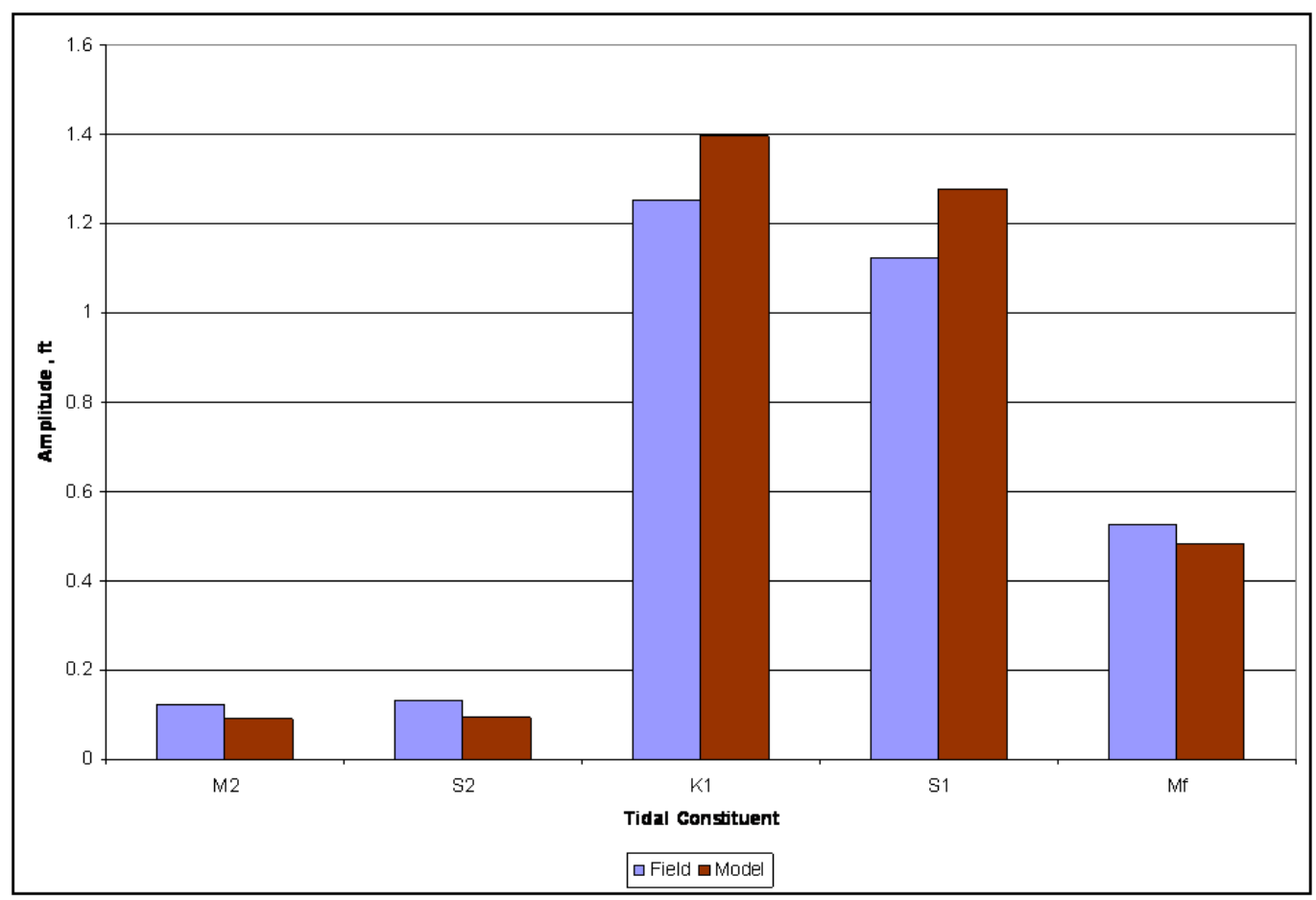

Figure 2-9. Tidal Component Analysis at Paris Rd - Amplitude.

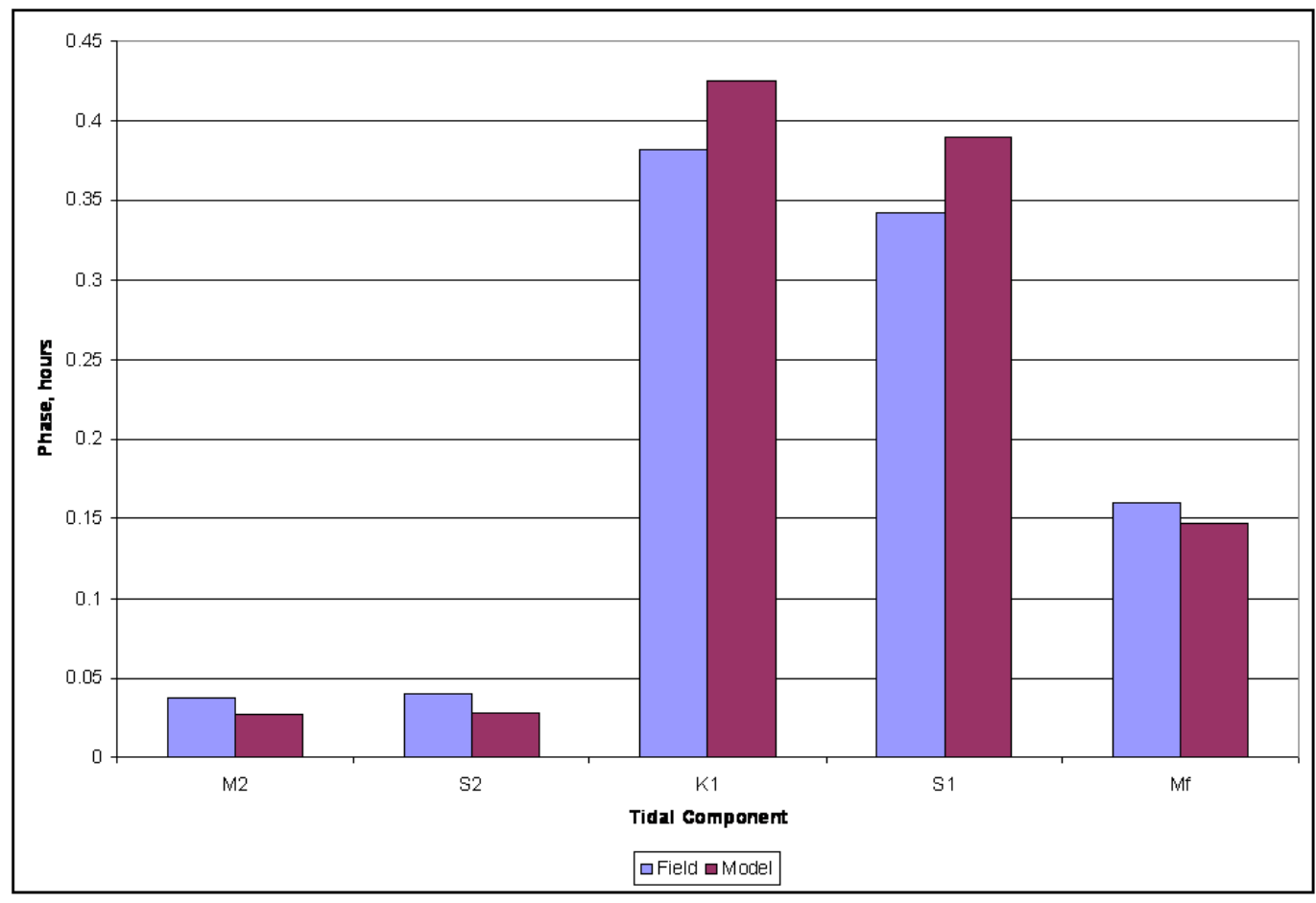

Figure 2-10. Tidal Component Analysis at Paris Rd - Phase. 
After the previous HPO study (Martin et al, 2010), ERDC gathered more field data (Tate et al, 2010) in 2008 at several locations in the study area (Figure 2-11) and the model was verified to the resulting discharge data (Figures 2-12 thru 2-14 and Tables 2-1 thru 2-3), using boundary conditions generated from 2008 data. Additionally, average velocity data across each transect from that same data gathering effort was compared to the $\mathrm{ADH}$ model results with favorable agreement. The average velocity across the transect in the study area for existing conditions was approximately $1.0 \mathrm{ft} / \mathrm{sec}$.

Considering the above results of the various analyses performed, the model results produced acceptable agreement with the field measurements for both the water surface elevations and the flow discharges. The average error between the computed and field discharge for line 1 was $11.26 \%$, for line 2 was $6.6 \%$ and for line 3 was $8.0 \%$. Overall the verification was considered to be reasonable.

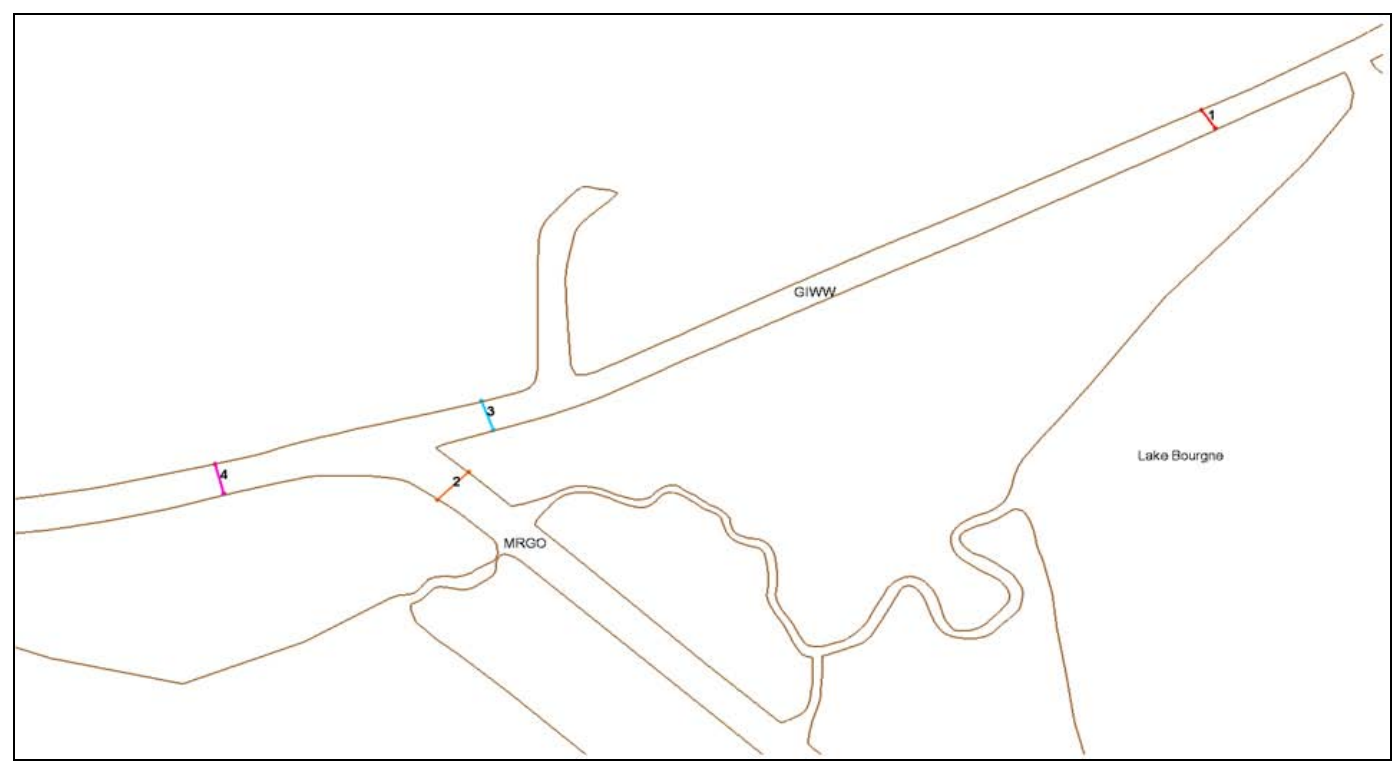

Figure 2-11. Field Data Transects. 


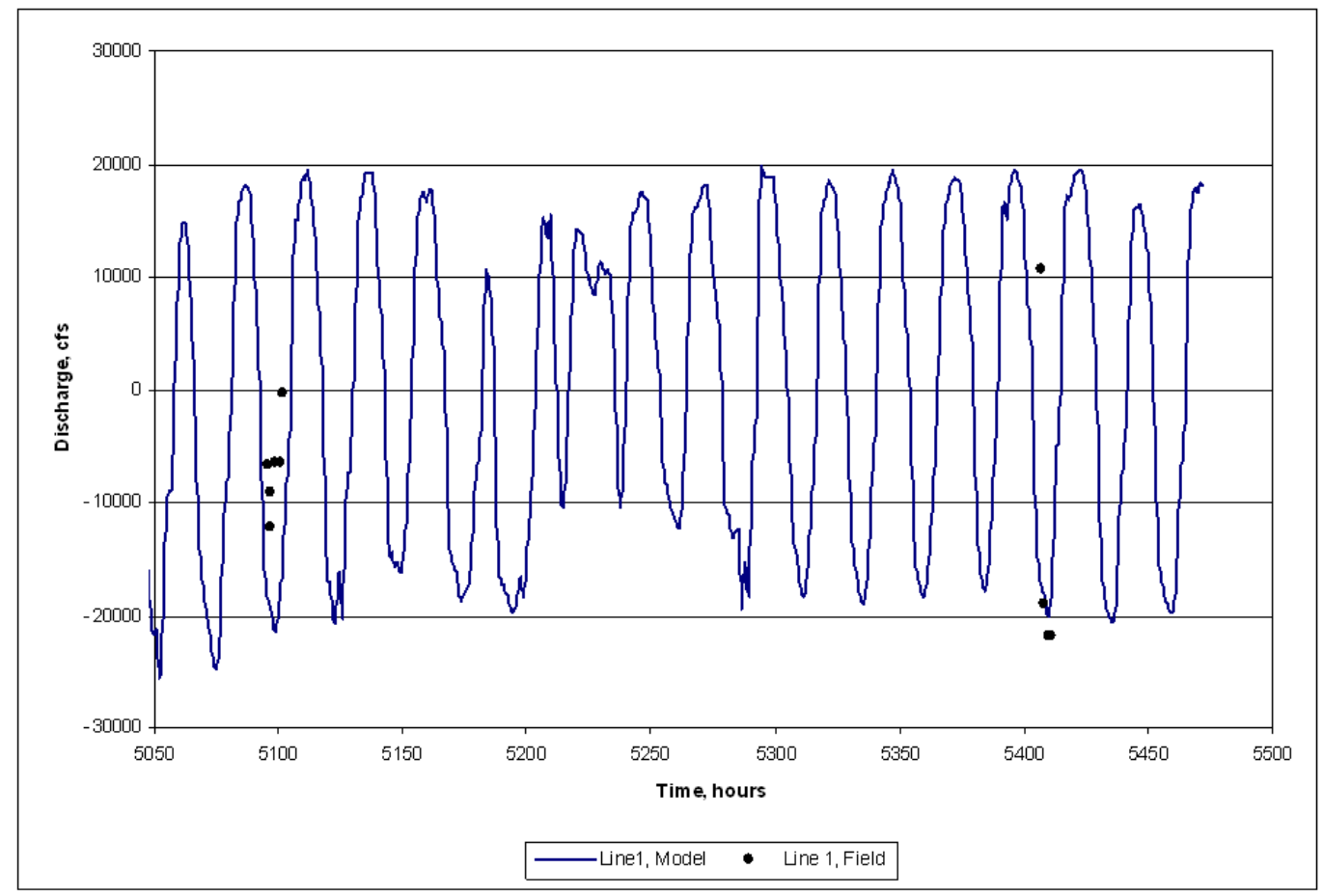

Figure 2-12. Discharge Comparison - Line 1.

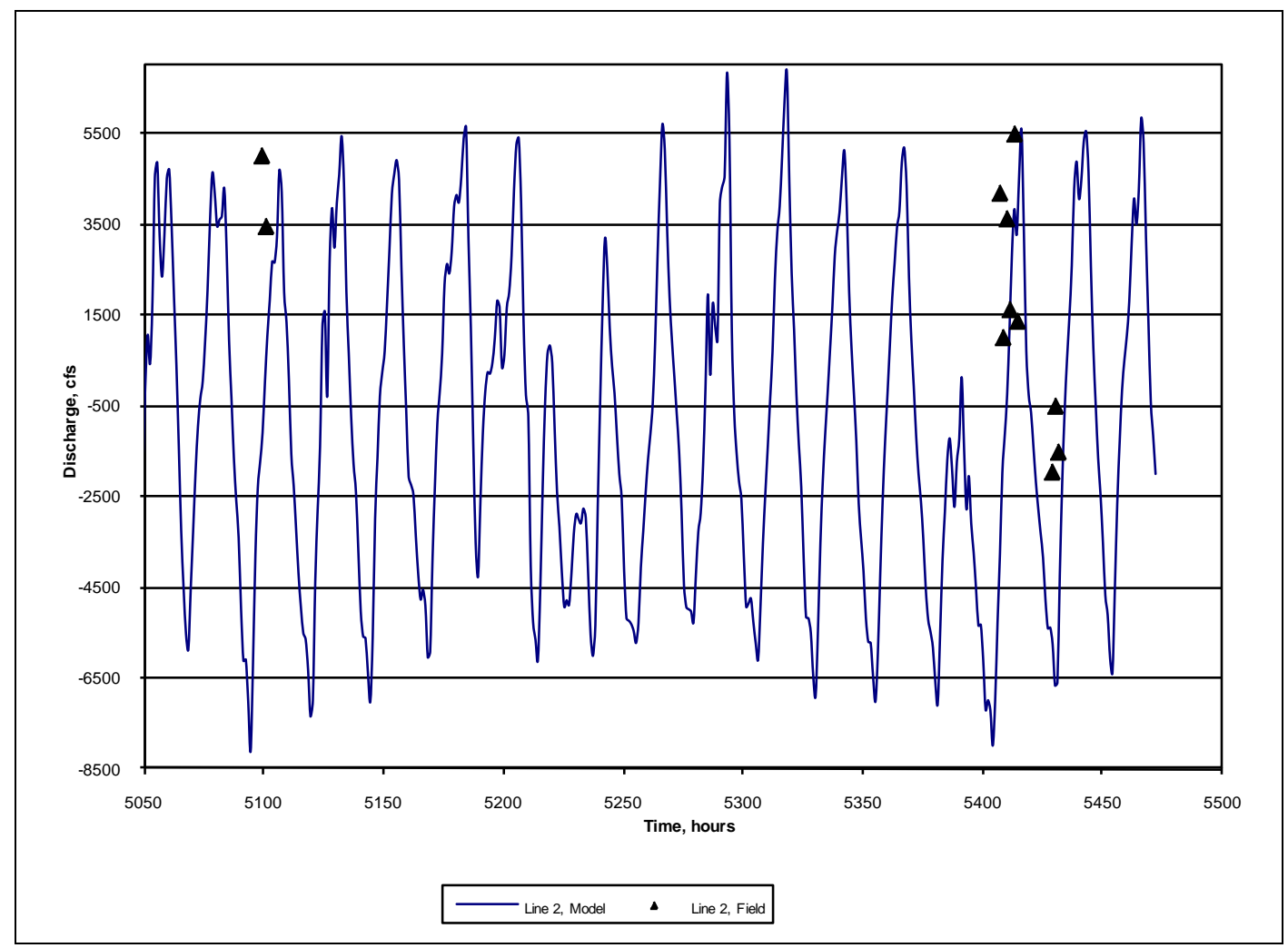

Figure 2-13. Discharge Comparison - Line 2. 


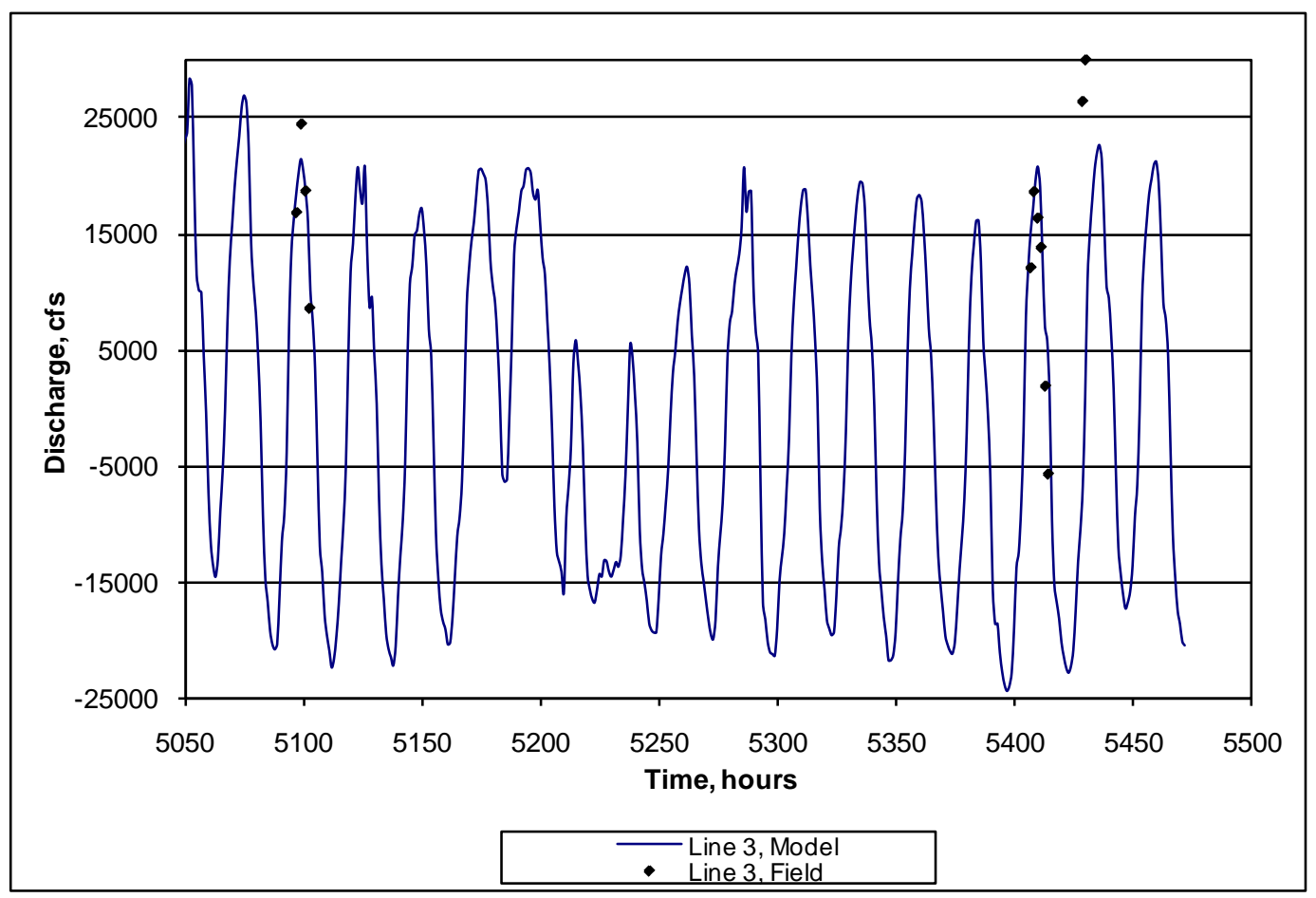

Figure 2-14. Discharge Comparison - Line 3.

Table 2-1. Discharge Comparison - Line 1.

\begin{tabular}{|l|l|l|l|}
\hline TIME (hours) & Line 1 Field Discharge (cfs) & Line 1 Model Discharge (cfs) & \% Error \\
\hline 5096 & 9165 & 13022 & -42.084 \\
\hline 5408 & 18951 & 18027 & 4.875732 \\
\hline 5411 & 20802 & 20087 & 3.43717 \\
\hline
\end{tabular}

Table 2-2. Discharge Comparison - Line 2

\begin{tabular}{|l|l|l|l|}
\hline TIME (hours) & Line 2 Field Discharge (cfs) & Line 2 Model Discharge (cfs) & \% Error \\
\hline 5100 & 3468 & 2640 & 23.88 \\
\hline 5408 & 1016 & 1185 & -16.63 \\
\hline 5410 & 3638 & 3304 & 9.18 \\
\hline 5411 & 1634 & 1650 & -0.98 \\
\hline 5413 & 5510 & 4540 & 17.60 \\
\hline
\end{tabular}

Table 2-3. Discharge Comparison - Line 3.

\begin{tabular}{|l|l|l|l|}
\hline TIME (hours) & Line 3 Field Discharge (cfs) & Line 3 Model Discharge (cfs) & $\%$ Error \\
\hline 5100 & 18665 & 18669 & -0.02 \\
\hline 5408 & 18609 & 19475 & -4.65 \\
\hline 5410 & 16331 & 20756 & -27.09 \\
\hline 5411 & 13780 & 13775 & 0.04 \\
\hline
\end{tabular}




\section{Plan Alternatives}

The plan alternative was developed with the aim at reducing flooding in the region due to storm passage while at the same time allowing for continued navigation of the system under non-severe weather conditions. The plan alternative (Figures 3-1 thru 3-4) was developed by modifying the mesh according to $\mathrm{CAD}$ drawings provided by HPO and consisted of several parts (Figure 3-1):

a. A dual gate structure on the GIWW east of the Michoud Canal

b. A $56 \mathrm{ft}$ by $8 \mathrm{ft}$ structure on Bayou Bienvenue

c. Secondary closure of MRGO (first closure is at la Loutre)

d. Floodwall connecting first three items built to $100 \mathrm{yr}$ specifications.

A proposed sector gate structure at Seabrook (Figure 3-1) was not included in the mesh but is part of a separate study (Tate et al, 2010). The sector gate on the northern side of the structure and the barge gate on the south were both $150 \mathrm{ft}$ in width. The outer guidewalls were approximately $500 \mathrm{ft}$ in length and the inner guidewalls were approximately $310 \mathrm{ft}$ in length (Figure 3-2). The bottoms of the guidewalls were $5 \mathrm{ft}$ above the channel bottom. The spacing under the guidewalls was simulated by using ADH's lid capability. This capability enabled investigators to treat the guidewalls as stationary vessels with a draft that maintained a $5 \mathrm{ft}$ spacing between the bottom of the vessels and the channel bottom. Figures 3-3 and 3-4 illustrate the mesh modifications and bathymetric changes, respectively, implemented for the GIWW structure.

The alternative was then run under an observed flow condition selected from the 2006 boundary conditions. The plan alternative was also used to simulate a storm surge condition without the tidal component.

\section{Observed Flow Condition}

The observed flow condition was selected as one that produced higher than normal velocities in the GIWW. One such condition existed during 
the selected month of J une 2006. The maximum flood/ ebb sequence occurred on J une 10-11 (ordinal days 161-162) during a spring tide with winds of approximately $15 \mathrm{mph}$.

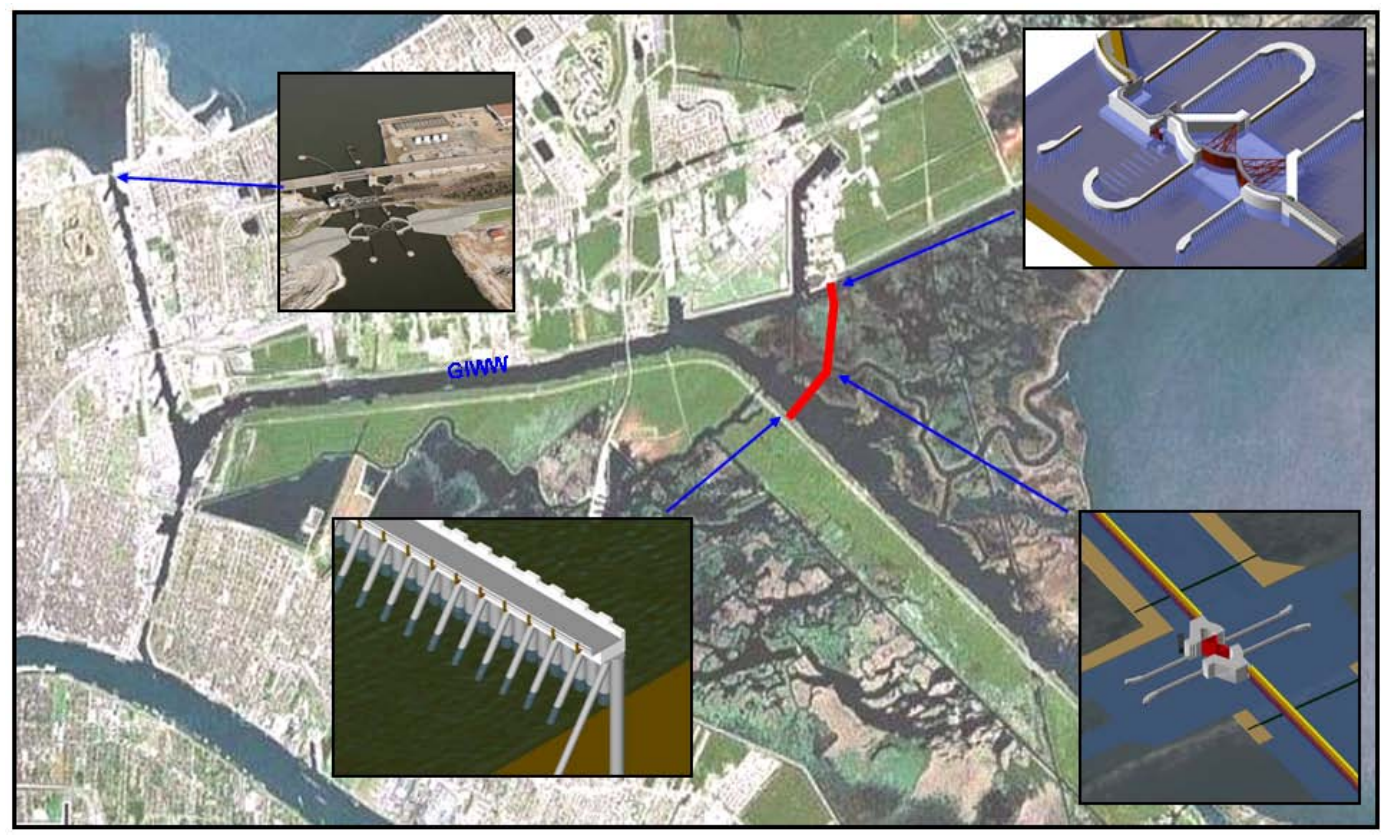

Figure 3-1. Surge Barrier Configuration.

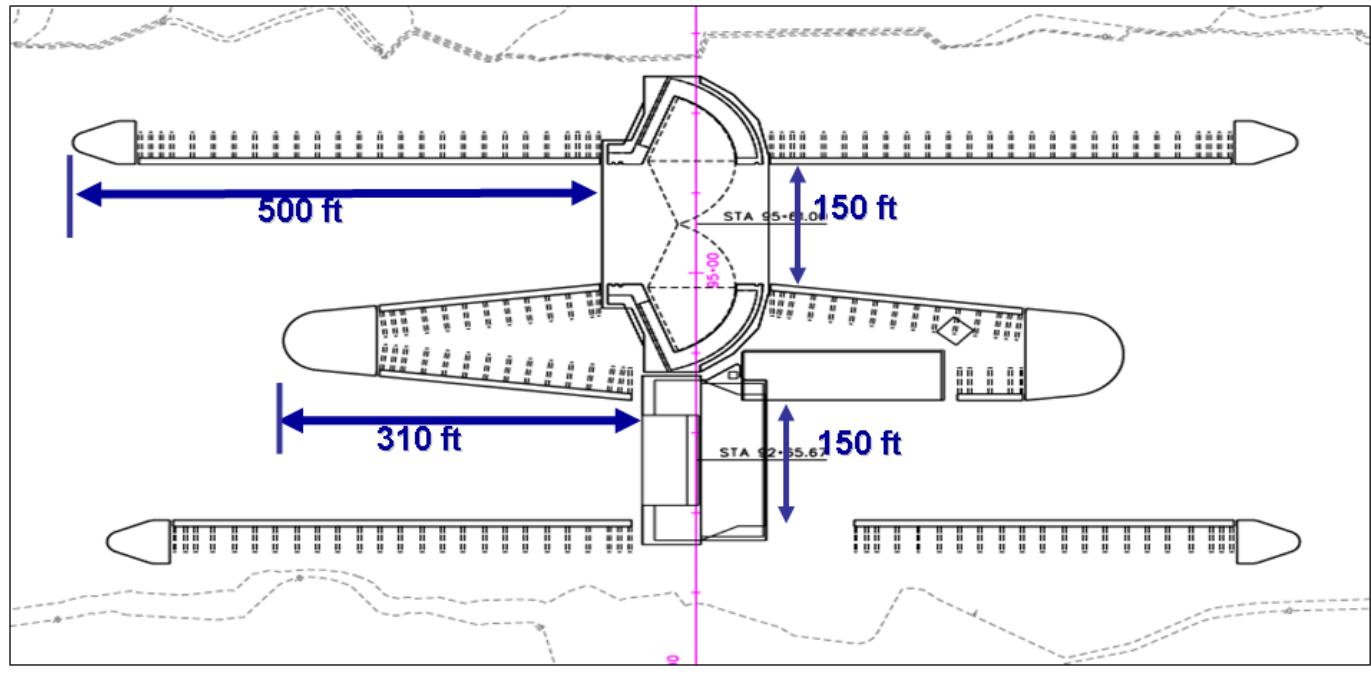

Figure 3-2. GIWW Structure Configuration. 


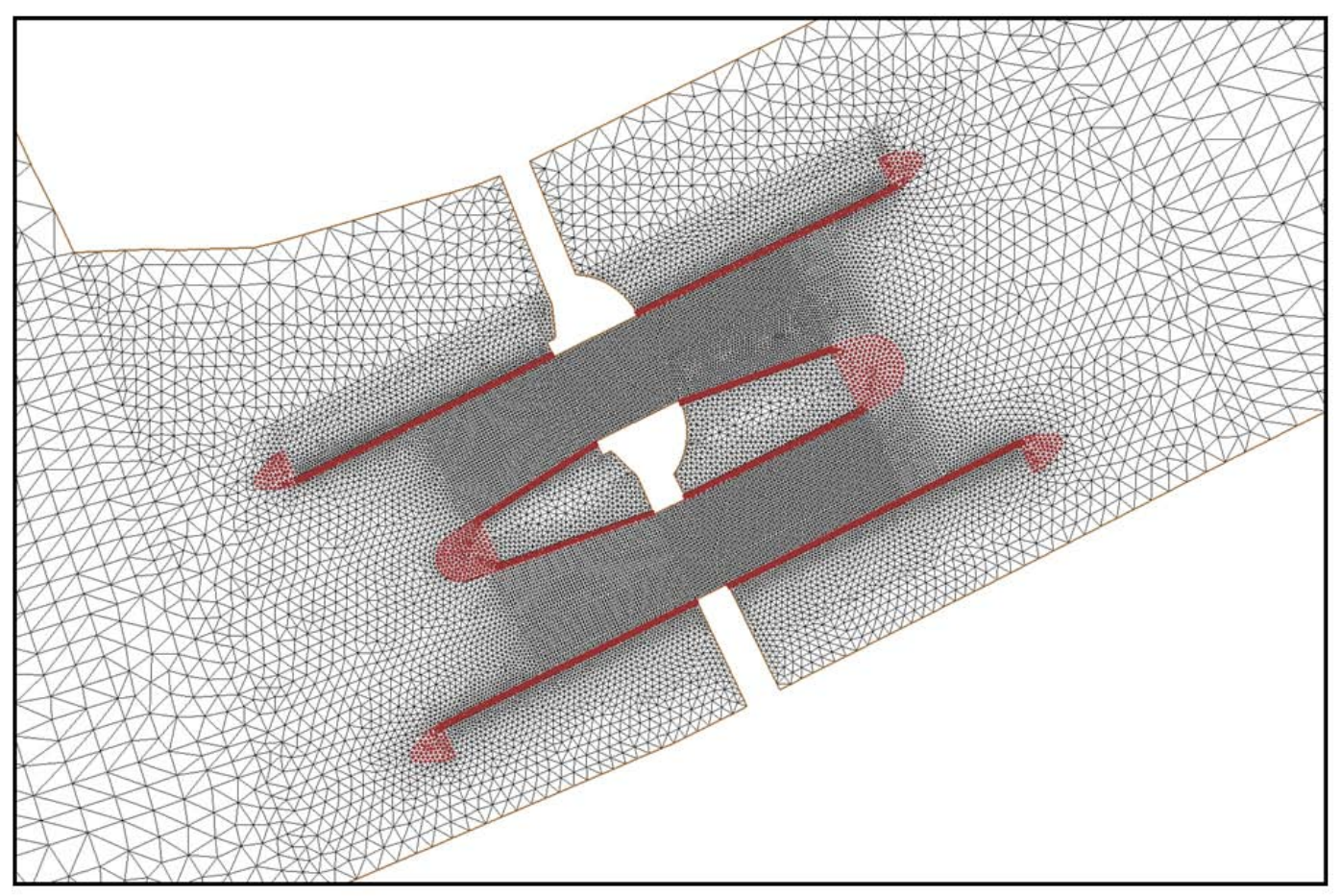

Figure 3-3. GIWW Floodgate Structure Mesh.

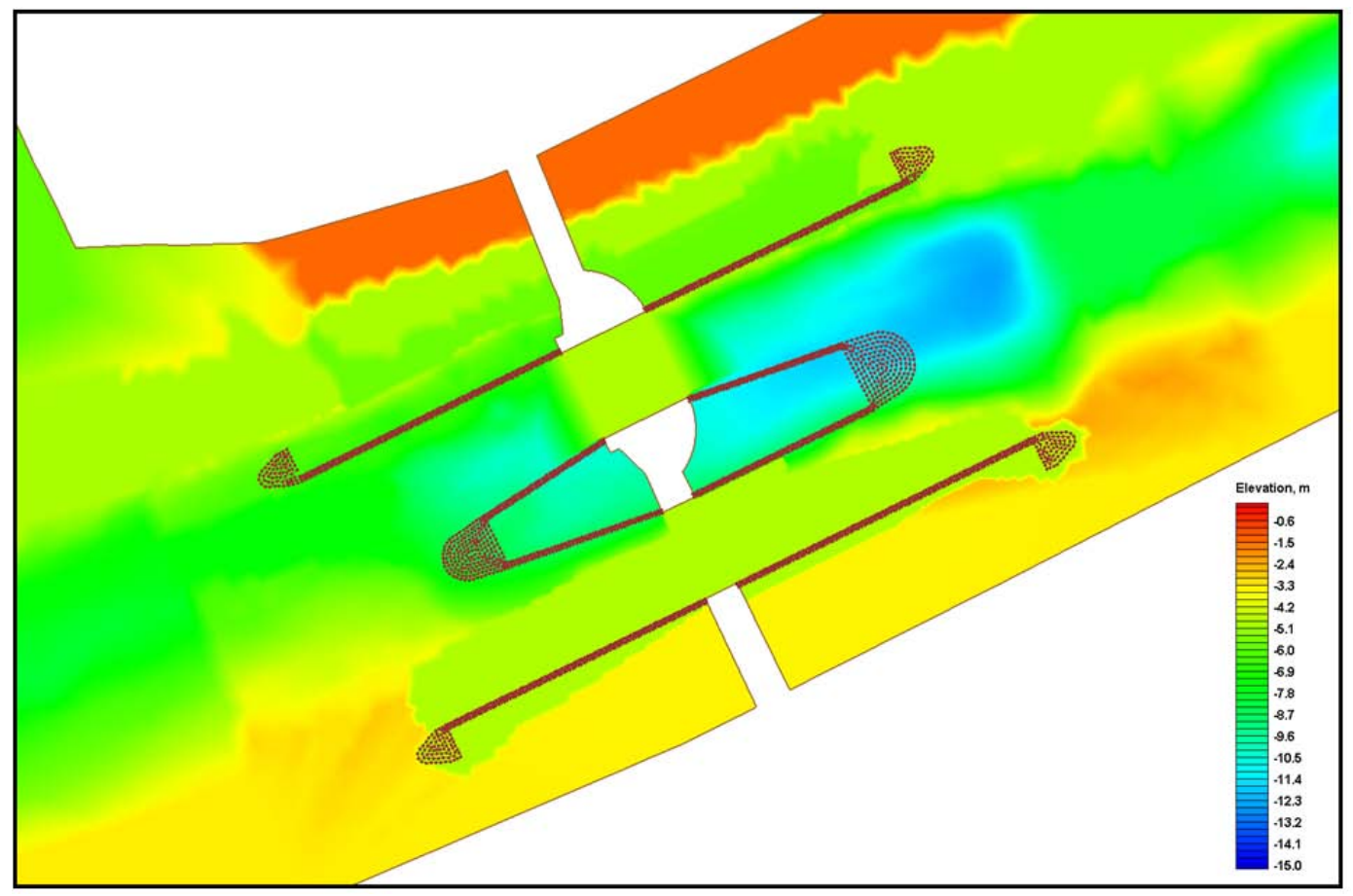

Figure 3-4. GIWW Floodgate Structure Contours. 


\section{Storm Surge Condition}

A suite of 152 storms was developed as part of the Flood Insurance Study (FIS) for Southeastern Louisiana. The surge signal from storm 53 (Corps of Engineers, 2008) was selected and applied along the tidal boundary (Figure 3-5). Storm 53 had a central pressure of 900 millibars, a radius to max winds of 18.4 nautical miles, and a forward speed of $11 \mathrm{knots}$. The track the storm followed was T7 (Figure 3-6). The effects of the normal tidal signal were not taken into account for this simulation as the rising surge produces much higher velocities in the GIWW structure than those observed under normal conditions even when a frontal passage is included.

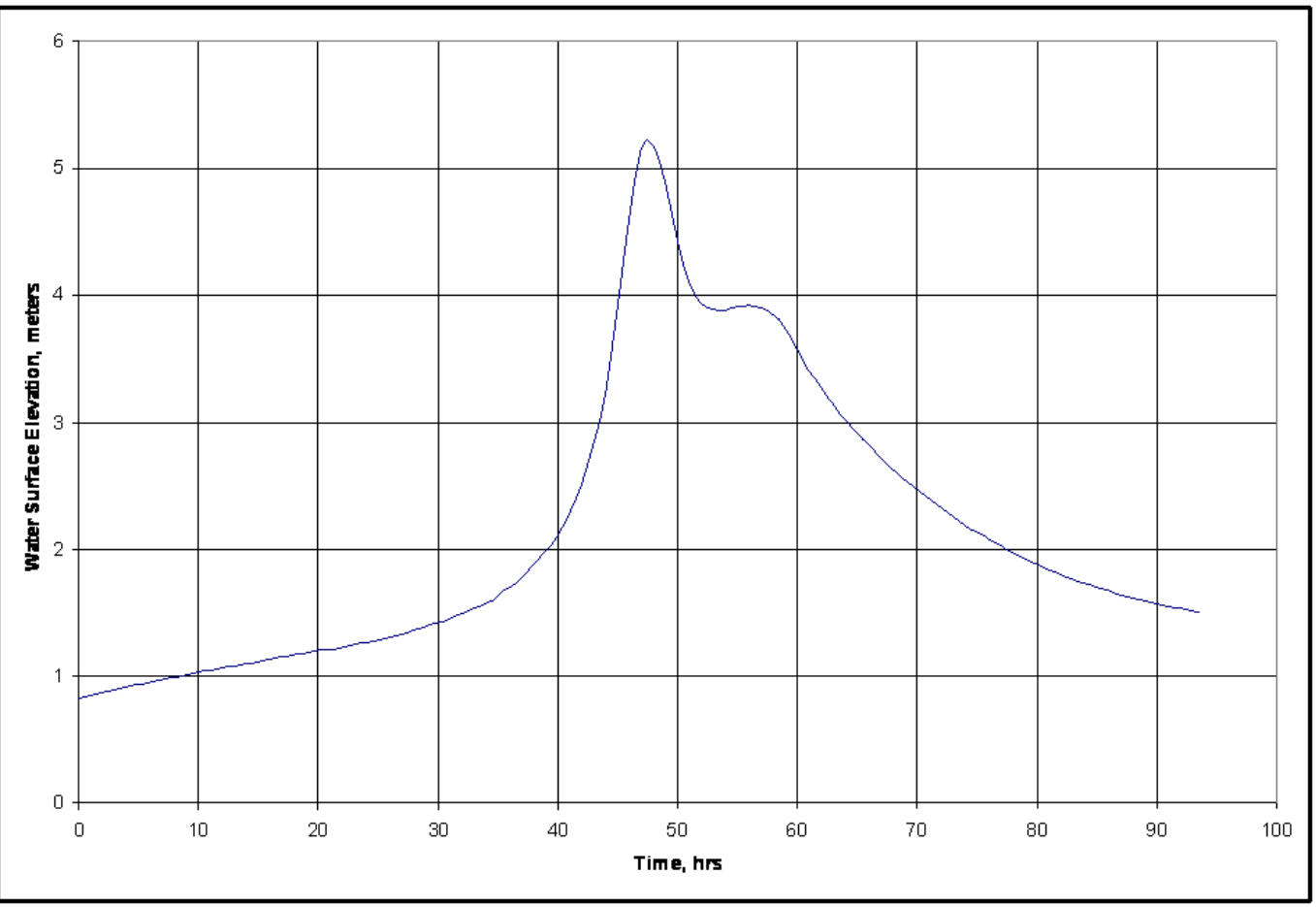

Figure 3-5. Storm Surge Signal. 


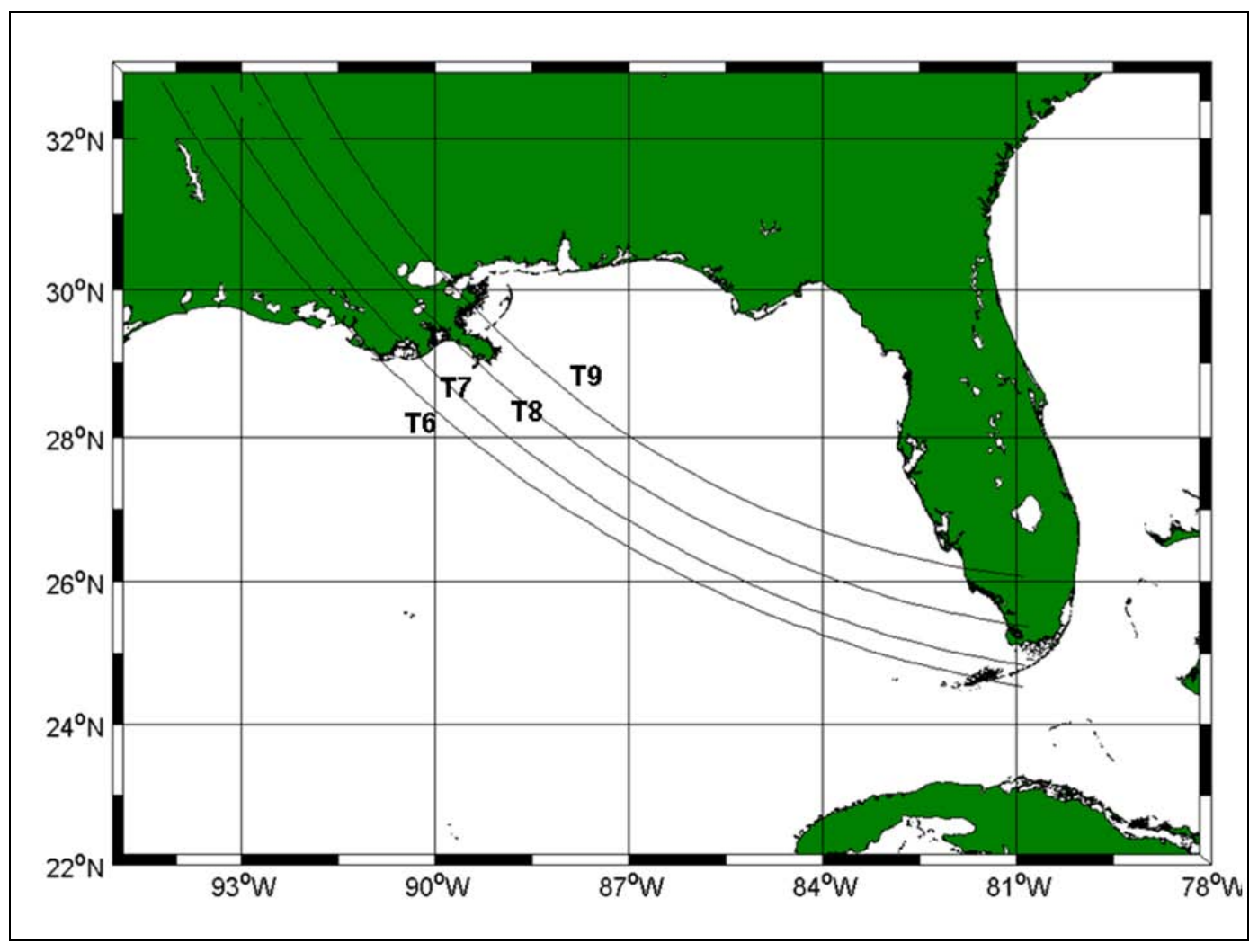

Figure 3-6. Storm Tracks used in FIS study. 


\section{Results}

\section{Observed Flow Condition}

Four simulations with the surge barrier in place were run for the observed flow condition. Currents from all four simulations were provided to ship navigation personnel at ERDC for use in ERDC's ship simulator. Pilots familiar with the GIWW near New Orleans were then brought to ERDC to navigate the GIWW structure with the model currents to assess the realism of the hydrodynamic simulations under existing conditions and the simulated vessel response to the current velocities and patterns associated with the implementation of the GIWW structure.

The first simulation was performed with all gates on all structures open. The barge gate on the GIWW gate was closed for the second simulation. The final two simulations were performed to represent vessel effects on current patterns for two different size vessels ( 54 feet wide and 108 feet wide) in the sector gate. These simulations were performed with the barge gate in the open position.

\section{All Gates Open}

For J une 2006, the maximum flood and ebb conditions occurred during a spring tide on J une 11 (ordinal day 162). The maximum velocities were measured at the two points in Figure 4-1 with the red point being the measurement location for the flood condition and the green point for the ebb condition. The predicted model velocities for the GIWW floodgate are illustrated in Figures 4-2 and 4-3. Maximum flood velocity in the model was approximately $1.7 \mathrm{~m} / \mathrm{sec}$ or $5.4 \mathrm{ft} / \mathrm{sec}$. The maximum ebb velocity was approximately $1.1 \mathrm{~m} / \mathrm{sec}$ or $3.7 \mathrm{ft} / \mathrm{sec}$. These maximum conditions occurred for the boundary conditions for 11 J une 2006.

An examination of the model results showed the velocities moving back and forth across the channel in a whip-like fashion as they exited GIWW structure's constriction. A snapshot of this condition is observed in Figure 4-2 where the current pattern west of the structure is centered just to the South of the centerline of the structure. As the flood phase progressed, the center of the current pattern moved north of the centerline of the channel and back again. This phenomenon is attributable to the rapid 


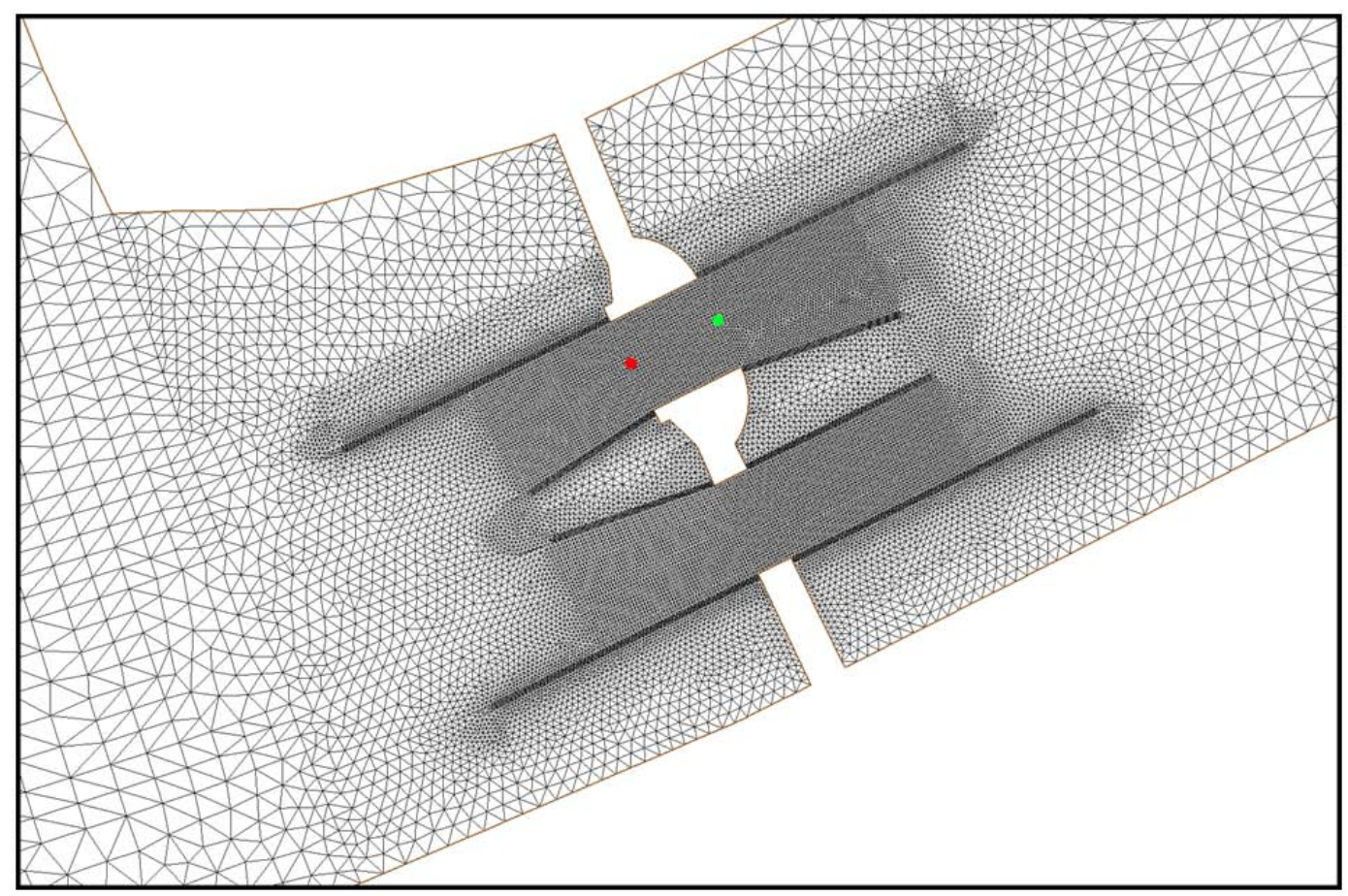

Figure 4-1. Velocity Measurement Locations.

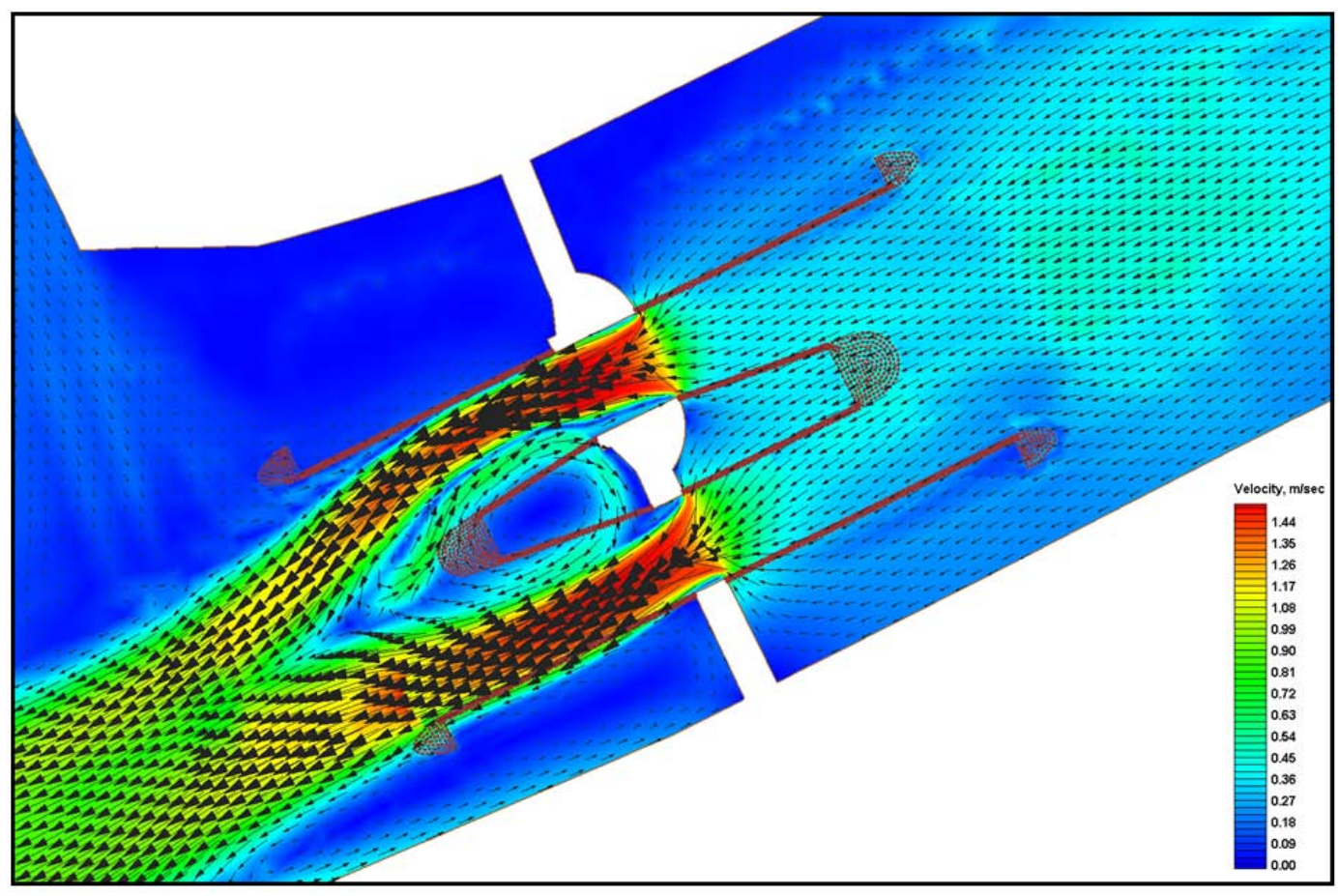

Figure 4-2. Maximum Flood Velocities in GIWW Structure. 


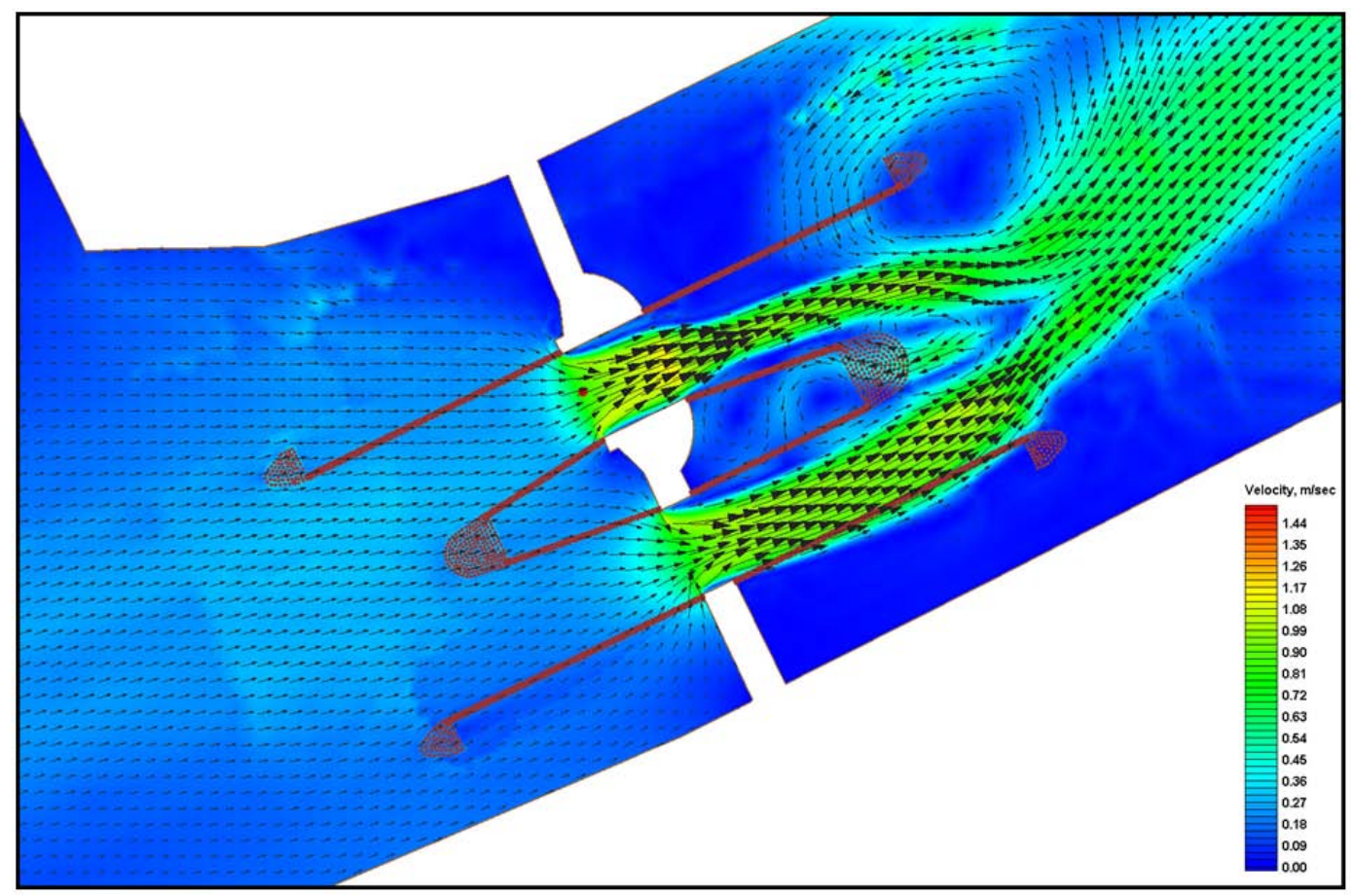

Figure 4-3. Maximum Ebb Velocities in GIWW Structure.

expansion of the cross-section outside of the structure. This phenomenon is observed on both the flood and ebb phases of the tide. Another aspect of this phenomenon is an eddy that sometimes forms at the tip of the guidewall opposite the center of the current pattern (see Figure 4-3). Another eddy that varies in size forms over the center guidewall for both flood (Figure 4-2) and ebb (Figure 4-3) conditions.

The navigation limitation on flow velocity is less than 3 miles per hour which is $4.4 \mathrm{ft} / \mathrm{sec}$ or $1.34 \mathrm{~m} / \mathrm{sec}$. The maximum ebb velocity for J une 2006 approaches this threshold and the maximum flood velocity exceeds it. Depending upon weather conditions, such as frontal passage, these velocities could be higher or lower. It is important to remember, though, that these conditions could occur at most once or twice during a tidal cycle and even then most probably only during either strong frontal storms and/ or strong spring tidal events. A closer examination of the boundary conditions for 2006 supports this hypothesis. An exceedance plot covering the entire year of 2006 in Figure 4-4 illustrates the low frequency nature of these high velocity events. Note that the percentile (y-axis) indicates the percentage of velocities that are below the value (x-axis). Therefore, Figure 4-4 shows that the navigational threshold of $4.4 \mathrm{ft} / \mathrm{sec}, 1.34 \mathrm{~m} / \mathrm{sec}$, is exceeded only 2 percent of the time annually for 2006 . 
Simulations performed with the proposed structure at Seabrook closed (see Figure 4-5) showed that closing the Seabrook structure reduced velocities in the GIWW structure approximately 50 percent (see Figures 4-6 and 4-7).

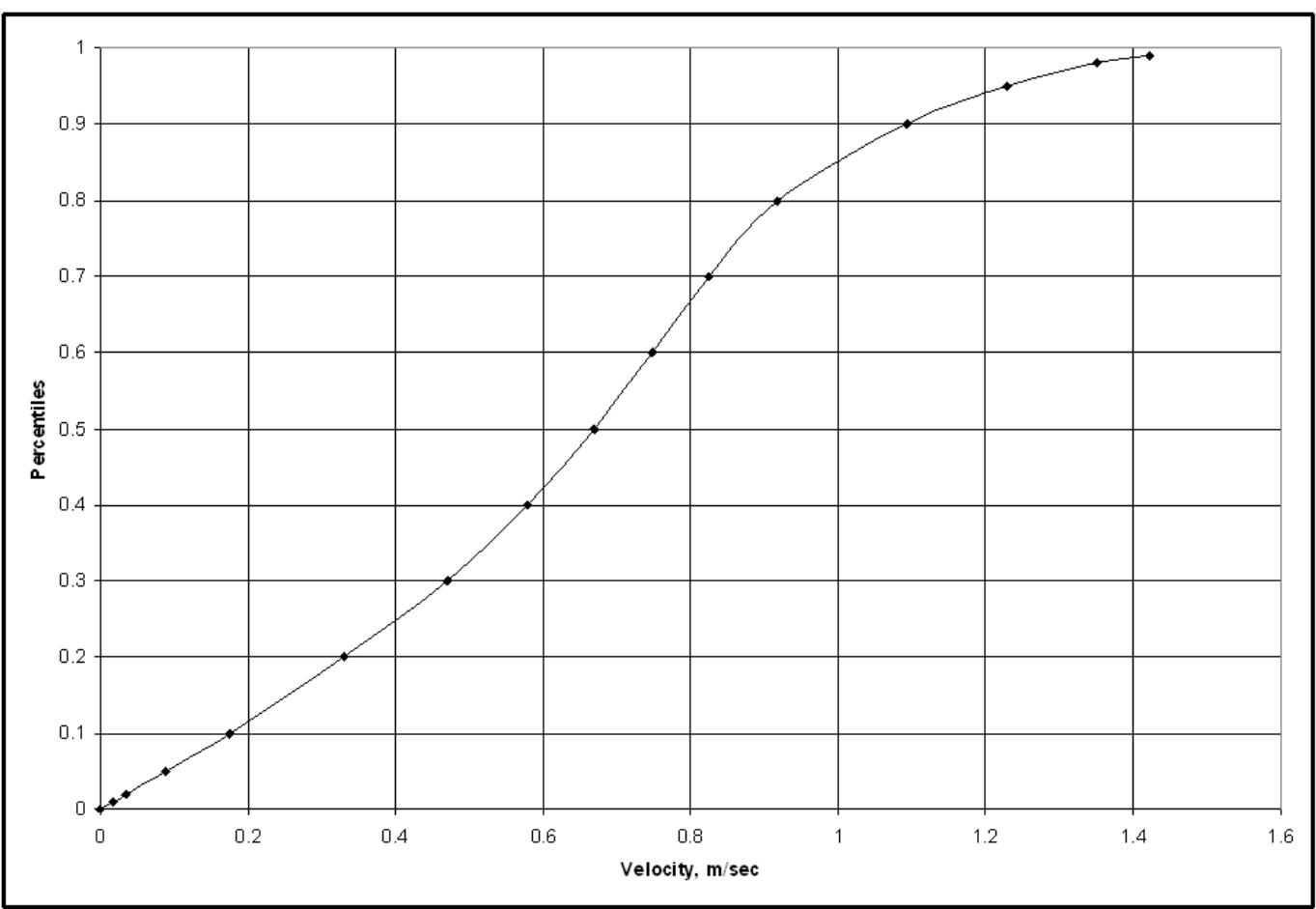

Figure 4-4. Exceedance Plot for year 2006.

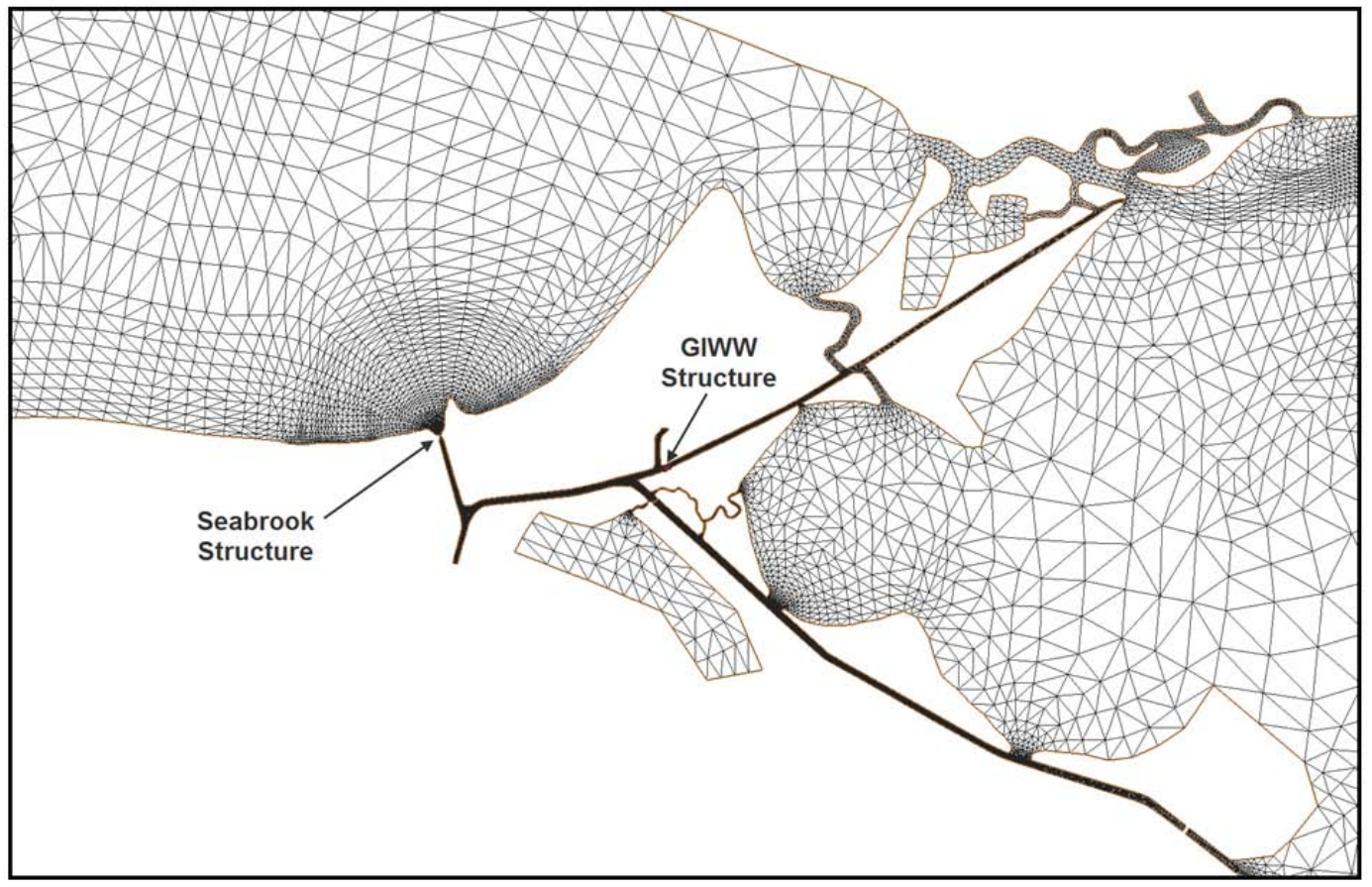

Figure 4-5. Location of Seabrook Structure. 


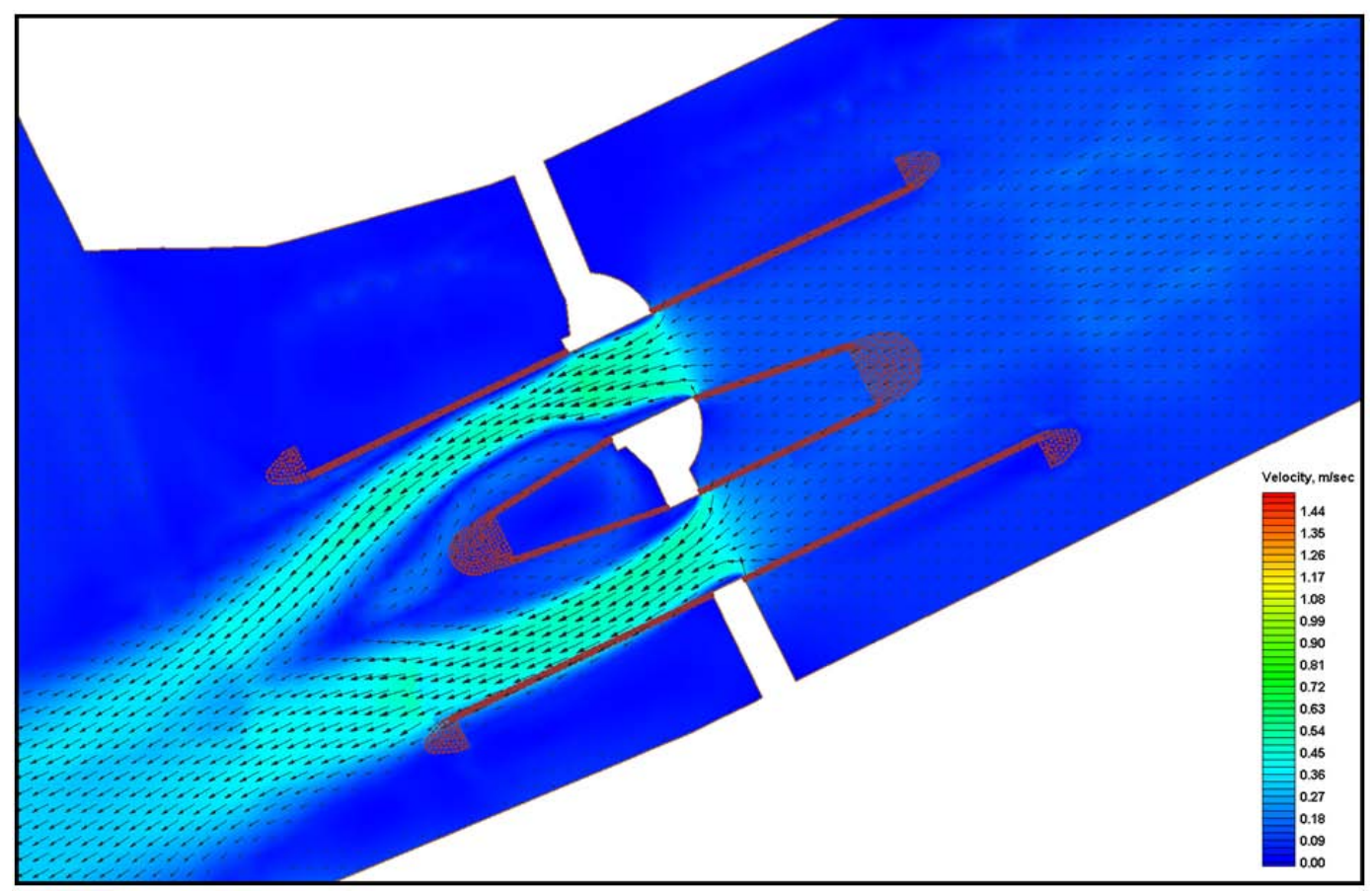

Figure 4-6. Maximum Flood Velocities in GIWW Structure with Seabrook Structure Closed.

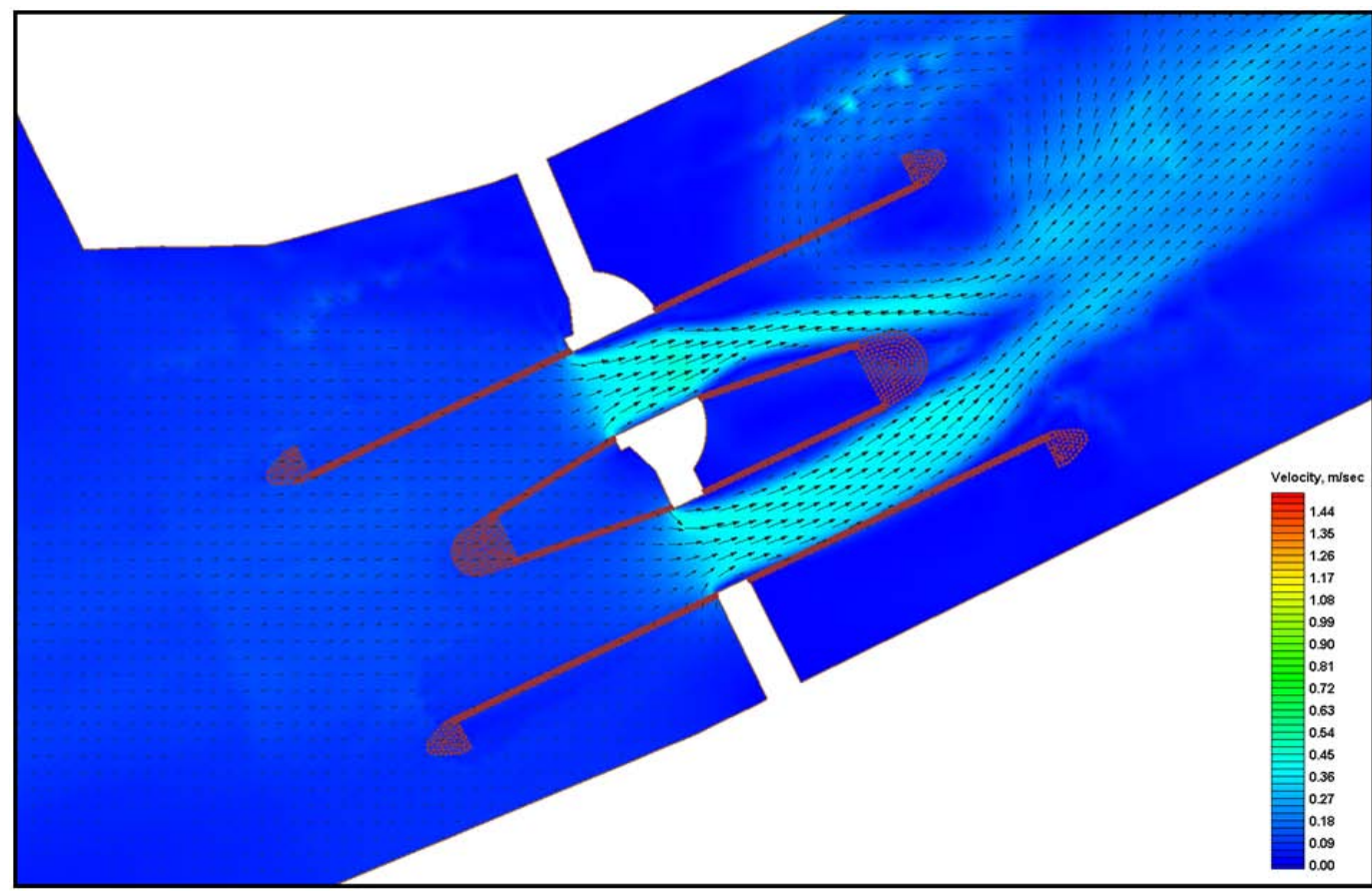

Figure 4-7. Maximum Ebb Velocities in GIWW Structure with Seabrook Structure Closed.

\section{Barge Gate Closed}

A simulation was also performed with the barge gate of the GIWW structure closed (Figures 4-8 and 4-9). The maximum velocities in the sector gate of the GIWW structure were then compared back to the 
simulation where all the gates were open (Table 4-1). Closing the barge gate increased the velocities in the sector gate approximately 40 percent for both the ebb and flood condition. The same measurement locations were used for this simulation as the all gates open simulation. The barge gate closed simulation was run for the J anuary 2006 simulation, but it is reasonable to assume a similar increase in velocity for the J une 2006 simulation which would result in ebb and flood velocities of $1.54 \mathrm{~m} / \mathrm{sec}$ $(5.05 \mathrm{ft} / \mathrm{sec})$ and $2.38 \mathrm{~m} / \mathrm{sec}(7.8 \mathrm{ft} / \mathrm{sec})$, respectively, for the barge gate closed scenario. An exceedance analysis of the structure velocities was not performed for the barge gate closed condition, as the barge gate would only be closed for an approaching storm and the period of time before the navigation limit is exceeded would depend on factors such as storm track, intensity, and forward speed.

A large eddy can be seen forming on the barge gate side of the structure when the flow pattern deflects towards the southern shore of the GIWW (see Figures 4-8 and 4-9).

Figures 4-2, 4-3, 4-8 and 4-9 also illustrate the fact that maximum velocities are stronger during the flood phase of the tide versus the ebb phase of the tide independent of the barge gate's closure status.

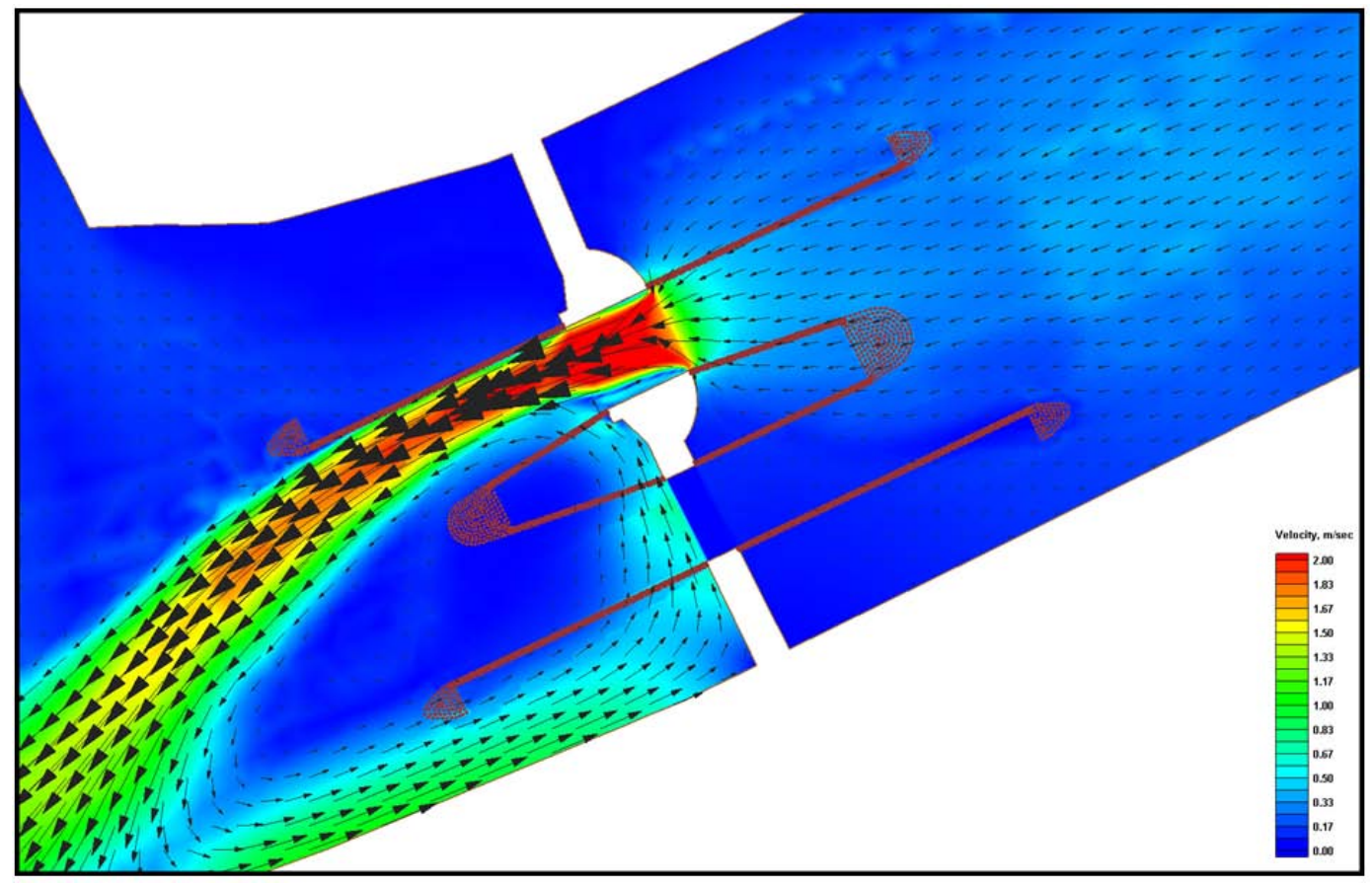

Figure 4-8. Maximum Flood Velocities in the GIWW Sector Gate with the Barge Gate Closed. 


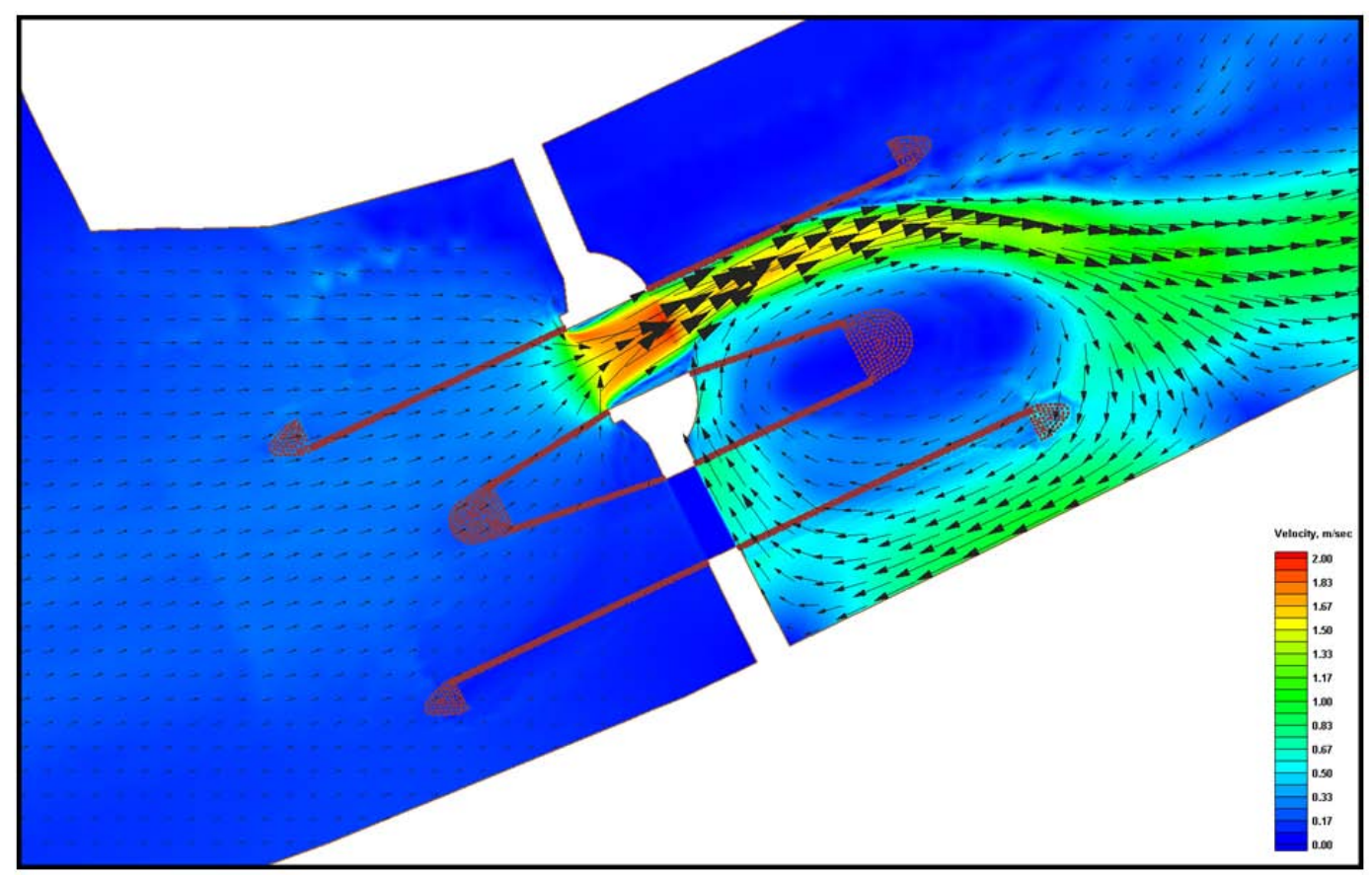

Figure 4-9. Maximum Ebb Velocities in the GIWW Sector Gate with the Barge Gate Closed.

Table 4-1. Velocity Comparison of All Structures Open to Barge Gate Closed.

\begin{tabular}{|l|l|l|}
\hline Structures Closed & $\begin{array}{l}\text { Maximum Flood Velocity, } \\
\mathrm{m} / \mathrm{sec}(\mathrm{ft} / \mathrm{sec})\end{array}$ & $\begin{array}{l}\text { Maximum Ebb Velocity, } \mathrm{m} / \mathrm{sec} \\
(\mathrm{ft} / \mathrm{sec})\end{array}$ \\
\hline None & $1.71(5.61)$ & $1.38(4.53)$ \\
\hline Barge Gate & $2.44(8.01)$ & $1.93(6.33)$ \\
\hline
\end{tabular}

\section{Boat Obstructing the Sector Gate}

These simulations were performed to simulate the approximate vessel effects in the sector gate of the GIWW structure. These effects were simulated by placing a vessel in the sector gate during a flood condition. By implementing these currents in ERDC's ship simulator, tow pilots were able to get a general sense of the effects they may encounter as their tow moves through the GIWW gate structure.

Two different width vessels were tested: 54 foot and 108 feet. The dimensions of the two vessels are illustrated in Figures 4-10 and 4-11. Figures 4-12 through 4-14 illustrate the current pattern changes due to the presence of a vessel. Due to the size of the tows used to obstruct the structure opening, the velocities are retarded when compared to those with the gate structure completely open (Figures 4-2 and 4-3).

Furthermore, the only eddy that forms appears to be the eddy over the center guidewall. 


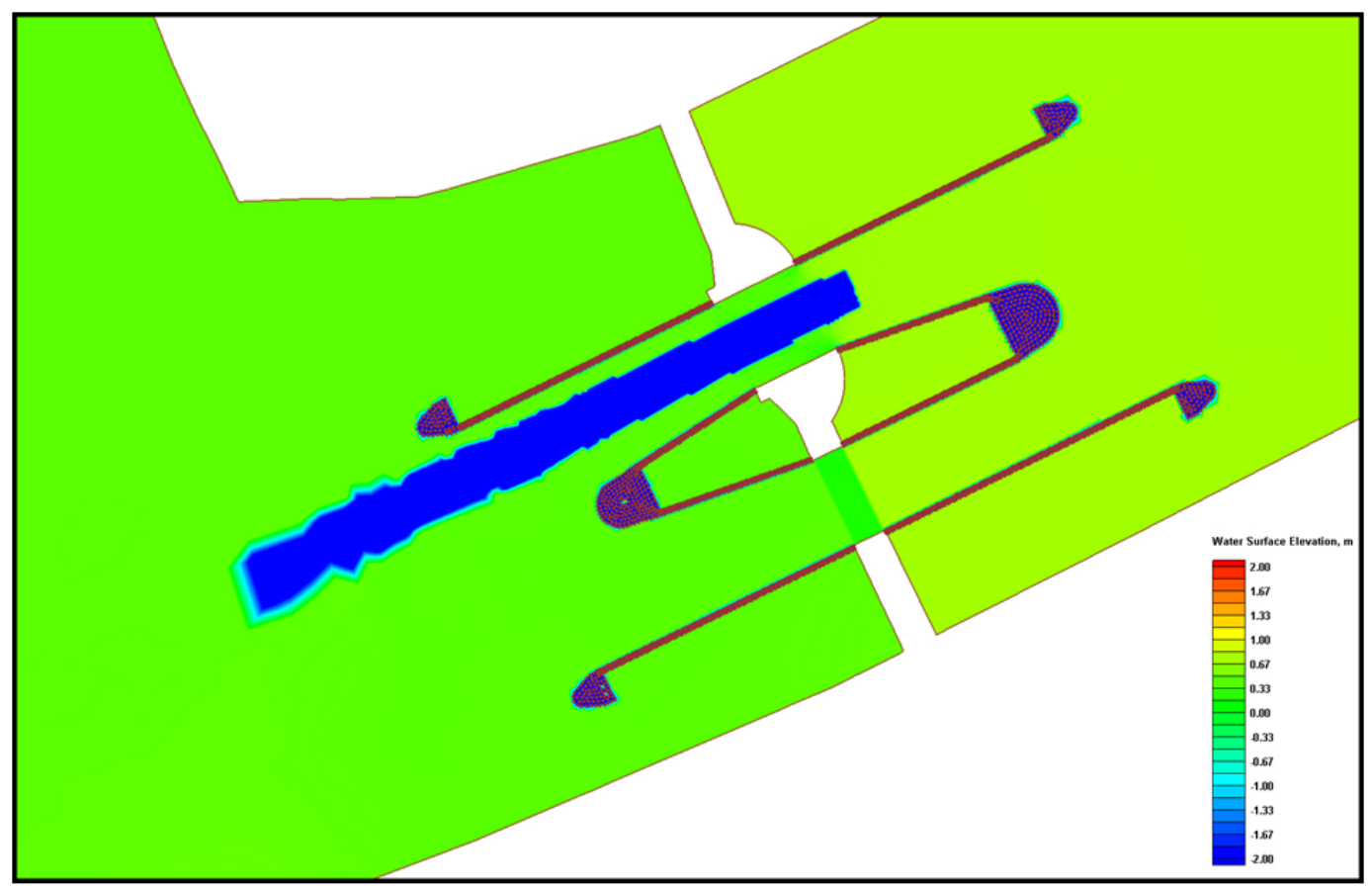

Figure 4-10. 54 foot Vessel Footprint.

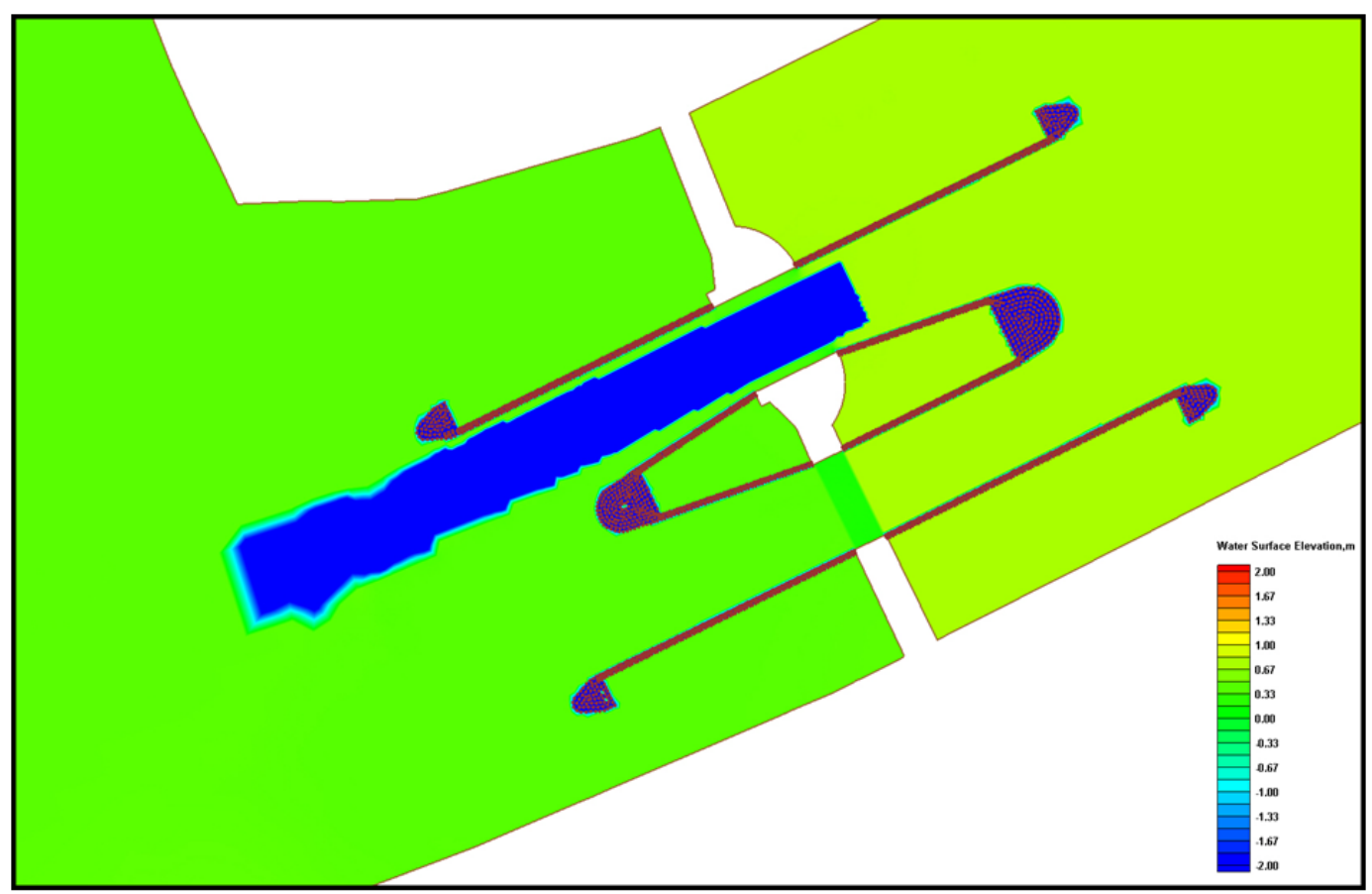

Figure 4-11. 108 foot Vessel Footprint. 


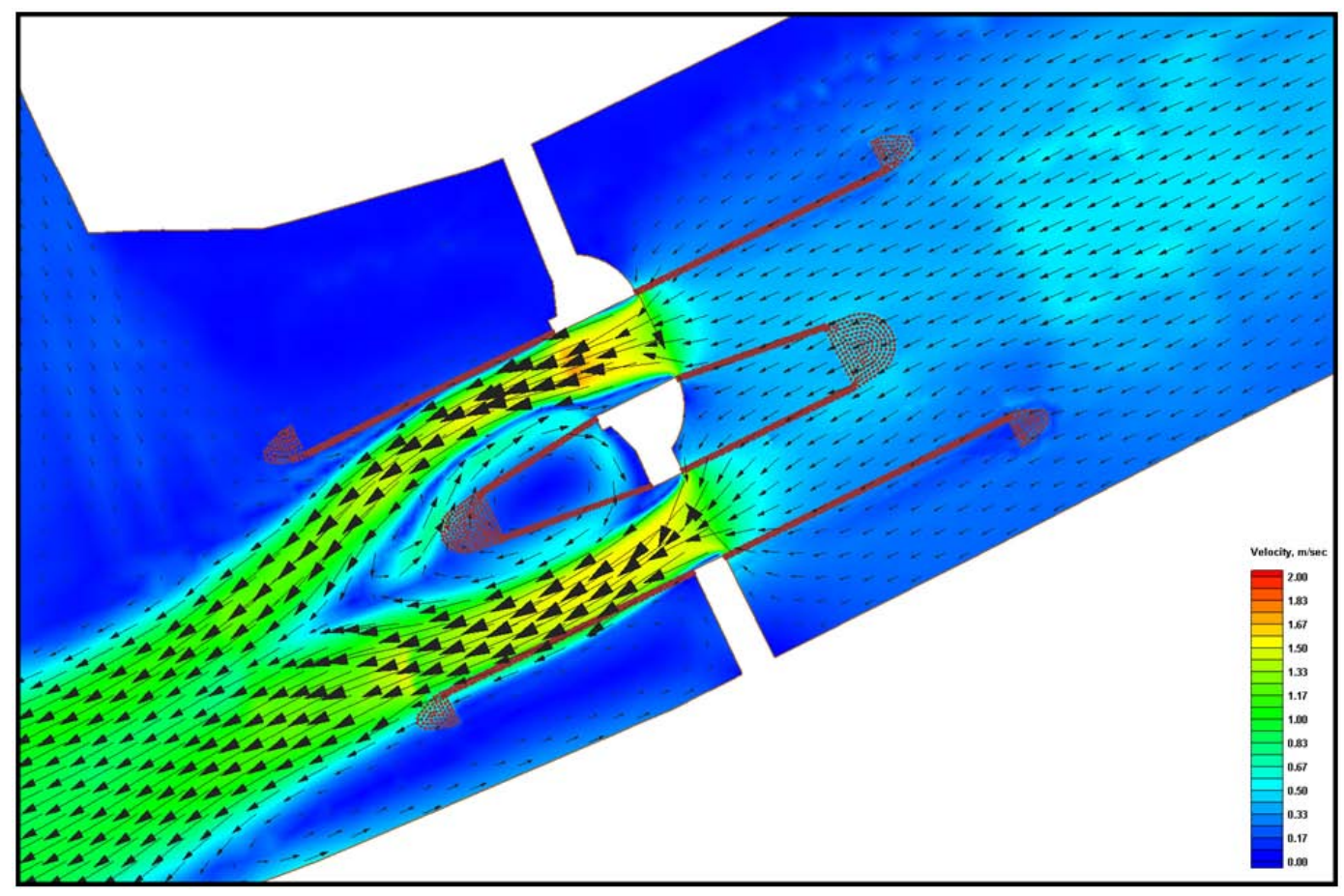

Figure 4-12. Flood Condition with no Vessel.

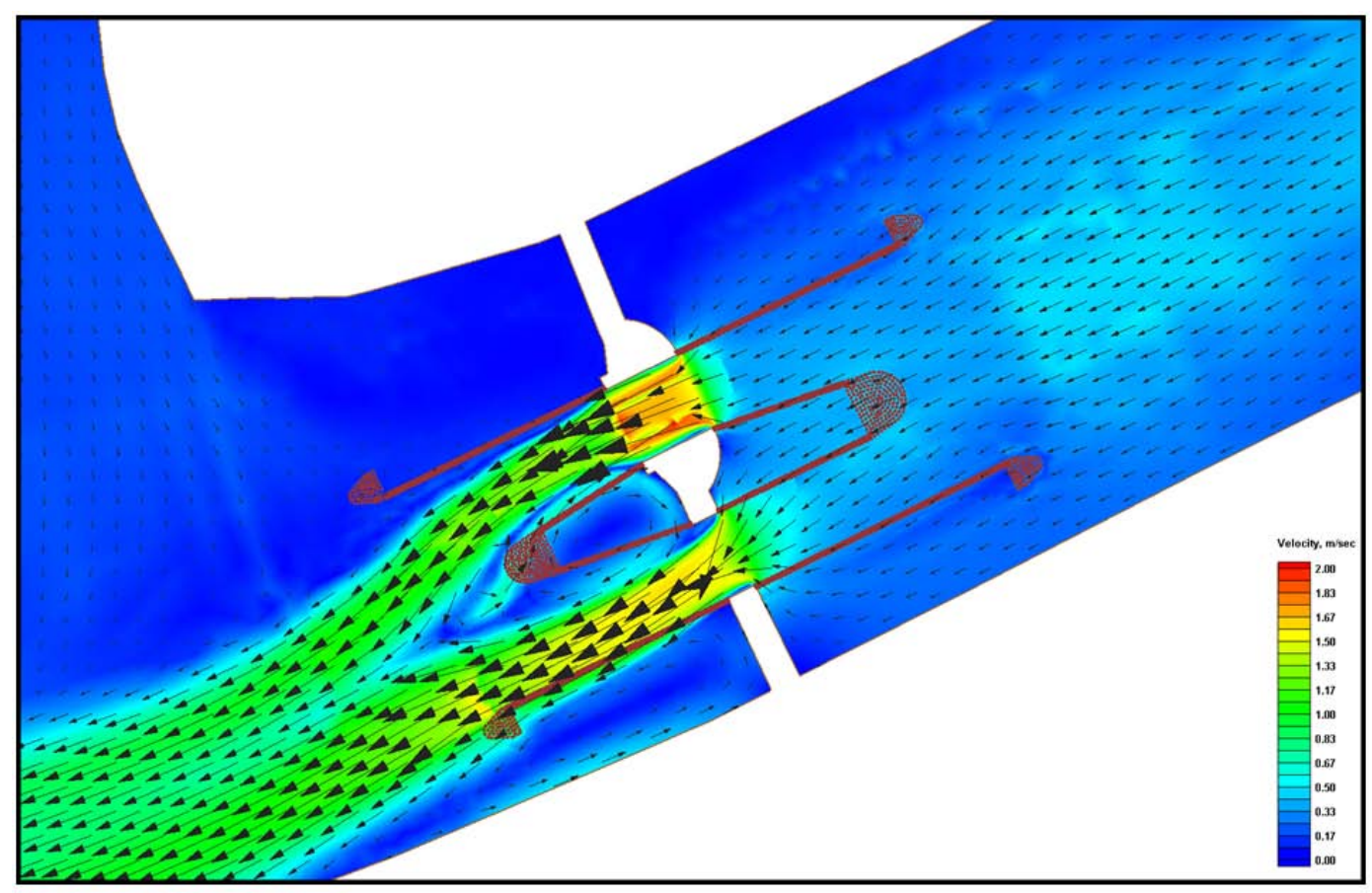

Figure 4-13. Flood Condition with $54 \mathrm{ft}$ Wide Vessel. 


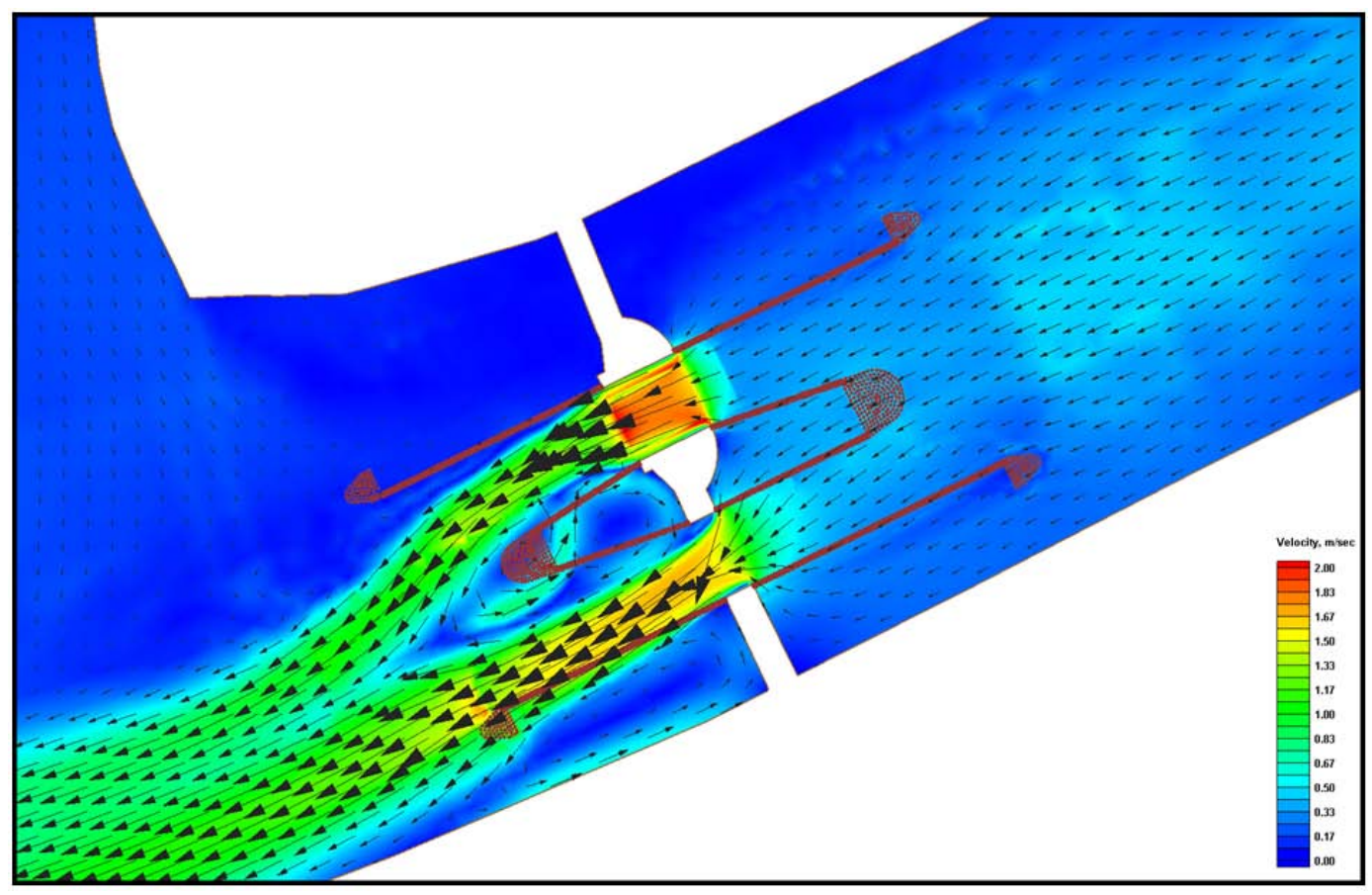

Figure 4-14. Flood Condition with $108 \mathrm{ft}$ Wide Vessel.

\section{Storm Surge Flow Conditions}

It should be noted that the storm surge condition was simulated with the surge beginning at the boundary and propagating through the model. No tidal component was included in the boundary conditions for the storm surge simulations, as the rising surge produces much higher velocities in the GIWW structure than those observed under normal conditions even when a frontal passage is included. The figures (4-15 through 4-20) are presented to illustrate circulation patterns in the system resulting from various gate closure configurations. The same time step was chosen for each of the conditions simulated. Table 4-2 shows the head differences across the GIWW structure and the resulting maximum velocity for different gate closure configurations. The maximum velocity is measured in the same location as the maximum flood conditions from the observed flow condition. The water surfaces to the east and west of the gate were measured at distance of approximately $80 \mathrm{~m}$ (262 ft) from the center of the structure.

With the base simulation (Figure 4-15), most of the flow enters the study area through the MRGO. Once the Lake Borgne Surge Barrier is implemented (Figure 4-16), the flow now enters the study area through the GIWW and BB only. Closing the barge gate on the GIWW structure (Figure 4-17) does not change how the flow enters the study area but it 


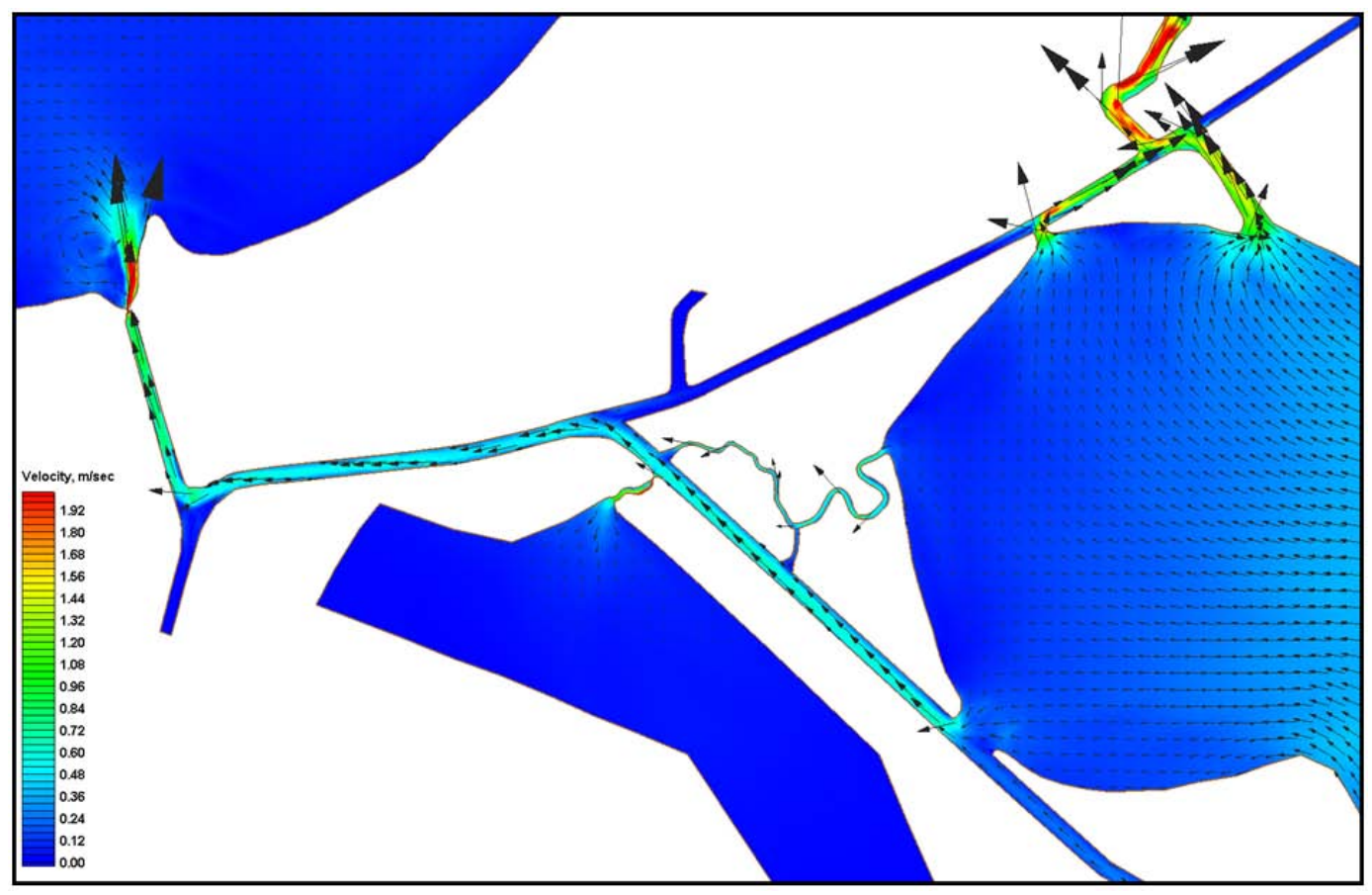

Figure 4-15. Storm Surge - Base Configuration.

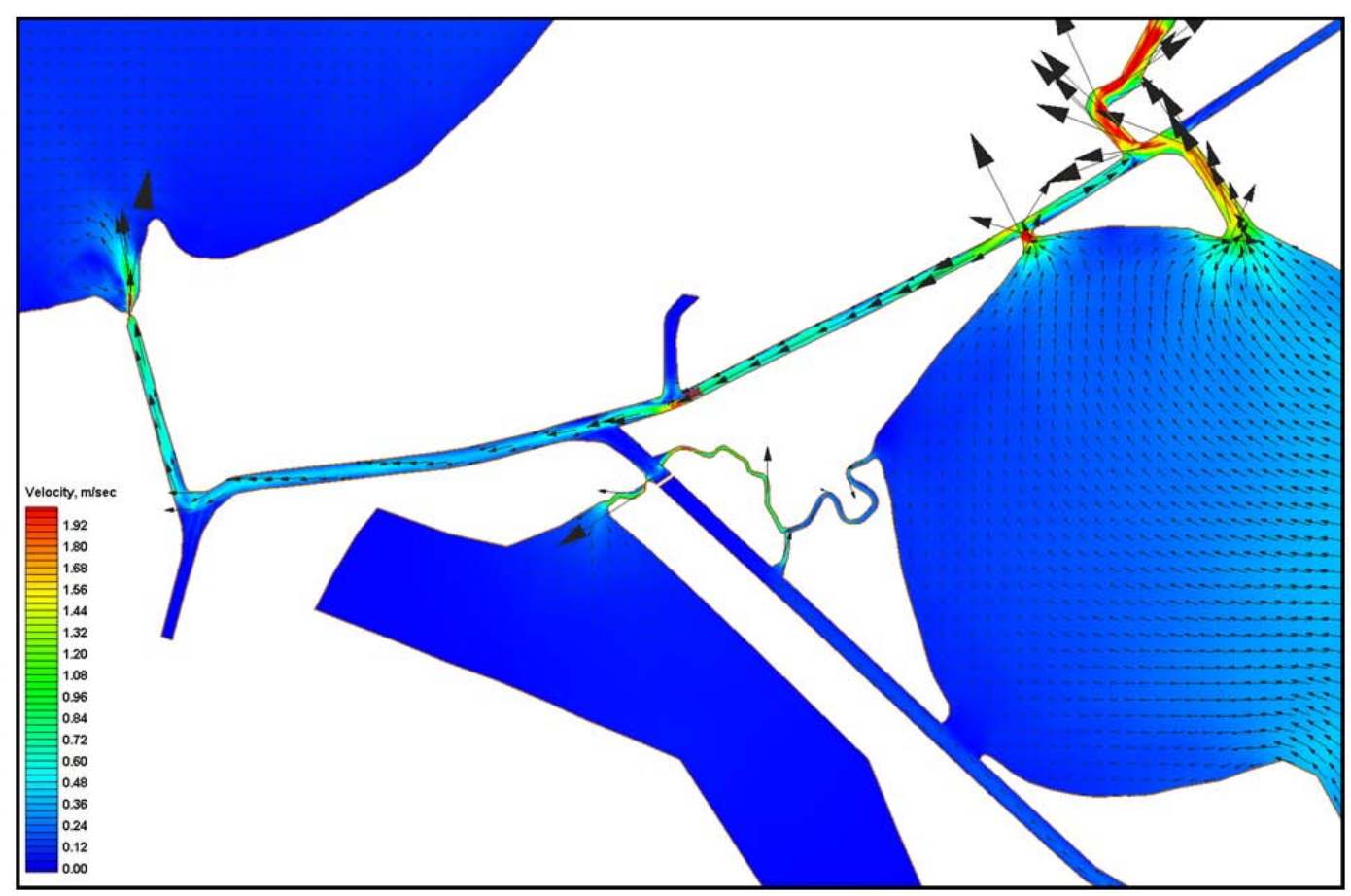

Figure 4-16. Storm Surge - Barrier with all gates open. 


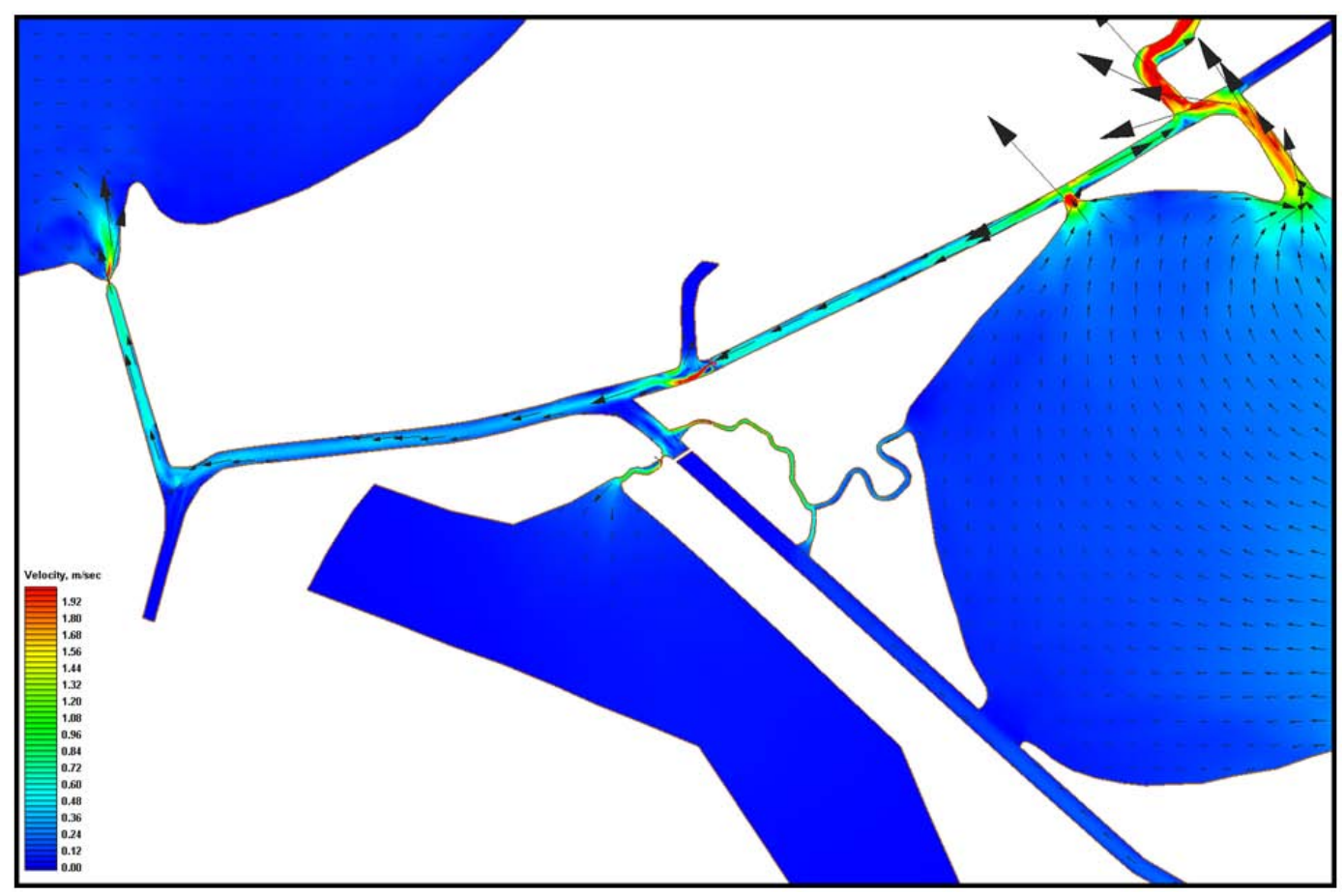

Figure 4-17. Storm Surge - Barge Gate Closed.

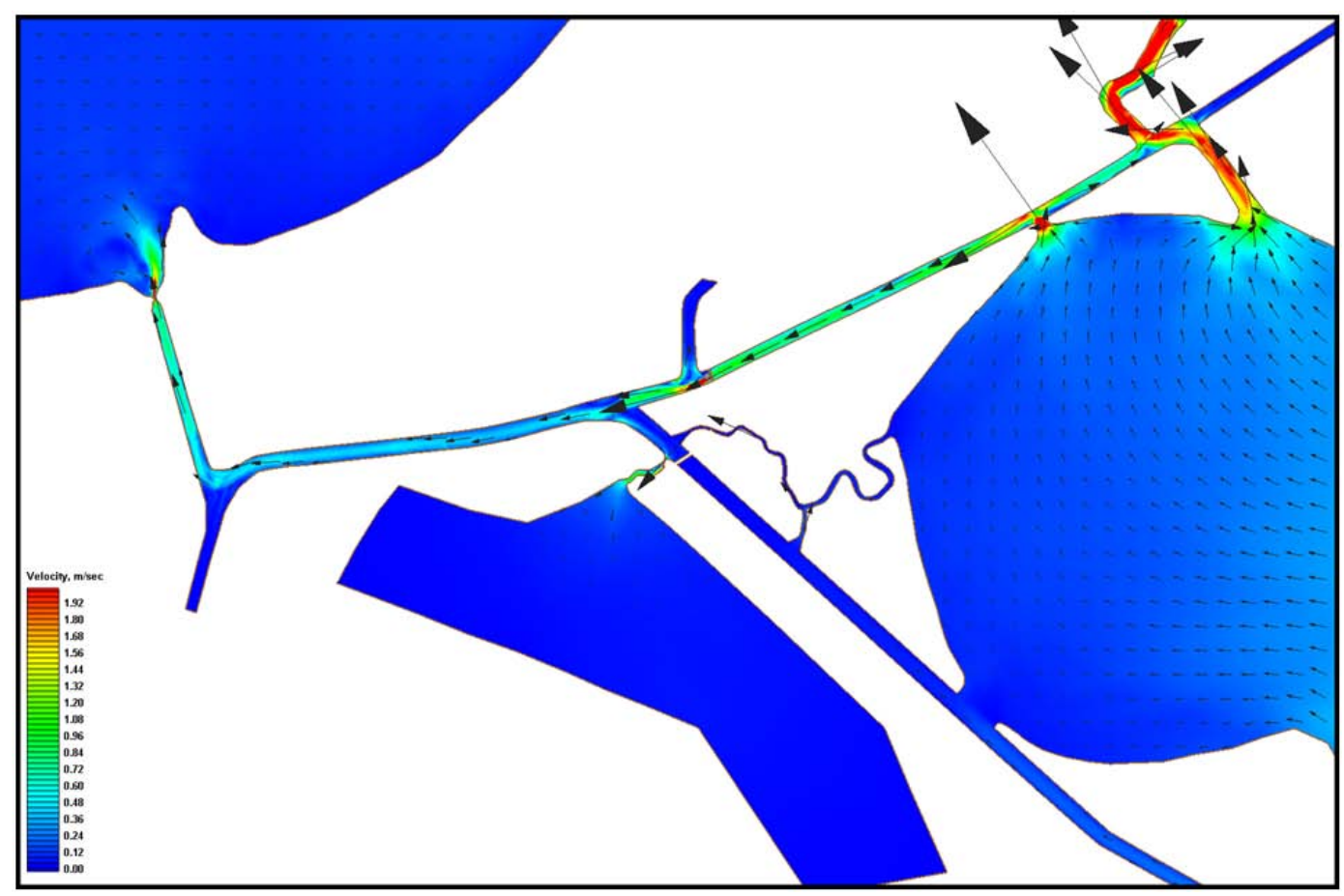

Figure 4-18. Storm Surge - BB Structure Closed. 


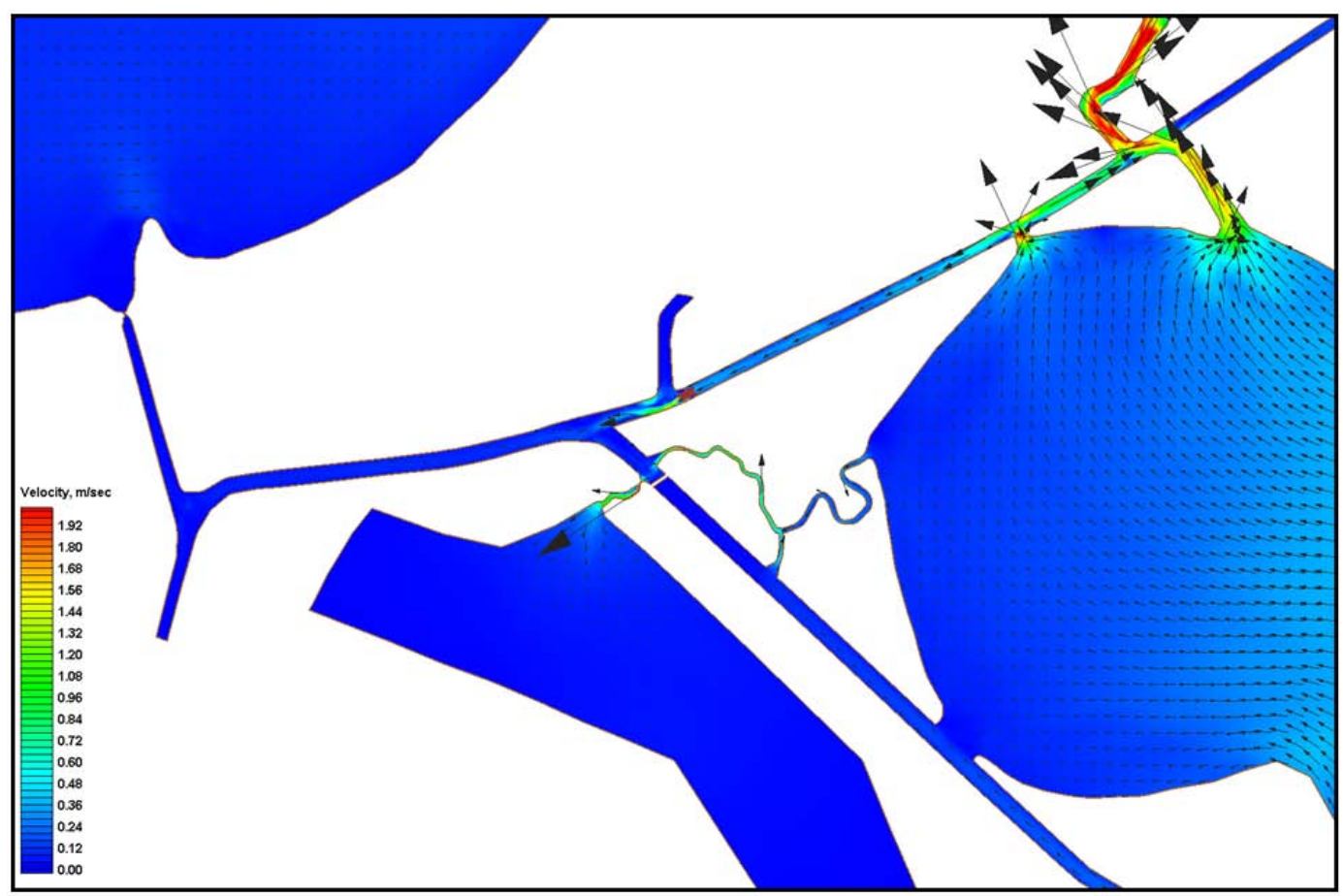

Figure 4-19. Storm Surge - Barrier with Seabrook Structure and Barge Gate Closed.

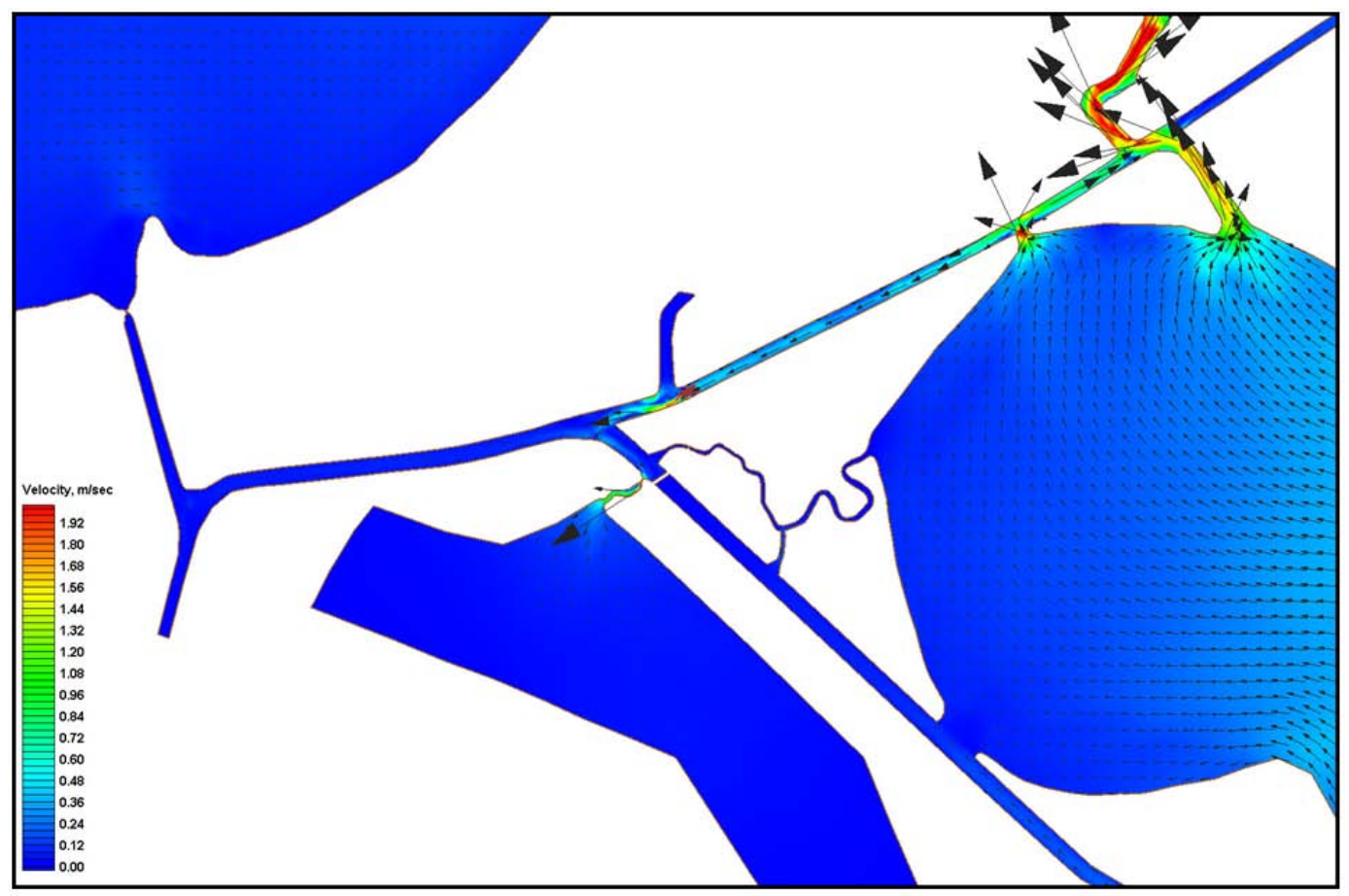

Figure 4-20. Storm Surge - Barrier with Seabrook Structure Closed, Barge Gate Closed, and BB Structure Closed. 
Table 4-2. GIWW Structure Head Differences and Velocities.

\begin{tabular}{|l|l|l|l|l|}
\hline & $\begin{array}{l}\text { Water Surface } \\
\text { Elevation }(\mathrm{m}), \\
\text { West of the } \\
\text { Structure }\end{array}$ & $\begin{array}{l}\text { Water Surface } \\
\text { Elevation }(\mathrm{m}), \\
\text { East of the } \\
\text { Structure }\end{array}$ & $\begin{array}{l}\text { Head Difference } \\
\text { across GIWW } \\
\text { Structure }\end{array}$ & $\begin{array}{l}\text { Maximum } \\
\text { Velocity, m/sec }\end{array}$ \\
\hline None & 2.19 & 2.71 & 0.52 & 3.72 \\
\hline BB & 1.91 & 2.59 & 0.68 & 4.26 \\
\hline $\begin{array}{l}\text { Barge Gate } \\
\text { (GIWW) }\end{array}$ & 1.67 & 2.83 & 1.16 & 5.37 \\
\hline $\begin{array}{l}\text { Barge Gate } \\
\text { (GIWW) and } \\
\text { Seabrook }\end{array}$ & 2.63 & 3.02 & 0.39 & 2.97 \\
\hline $\begin{array}{l}\text { Barge Gate } \\
\text { (GIWW), } \\
\text { Seabrook, and } \\
\text { BB }\end{array}$ & 2.25 & 2.95 & 0.7 & 4.07 \\
\hline
\end{tabular}

does increase the flow velocities in the GIWW structure. Closing the BB structure only (Figure 4-18) now sends all the flow into the study area through the GIWW and increases the velocities in the GIWW structure and beyond. Closing the barge gate on the GIWW structure in conjunction with the proposed Seabrook structure (Figure 4-19) does increase the flow velocity in the GIWW structure somewhat but does not change the overall circulation when compared to the scenario with all structures open. Furthermore, this condition shows the effects closing the proposed Seabrook structure has over closing the barge gate alone. The velocity reduction caused by closing the proposed Seabrook structure is illustrated in the GIWW west of the structure by comparing Figures 4-17 and 4-19. Figure 4-20 illustrates the effects of closing the barge gate, the BB structure, and the proposed Seabrook structure. Even with the additional closure of the Bayou Bienvenue sector gate, the velocities still remain low west of the GIWW structure when compared to those in figure 4-17.

Examination of Table 4-2 reveals that even though the BB closed scenario and the scenario with BB, Seabrook, and the barge gate closed have similar head differences, the velocities through the GIWW structure for the two scenarios are noticeably different. This condition may be attributable to the closure of the Seabrook structure which was shown to reduce velocities in the observe flow scenario. Figure 4-21 shows the velocities in the GIWW structure as they relate to the head difference across the structure. 


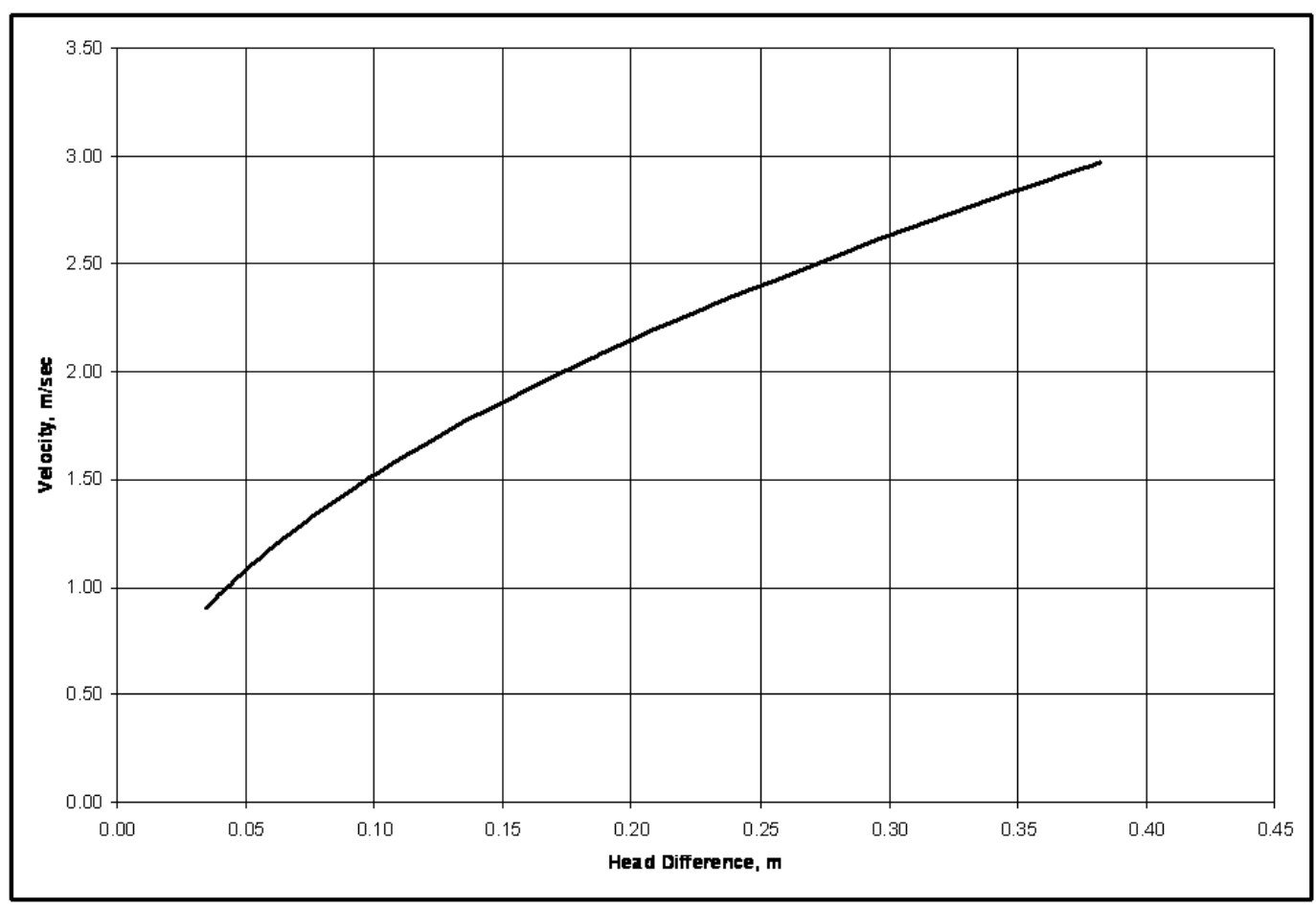

Figure 4-21. Velocity in Sector Gate versus Head Difference Across Gate. 


\section{Conclusions}

Numerical model simulations show that implementation of the Lake Borgne Surge Barrier does produce velocities in the GIWW floodgate structure which exceed the threshold of $4.4 \mathrm{ft} / \mathrm{sec}$ set by the navigation industry by approximately 23 percent. These events are low frequency events, occurring approximately 2 percent of the time, and most likely occur under spring tidal conditions that are exacerbated by passage of weather fronts.

Closing the proposed structure at Seabrook reduces the velocities in the GIWW floodgate structure by approximately 50 percent. This velocity reduction puts the structure velocities well within limits set by the navigation industry.

Storm surge simulations illustrated the impacts of each proposed structure on system circulation including the structure at Seabrook. Implementing the barrier and leaving all gate structures open prevents flow from entering the system through the MRGO and increases velocities in the GIWW. Closing the various structures in the barrier simply changes the amount flow through the GIWW structure and thereby changes the velocities in the GIWW structure. Closing the Bayou Bienvenue structure and/ or the barge gate, while leaving the proposed Seabrook structure open, increases velocities in the GIWW sector gate opening. Closing the Seabrook structure in any of the closure configurations the Lake Borgne Surge Barrier always decreased velocities in the GIWW sector gate opening for the respective closure configuration.

Vessel effects simulations were performed to provide ERDC's navigation personnel with currents resulting from vessel effects. Implementing these currents in ERDC's ship simulator gave tow pilots a general sense of the effects they would experience as their tow passed through the GIWW structure. 


\section{References}

Berger, C., and Stockstill, R. L. 1995. Finite Element for High Velocity Channels. J ournal of Hydraulic Engineering, 121 (10), 710-716.

Martin, S. K., T. O.McAlpin, and D.C. McVan. 2010. Hydrodynamic and Salinity Analysis of Hydrodynamic and Salinity Analysis of Conceptual Surge Barrier Designs in the Lake Pontchartrain Region. CHL-TR-10-9. Vicksburg, MS: U.S. Army Engineering Research and Development Center.

McAnally, W. H., and R. C.Berger. 1997. Salinity Changes in Pontchartrain Basin Estuary Resulting from Bonnet Carre` Freshwater Diversion. Technical Report CHL-97-2. Vicksburg, MS: U.S. Army Waterways Experiment Station.

McCorquodale, J . Alex, Georgiou, Ioannis, Retana, Angel Gabriel, Barbe, Donald, and Guillot, Martin J . 2007. Hydrodynamic Modeling of the Tidal Prism in the Pontchartrain Basin Estuary. New Orleans, LA: Dept. of Civil and Environmental Engineering, University of New Orleans.

Outlaw, Douglas G. 1982. Lake Pontchartrain and vicinity hurricane protection plan; Report 1, Prototype data acquisition and analysis. Technical Report HL-82-2. Vicksburg, MS: U.S. Army Waterways Experiment Station.

Savant, G., and Berger, C.2010. Intelligent Adaptive Time Step Control for Modeling Rapidly-Evolving Hydrodynamic Flows in Adaptive Hydraulics (ADH). System Wide Water Resources Program Technical Note.

"SMS version 8.0 Reference Manual for the Surface Water Modeling System," 2002, Brigham Young University, 1997, Engineering Graphics Laboratory, Provo, Utah [http:// chl.wes.army.mil/software/ tabs/ docs.htp].

Tate, J . N., A. R Carrillo, R. C.Berger, and B. J.Thibodeaux. 2002. Salinity Changes in Pontchartrain Basin Estuary, Louisiana, Resulting from Mississippi River-Gulf Outlet Partial Closure Plans with Width Reduction. CHL-TR-02-12. Vicksburg, MS: U.S. Army Engineering Research and Development Center.

Tate, J . N., T. C.Lackey, and T. O.McAlpin. 2010. Seabrook Fish Larval Transport Study. Draft Technical Report. Vicksburg, MS: U.S. Army Engineering Research and Development Center.

United States Army Corps of Engineers. 2006. Louisiana Coastal Protection and Restoration. Preliminary Technical Report to United States Congress.

United States Army Corps of Engineers, U.S. Army Engineer District, New Orleans. 2008. Flood Insurance Study: Southeastern Parishes, Louisiana - Draft Intermediate Submission 2: Offshore Water Levels and Waves. Report prepared for the Federal Emergency Management Agency, Region 6. 


\section{Appendix A: Description of the ADaptive Hydraulics (ADH) Modeling System}

$\mathrm{ADH}$ is a state-of-the-art ADaptive Hydraulics Modeling system developed by the US Army Engineer Engineering Research and Development Center Coastal and Hydraulics Laboratory. It is capable of simulating both saturated and unsaturated groundwater, overland flow, three-dimensional Navier-Stokes flow, and two- or three-dimensional shallow water problems with the current study utilizing the two-dimensional shallow water module. The 2D shallow-water equations used for this application are a result of the vertical integration of the equations of mass and momentum conservation for incompressible flow under the hydrostatic pressure assumption. Written in conservative form, the 2D shallow water equations are:

$$
\frac{\partial \mathrm{U}}{\partial \mathrm{t}}+\frac{\partial \mathrm{F}}{\partial \mathrm{x}}+\frac{\partial \mathrm{G}}{\partial \mathrm{y}}+\mathrm{H}=0
$$

where

$$
\begin{gathered}
\mathrm{U}=\left\{\begin{array}{l}
\mathrm{h} \\
\mathrm{uh} \\
\mathrm{vh}
\end{array}\right] \\
\mathrm{F}=\left\{\begin{array}{c}
\mathrm{u}^{2} \mathrm{~h}+\frac{1}{2} g \mathrm{~h}^{2}-\mathrm{h} \frac{\sigma_{\mathrm{xx}}}{\mathrm{p}} \\
\mathrm{uvh}-\mathrm{h} \frac{\sigma_{\mathrm{yx}}}{\mathrm{p}}
\end{array}\right\} \\
\mathrm{G}=\left\{\begin{array}{c}
\mathrm{vh} \\
\mathrm{uvh}-\mathrm{h} \frac{\sigma_{\mathrm{xy}}}{\mathrm{p}} \\
\mathrm{v}^{2} \mathrm{~h}+\frac{1}{2} \mathrm{gh}-\mathrm{h} \frac{\sigma_{\mathrm{yy}}}{\mathrm{p}}
\end{array}\right\}
\end{gathered}
$$


and

$$
H=\left\{\begin{array}{c}
0 \\
g h \frac{\partial z_{b}}{\partial x}+n^{2} g h \frac{u \sqrt{u^{2}+v^{2}}}{C_{0} h^{1 / 3}} \\
g h \frac{\partial z_{b}}{\partial y}+n^{2} g h \frac{v \sqrt{u^{2}+v^{2}}}{C_{0} h^{1 / 3}}
\end{array}\right\}
$$

where:

$$
\begin{aligned}
\rho= & \text { fluid density } \\
\mathrm{g}= & \text { gravitational acceleration } \\
\mathrm{Zb}= & \text { riverbed elevation } \\
\mathrm{n}= & \text { Manning's roughness coefficient } \\
\mathrm{h}= & \text { flow depth } \\
\mathrm{u}= & \mathrm{x} \text {-component of velocity } \\
\mathrm{v}= & \mathrm{y}-\text { component of velocity } \\
\mathrm{C}_{\mathrm{O}}= & \text { dimensional conversion coefficient ( } 1 \text { for SI units, } 1.486 \text { for } \\
& \text { U.S. customary units) } \\
\sigma^{\prime} \mathrm{s}= & \text { the Reynolds stresses due to turbulence, where the first } \\
& \text { subscript indicates the direction, and the second indicates the } \\
& \text { face on which the stress acts. }
\end{aligned}
$$

The Reynolds stresses are determined using the Boussinesq approach to the gradient in the mean currents:

$$
\begin{gathered}
\sigma_{\mathrm{xx}}=2 p v_{\mathrm{t}} \frac{\partial \mathrm{u}}{\partial \mathrm{x}} \\
\sigma_{\mathrm{yy}}=2 p v_{\mathrm{t}} \frac{\partial \mathrm{v}}{\partial \mathrm{y}}
\end{gathered}
$$

and

$$
\sigma_{\mathrm{xy}}=\sigma_{\mathrm{yx}}=2 p v_{\mathrm{t}}\left(\frac{\partial \mathrm{u}}{\partial \mathrm{y}}+\frac{\partial \mathrm{v}}{\partial \mathrm{x}}\right)
$$

where $v_{\mathrm{t}}=$ kinematic eddy viscosity (which varies spatially). 
The ADH shallow-water equations are placed in conservative form so that mass balance and the balance of momentum and pressure are identical across an interface. This is important in order to match the speed and height of a surge or hydraulic jump.

The equations are represented in a finite element approach. The quality of the numerical solution depends on the choice of the basis/trial function and the test function. The trial function determines how the variables are represented and the test function determines the manner in which the differential equation is enforced. In the Galerkin approach the test functions are chosen to be identical with the trial functions. When the flow is advection-dominated, the Galerkin approach produces oscillatory behavior. The Galerkin form of the test function cannot detect the presence of a node-to-node oscillation and so allows this spurious solution. The approach used in $\mathrm{ADH}$ is to enrich the standard Galerkin test function with an additional term that can detect and control this spurious solution.

This Petrov-Galerkin method used here is based on elemental constants for coefficients. This reduces the stabilization to the nonconservative form. This is not a problem for conservation since the stabilization is only applied within the elements and uses the Galerkin test function to enforce "flux" balance across element edges. For illustration, consider the shallowwater equations in nonconservative form

$$
\frac{\partial U}{\partial t}+A \frac{\partial U}{\partial x}+B \frac{\partial U}{\partial y}+H=0
$$

where $A=\frac{\partial F}{\partial U}$ and $B=\frac{\partial G}{\partial U}$. The trial functions (or interpolation/basis functions) are the Lagrange polynomials. These are piecewise linear functions that are continuous across element boundaries. Spatial derivatives, however, are not continuous across these element edges. Each of the dependent and independent variables is interpolated via these trial functions. For example,

$$
\tilde{u}(x)=\sum_{j=1}^{N} \varphi_{j}(x) u_{j}
$$


means that the approximate solution is made up of the sum of the products of the trial function for node $j$ and the nodal value at that location. The test function is chosen as:

$$
\varphi_{i}^{*}=\varphi_{i} I+a\left(\frac{\partial \varphi_{i}}{\partial x} A+\frac{\partial \varphi_{i}}{\partial y} B\right)
$$

where,

$$
a=0.51\left[\bar{v} \bullet \bar{v}+g h+\left(\frac{l}{\Delta t}\right)^{2}\right]^{-1 / 2}
$$

$$
\begin{aligned}
1 & =\left(\Omega_{\mathrm{e}}\right)^{1 / 2}, \text { the square of the element area } \\
\bar{v} & =(\bar{u}, \bar{v}), \text { the element average velocity components } \\
\Delta t & =\text { time step size }
\end{aligned}
$$

The finite element statement becomes:

$$
\begin{gathered}
\int_{\Omega}\left(\varphi_{i} \frac{\partial U_{i}}{\partial t}-\frac{\partial \varphi_{i}}{\partial x} F_{l}-\frac{\partial \varphi_{i}}{\partial y} G_{l}+\varphi_{i} H_{l}\right) d \Omega+ \\
\int_{\partial \Omega} \varphi i\left\{F_{l} \mathrm{n}_{x}+G_{l} \mathrm{n}_{y}\right\} d s+\sum_{e} \int_{\Omega e} a\left(\frac{\partial \varphi_{i}}{\partial x} A_{l}+\frac{\partial \varphi_{i}}{\partial y} B_{l}\right) \\
\left(\frac{\partial U_{l}}{\partial t}+A_{l} \frac{\partial U_{l}}{\partial x}+B_{l} \frac{\partial U_{l}}{\partial y}+H_{l}\right)=0
\end{gathered}
$$

where, the subscript $l$ indicates the finite element approximation. The Petrov-Galerkin contributions are integrated over the interior of the elements, but not across element edges. This contribution stabilizes the Galerkin approach. This scheme utilizes a single scaling factor, $\alpha$. This is different from the scheme reported in Berger and Stockstill (1995). That scheme involved scaling each eigenvalue, but that method does not converge using the iterative solver in ADH. Instead, a single value scaling (Equation 12) is used.

One of the major benefits of $\mathrm{ADH}$ is its ability to adapt the mesh in areas where additional resolution is needed to properly resolve the 
hydrodynamics. This process is done by normalizing the results so that an error quantity is determined for each element. If this error exceeds the tolerance set by the user, then the element is refined. ADH is also able to unrefined previously refined areas when the added resolution is no longer needed. ADH contains other essential features such as wetting and drying, completely coupled sediment and salt transport, and wind effects. A series of modularized libraries make it possible for $\mathrm{ADH}$ to include vessel movement, friction descriptions, as well as a host of other crucial features. $\mathrm{ADH}$ can run in parallel or on a single processor and runs on both Windows systems and UNIX based systems.

$\mathrm{ADH}$ allows the user to specify the time step to be utilized as an independent time series or as an option for the time step size to be computed internally as the simulation progresses using a modification of the standard Pseudo Transient Continuation (PTC) scheme. Savant and Berger (2010) provides the numerical details utilized by ADH for PTC time stepping. 


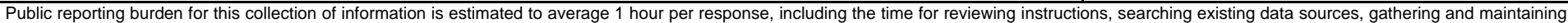

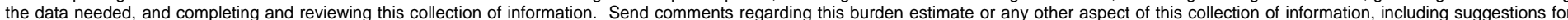

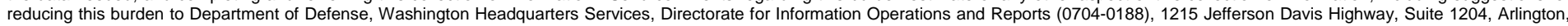

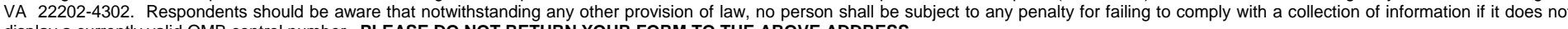
display a currently valid OMB control number. PLEASE DO NOT RETURN YOUR FORM TO THE ABOVE ADDRESS.

\begin{tabular}{|l|l|l} 
1. REPORT DATE (DD-MM- $Y Y Y Y)$ & 2. REPORT TYPE & 3. DATES COVERED (FrOm - To)
\end{tabular}

\begin{tabular}{l|l} 
September 2010 & Final report
\end{tabular}

\section{TITLE AND SUBTITLE}

Lake Borgne Surge Barrier Study

5a. CONTRACT NUMBER

5b. GRANT NUMBER

5c. PROGRAM ELEMENT NUMBER

6. AUTHOR(S)

S. Keith Martin, Gaurav Savant, and Darla C. McVan

5d. PROJECT NUMBER

5e. TASK NUMBER

5f. WORK UNIT NUMBER

\section{PERFORMING ORGANIZATION NAME(S) AND ADDRESS(ES)}

8. PERFORMING ORGANIZATION REPORT NUMBER

U.S. Army Engineer Research and Development Center

Coastal and Hydraulics Laboratory

ERDC/CHL TR-10-10

3909 Halls Ferry Road

Vicksburg, MS 39180-6199

\section{SPONSORING / MONITORING AGENCY NAME(S) AND ADDRESS(ES)}

U.S. Army Corps of Engineers

New Orleans District, Hurricane Protection Office

7400 Leake Avenue, P.O. Box 60267

New Orleans, LA 70160-0267

12. DISTRIBUTION / AVAILABILITY STATEMENT

Approved for public release; distribution is unlimited.

\section{SUPPLEMENTARY NOTES}

\section{ABSTRACT}

A two-dimensional hydrodynamic model of the Lake Borgne Surge Barrier was developed specifically for simulating currents within the surge protection structure on the Gulf Inter-Coastal Waterway (GIWW) for the purposes of determining the impacts of the GIWW structure on navigation. The model was validated against observed data and applied using boundary conditions capable of producing currents in the structure that would be hazardous to navigation.

\begin{tabular}{|c|c|c|c|c|c|}
\hline \multirow{2}{*}{\multicolumn{2}{|c|}{$\begin{array}{l}\text { 15. SUBJECT TERMS } \\
\text { Adaptive Hydraulics } \\
\text { Barge gate }\end{array}$}} & \multirow{2}{*}{\multicolumn{2}{|c|}{$\begin{array}{l}\text { Guidewalls } \\
\text { Gulf Intracoastal Waterway }\end{array}$}} & \multirow{2}{*}{\multicolumn{2}{|c|}{ Lake Borgne Surge Barrier }} \\
\hline & & & & & \\
\hline \multicolumn{3}{|c|}{ 16. SECURITY CLASSIFICATION OF: } & $\begin{array}{l}\text { 17. LIMITATION } \\
\text { OF ABSTRACT }\end{array}$ & $\begin{array}{l}\text { 18. NUMBER } \\
\text { OF PAGES }\end{array}$ & $\begin{array}{l}\text { 19a. NAME OF RESPONSIBLE } \\
\text { PERSON }\end{array}$ \\
\hline $\begin{array}{l}\text { a. REPORT } \\
\text { UNCLASSIFIED }\end{array}$ & $\begin{array}{l}\text { b. ABSTRACT } \\
\text { UNCLASSIFIED }\end{array}$ & $\begin{array}{l}\text { c. THIS PAGE } \\
\text { UNCLASSIFIED }\end{array}$ & & 54 & $\begin{array}{l}\text { 19b. TELEPHONE NUMBER (include } \\
\text { area code) }\end{array}$ \\
\hline
\end{tabular}

